Universidade de São Paulo

Faculdade de Economia, Administração e Contabilidade

Departamento de Economia

\title{
Benefícios Governamentais e Investimentos no Setor de Petróleo na presença de custos cumulativos: uma análise com base em Opções Reais
}

Fernando Antonio Slaibe Postali

Orientador: Prof. Dr. Paulo Picchetti

SÃO PAULO

2004 
Universidade de São Paulo

Faculdade de Economia, Administração e Contabilidade

Departamento de Economia

\section{Benefícios Governamentais e Investimentos no Setor de Petróleo na presença de custos cumulativos: uma análise com base em Opções Reais}

Fernando Antonio Slaibe Postali

Orientador: Prof. Dr. Paulo Picchetti

Tese apresentada ao Departamento de Economia da Universidade de São Paulo como um dos pré-requisitos para a obtenção do título de Doutor em Economia

SÃO PAULO 


\section{FICHA CATALOGRÁFICA}

Elaborada pela Seção de Publicações e Divulgação do SBD/FEA/USP

Postali, Fernando Antonio Slaibe

Benefícios governamentais e investimentos no setor de petróleo na presença de custos cumulativos : uma análise com base em opções reais / Fernando Antonio Slaibe Postali. -- São Paulo, 2004.

$153 \mathrm{f}$.

Tese (Doutorado) - Universidade de São Paulo, 2004

Bibliografia.

1. Economia 2. Opções reais 3. Investimentos 4. Petróleo 5. 5. Royalties II. Faculdade de Economia, Administração e Contabilidade da USP. II. Título.

CDD - 330 
Prof. Dr. Adolpho José Melfi

Reitor

Profa. Dra. Maria Tereza Leme Fleury

Diretora da Faculdade de Economia, Administração e Contabilidade

\section{Prof. Dr. Ricardo Abromovay}

Chefe do Departamento de Economia

\section{Profa. Dra. Fabiana Rocha}

Coordenadora de Pós Graduação 


\section{Conteúdo}

0.1 Introdução . . . . . . . . . . . . . . . . . . . . . 14

1 Opções Reais e Teoria do Investimento 19

1.1 Introdução . . . . . . . . . . . . . . . . . . . . . 20

1.2 Revisão Bibliográfica . . . . . . . . . . . . . . . . . . . 29

1.3 Modelo Genérico . . . . . . . . . . . . . . . . . . . . 40

1.3.1 Opção de investimento . . . . . . . . . . . . . . . . . . 44

1.3.2 Opção de abandono . . . . . . . . . . . . . . . . . 45

1.3.3 Opção de expansão . . . . . . . . . . . . . . . 46

1.4 Síntese do capítulo . . . . . . . . . . . . . . . 46

2 A trajetória do Preço do Petróleo 48

2.1 Processos Estocásticos do preço do petróleo . . . . . . . . . . . . 48

2.2 Testes de Raiz Unitária . . . . . . . . . . . . . . . . . . . . 58

2.3 Reversão à Média e Meia Vida . . . . . . . . . . . . . . . . . . . 70

2.4 Síntese do Capítulo . . . . . . . . . . . . . . . . . 76

$\begin{array}{lll}3 & \text { O Modelo } & \mathbf{7 8}\end{array}$

3.1 Valor Unitário da Reserva Desenvolvida . . . . . . . . . . . . . 80

3.1.1 Sem opção de paralisação temporária . . . . . . . . . . 95

3.1.2 Com opção de paralisação temporária . . . . . . . . . . . . 97

3.2 Valor Unitário da Reserva Não-Desenvolvida . . . . . . . . . . . . 99 
3.3 Preços Críticos de Investir e Paralisar . . . . . . . . . . . . . . . . 102

4 Resultados $\quad 107$

4.1 Resultados gerais . . . . . . . . . . . . . . . . 110

4.2 Benefícios governamentais e investimento . . . . . . . . . . . . 124

5 Conclusões 


\section{Lista de Figuras}

1-1 Valor da Espera X Valor da Reserva . . . . . . . . . . . . . . 28

1-2 Esquematização-tempo discreto . . . . . . . . . . . . . . . . 31

2-1 Processo Ornstein-Uhlembeck Geométrico ． . . . . . . . . . . 50

2-2 Preço do petróleo, em $\$ 1999$. . . . . . . . . . . . . 59

2-3 Meias vidas estimadas, em anos . . . . . . . . . . . . . 75

3-1 Produção e Custos Unitários no tempo . . . . . . . . . . . 83

3-2 Valor da Reserva e Opção . . . . . . . . . . . . . . . . . 105

4-1 Variando taxa de juros . . . . . . . . . . . . . . . 113

4-2 Variando taxa de crescimento do preço . . . . . . . . . . . 113

$4-3 \quad$ Variando o convenience yield $-\delta \ldots . . \ldots . \ldots 113$

4 -4 Variando $\delta$ para diferentes incertezas . . . . . . . . . . . 114

4-5 Variando desvio padrão do preço do petróleo . . . . . . . . . . . . 114

4-6 Variando o coeficiente de correlação preço-custo . . . . . . . . . . 114

4-7 Variando a taxa de crescimento do custo unitário - $\phi$. . . . . 115

4-8 Variando investimento por barril . . . . . . . . . . . . . . 115

4-9 Variando alíquota dos royalties . . . . . . . . . . . 115

4-10 Alíquotas muito altas . . . . . . . . . . . . . . . . 116

4-11 Incerteza e Royalties . . . . . . . . . . . . . . . . . . 116

4-12 Variação de royalties para $\phi=10 \%$ e $\phi=15 \% \ldots \ldots . . . . .116$

4-13 Variando alíquota de Participações Especiais - R. . . . . . . . . . 117 
4-14 Participações especiais e taxas de juros - I . . . . . . . . . . 117

4-15 Participações especiais e taxas de juros - II . . . . . . . . . . . . 117

4-16 Variando up lift rate . . . . . . . . . . . . . . . . . . . 118

4-17 Participações especiais e taxa de aumento de custos . . . . . . . . 118

4-18 Participações especiais e incerteza de custo . . . . . . . . . . 118 


\section{Lista de Tabelas}

1.1 Comparação entre opções sobre ações e opções reais . . . . . . . 24

1.2 Opção de Compra e Opções sobre reservas não desenvolvidas . . 25

1.3 Aplicações mais comuns de opções reais . . . . . . . . . . . . . . 38

2.1 Coeficiente autorregressivo, meia vida e tamanho da série . . . . . 65

2.2 Teste de Raiz Unitária de Phillips-Perron . . . . . . . . . . . . . 66

2.3 Teste KPSS . . . . . . . . . . . . . . . . . . . . . 66

2.4 Teste de raiz unitária com duas quebras - Lee Strazicich 2003 . . . 70

2.5 Coeficientes Ornstein-Uhlenbeck . . . . . . . . . . . . . . . 72

2.6 Coeficientes Ornstein-Uhlenbeck Geométrico . . . . . . . . . . 73

3.1 Preço crítico e decisão ótima . . . . . . . . . . . . . . . . . . . . . 99

4.1 Parâmetros do Modelo . . . . . . . . . . . . . . . . . . . . 108

4.2 Resultados de referência . . . . . . . . . . . . . . . 111

4.3 Preços Críticos para valores selecionados de royalties . . . . . . . 126

4.4 Preços críticos sem opção de paralisação . . . . . . . . . . . . 129

4.5 Preços críticos com opção de paralisação sem custos . . . . . . . . 129

4.6 Preços críticos com opção de paralisação e $=0,5$. . . . . . . . 130

4.7 Preços críticos com opção de paralisação com custo e $=1$. . . . 130

4.8 Grau de Distorção sem opção de parada . . . . . . . . . . . . . . 131

4.9 Grau de distorção com opção de interrupção ao custo e = 1 . . . 132

4.10 Receita esperada por barril, em dólar, para $\mathrm{P}=28, \mathrm{C}=\mathrm{I}=3$. . 133 
4.11 Receita esperada por barril, para $\mathrm{P}=28, \mathrm{C}=3, \mathrm{I}=9 \ldots 134$ 


\section{Agradecimentos}

O número de pessoas que contribuiu, direta ou indiretamente, para este trabalho é tão grande que qualquer lista sempre será incompleta. Mesmo assim, aí vão aqueles que tiveram participação decisiva e com os quais me sinto em grande dívida.

Em primeiro lugar, agradeço à minha família, em especial meus pais, irmão e irmã por sempre me apoiarem e estarem presentes.

Ao meu orientador, Paulo Picchetti, minha enorme gratidão, que desde o mestrado acompanha o meu trabalho e que, novamente, aceitou orientar minha tese.

Aos professores Fabio Kanczuk e Gerson Francisco, pelos valiosos comentários e sugestões durante o exame de qualificação; agradeço também a Marcos Eugênio da Silva e Edmilson dos Santos por terem aceitado compor a banca de defesa.

Meus agradecimentos também aos professores do IPE com os quais tive oportunidade de trabalhar ou cujas disciplinas cursei. Em especial, a Elizabeth Farina, Fabiana Rocha, Francisco Anuatti, Eduardo Haddad, Reinaldo Fernandes, Naercio Menezes Filho e Raul Cristovão dos Santos;

Ao longo destes anos, fiz vários amigos na USP. Alguns deles contribuíram diretamente com esta tese, através de comentários, críticas e sugestões. Em particular, agradeço a Alan Genaro De Dario pelo auxílio técnico e a Matheus Albergaria Magalhães, pelos comentários.

Agradeço também aos amigos e colegas com os quais convivi no IPE, cujas discussões estão de certa forma aqui incorporadas. Não vou citá-los um a um, pois são muitos. Um agradecimento especial à Simone Teixeira pela paciência em sempre me ouvir e aconselhar.

Ao $\mathrm{CNPq}$, pelo financiamento; 


\section{Resumo:}

Esta tese tem como objetivo estudar os efeitos dos benefícios governamentais nos investimentos em petróleo e gás no Brasil, sob a abordagem da teoria das opções reais, a qual encara o investimento como uma call cujo ativo subjacente é o valor do projeto e cujo preço de exercício são os gastos no investimento. A vantagem desta abordagem é a avaliação do impacto de diversas flexibilidades operacionais, que assumem a forma de opções, sobre a decisão de investir. Tais flexibilidades são ignoradas em uma análise tradicional de valor presente líquido, podendo conduzir a uma sub-avaliação da jazida de petróleo e a decisões errôneas de investimento. Após uma análise quantitativa da série de preço internacional do petróleo, conclui-se que o Movimento Browniano Geométrico representa uma aproximação aceitável para representar a evolução do valor do barril, uma das variáveis de estado da qual o valor das reservas depende. Assume-se, também, que o valor da reserva depende do custo marginal de extração, o qual é crescente à medida que a jazida se esgota - uma propriedade peculiar aos recursos nãorenováveis conhecida como Efeito Jevons. Sob tais hipóteses, procura-se analisar como os royalties e as participações especiais no Brasil afetam a razão preço-custo que torna o agente indiferente entre investir ou não no desenvolvimento de um campo de petróleo ou gás, no contexto do término da fase de exploração e início da fase de desenvolvimento. 
Abstract:

This thesis has the aim of studying the effects of petroleum and gas government's benefits on investments, under the approach of Real Option theory, which considers the investment as a call whose underlying asset is the value of the project and whose strike price is the expense in investment. The advantage of this approach is the evaluation of several operational flexibilities - as options - on the decision to invest. These flexibilities are ignored in a traditional Net Present Value approach, which may lead to an undervaluation of the oil deposit and to an erroneous decision to invest. After a quantitative analysis on the international oil price series, we conclude that Geometric Brownian Motion is an acceptable proxy to perform the evolution of the barrel's value, which is one of the state variables the value of reserve depends on. We also assume that the value of reserve depends on the marginal cost of extraction, which is increasing as the reservoir depletes - a peculiar property of nonrenewable resources known as Jevon's Effect. Under such assumptions, we search to evaluate how royalties and special participation in Brazil affect the ratio price-cost which makes the agent be indifferent between invest or not invest in the development of a oil or gas field, in the context of the end of exploration phase and the beginning of the development. 


\subsection{Introdução}

O setor brasileiro de petróleo e gás natural vem sofrendo intensas transformações institucionais desde meados da década de 90. Tais mudanças foram desencadeadas pela aprovação da Emenda Constitucional n ${ }^{\circ} 9 / 95$, que quebrou o monopólio estatal nas atividades de exploração, refino e produção de petróleo no Brasil e pela Lei nº 9478/97, conhecida como "Lei do Petróleo", que fornece as diretrizes regulatórias fundamentais para o setor. Desde junho de 1999 foram realizadas seis rodadas de concessão de áreas de exploração de petróleo e gás, com sucesso considerável na abertura do setor à iniciativa privada ${ }^{1}$.

A nova legislação não altera o princípio constitucional de que "a pesquisa $e$ a lavra das jazidas de petróleo e gás natural e outros hidrocarbonetos líquidos", bem como importação e exportação de derivados e o seu transporte dutoviário ou marítimo constituem monopólio da União (CF, 1988, art. 177), mas autoriza o Governo a contratar terceiros para a execução de tais atividades. Assim, a partir das mencionadas rodadas de licitação, além da Petrobrás, mais de duas dezenas de empresas possuem projetos de exploração de petróleo e gás natural em campos terrestre e da plataforma continental brasileira.

A quebra do monopólio da Petrobrás e o crescimento da competição no setor alteraram de forma significativa o papel do Estado. De forma bastante genérica, as mudanças visam transformar o Estado brasileiro em agente regulador, em substituição ao seu papel de agente produtor único, desempenhado por mais de quarenta anos, desde o nascimento da indústria do petróleo no Brasil. Para desempenhar seu papel regulador, a União criou a Agência Nacional do Petróleo - ANP - administradora dos interesses do Governo junto às empresas privadas.

Uma companhia que adquire direitos de exploração sobre certa área está comprando um ativo que pode desenvolver imediatamente ou mais tarde, dependendo

\footnotetext{
${ }^{1}$ É importante ressaltar que o sucesso da abertura do setor na iniciativa foi bem sucedido apenas no setor de exploração. No setor de refino, a grande maioria das refinarias ainda é de propriedade da Petrobrás. Para um panorma do setor, ver ZAMITH (2001).
} 
das condições de mercado. Este projeto, portanto, é uma opção - o direito de decidir quando uma reserva será desenvolvida, dentro de certos limites temporais. Além disso, durante a fase de produção, a companhia pode decidir acelerar a extração a fim de aproveitar um momento de alta no preço do petróleo ou, similarmente, reduzir ou paralisar a produção em períodos de preço muito baixo. Por outro lado, a velocidade de extração do recurso está diretamente ligada ao crescimento dos custos unitários, um fenômeno conhecido na literatura como "Efeito Jevons": devido à limitação física do estoque, à medida que a produção se acumula (equivalendo ao esgotamento da jazida), o custo marginal se eleva, em virtude da progressiva diminuição da pressão nos poços. Desta forma, se os custos se tornarem proibitivos, o produtor tem a opção de abandonar a atividade. A cumulatividade dos custos (ou, de forma análoga, a finitude natural dos estoques dos recursos) se tornou um aspecto relativamente esquecido conforme a análise de opções reais foi ganhando espaço na literatura como método dominante de avaliação das jazidas.

A desconsideração destas opções e a avaliação apenas com base na razão preço-custo corrente pode levar a uma sub-avaliação do valor da reserva. Se uma companhia não incorporar as flexibilidades na avaliação da jazida, ela pode tomar decisões erradas, como sub-investir, oferecer um lance muito alto para a obtenção da concessão ou mesmo perdê-la para outros rivais quando tinha por objetivo genuíno adquiri-la.

Considere, por exemplo, uma situação em que a firma decida avaliar a reserva com base no critério do Valor Presente Líquido - VPL. Ela deverá tomar sua decisão e planejar o timing do desenvolvimento/extração com base na projeção dos fluxos de caixa futuros descontados, de acordo com o custo de desenvolvimento e com uma taxa esperada de crescimento de preços. Como o preço do petróleo é uma variável sujeita a um alto grau de incerteza, o investidor aplicará um prêmio de risco à taxa de desconto do fluxo de caixa, reduzindo o valor da reserva e, conseqüentemente, dificultando o investimento. Este procedimento, entretanto, pode 
ser míope no sentido de não levar em consideração a opção de adiar a tomada de decisão ou mesmo controlar a seqüência temporal dos gastos em desenvolvimento. Esta opção é uma flexibilidade que confere valor ao empreendimento, na medida em que evita perdas resultantes de más condições econômicas, já que, nesta situação, o investimento seria adiado ou cancelado. Em outras palavras, as opções fornecem um piso para o valor da reserva, impedindo que o projeto opere com lucros negativos.

Se as reservas não-desenvolvidas são consideradas uma opção de investir, pode-se avaliá-las com mais propriedade e, portanto, determinar o melhor momento de desenvolvê-las e extrair seus recursos. O desenvolvimento da reserva é entendido como o exercício de uma opção de compra (call) cujo strike são os gastos em investimento. Assim, a melhor atitude diante da incerteza pode ser manter em aberto a opção de desenvolvimento, à espera de novas informações.

O governo brasileiro, assim como o de muitos países, oferece à iniciativa privada o direito de exploração de recursos do subsolo terrestre e da plataforma continental em troca do pagamento de Benefícios Governamentais. A Lei do Petróleo no Brasil prevê três modalidades: Bônus de Assinatura - lance vencedor no leilão de licitação - , Royalties - percentual da receita bruta de produção e Participações Especiais, incidentes sobre a renda de projetos com grande produção. Cada modalidade apresenta um impacto sobre o risco e sobre o valor da reserva afetando, conseqüentemente, a decisão de investir.

Uma empresa privada candidata à obtenção de concessão de exploração deve se inscrever no leilão de licitação, desde que satisfaça os requisitos jurídicos e financeiros impostos no edital. O maior lance, em conjunto com alguns outros critérios $^{2}$, define o consórcio vencedor que obtém, por até 9 anos, o direito de empreender estudos prospectivos na região, mediante a obrigação de realizar o

\footnotetext{
${ }^{2}$ Em essência, são julgados três quesitos: lance, porcentagem de bens adquiridos junto a fornecedores no país na fase de exploração e porcentagem de bens adquiridos de fornecedores no Brasil no desenvolvimento. O peso de cada quesito e os lances mínimos de cada área podem variar de rodada para rodada. [ZAMITH (2001)].
} 
programa exploratório mínimo definido pela agência ${ }^{3}$. Até o término do período exploratório, o concessionário deve decidir pelo desenvolvimento da área ou pela sua devolução ao governo ${ }^{4}$. Caso decida produzir o recurso, a firma deve apresentar um Plano de Desenvolvimento à ANP, que pode aprová-lo ou exigir modificações. Concluído o procedimento, o concessionário obtém o direito de extrair e vender o petróleo da área por até 27 anos.

Uma breve reflexão sobre o processo resumido acima nos leva às seguintes questões: que parâmetros de decisão a firma leva em conta no momento de optar pela comercialidade da reserva? Como as políticas governamentais, notadamente a tributação sobre o setor, afetam a decisão de investir? Qual a melhor maneira de extrair os benefícios governamentais sem inviabilizar projetos potencialmente lucrativos?

O objetivo deste trabalho é analisar os impactos dos benefícios governamentais sobre os investimentos no setor de petróleo e gás, à luz da teoria das opções reais. Procura-se, neste contexto, avaliar como os tributos sobre o setor afetam a disposição de investir em desenvolvimento de campos de petróleo. A literatura mostra que, sob a análise de Valor Presente Líquido, algumas modalidades tributárias são neutras em detrimento de outras. Procura-se averiguar se estas conclusões se mantêm quando se incorporam as diversas flexibilidades com as quais um projeto de investimento se depara.

Embora haja trabalhos que incorporem o efeito da cumulatividade dos custos [eg.: CHERIAN et. al (2000)], em geral as soluções analíticas são impossíveis, e as soluções numéricas são muito complexas. Neste trabalho, propõe-se uma maneira mais simples de incorporar o Efeito Jevons na análise, com vistas a

\footnotetext{
${ }^{3} \mathrm{Na}$ última rodada de licitação, realizada em 17 e 18 de agosto de 2004, foi incluído o programa exploratório mínimo oferecido pelo concessionário como critério de avaliação. KRETZER (1993) faz algumas ressalvas a este modelo, utilizado em algumas áreas no Mar do Norte, já que pode induzir a um investimento sobre-ótimo.

${ }^{4}$ A legislação prevê que, sob condições muito específicas, o concessionário pode pedir uma prorrogação de até 5 anos na fase de exploração, sob certo custo.
} 
tentar reconciliar a avaliação das opções reais com os fatos estilizados da teoria dos recursos não renováveis [CAIRNS (1998)]. Para isso, assumimos a hipótese de que os custos operacionais unitários são inversamente proporcionais ao tamanho físico dos recurso e, como conseqüência, é possível unificar os parâmetros de crescimento de custos e de decaimento das reservas.

Esta tese está dividida da seguinte forma: no capítulo 1, apresentamos uma revisão da literatura relacionada ao tema das opções reais, englobando as principais críticas ao fluxo de caixa descontado, procurando mostrar como o novo ferramental permite superar suas deficiências. Apresentamos ainda um modelo genérico que caracteriza algumas opções como casos particulares de flexibilidades gerenciais; no capítulo 2, empreendemos alguns testes em uma série secular de preço internacional do petróleo, com vistas a identificar propriedades que justifiquem a utilização do movimento browniano geométrico como uma aproximação razoável da trajetória desta variável (em alternativa a abordagens que a modelam como um movimento de reversão à média); no capítulo 3, apresentamos o modelo teórico a ser utilizado para avaliar os impactos da estrutura de benefícios governamentais sobre a decisão de investir; no capítulo 4, apresentamos os principais resultados e procuramos identificar a estrutura tributária menos distorciva sobre os investimentos. Há, ainda, um capítulo que sintetiza as principais conclusões do trabalho. 


\section{Capítulo 1}

\section{Opções Reais e Teoria do Investimento}

Apesar da sua intuitividade e facilidade operacional, a teoria do valor presente tem se mostrado insuficiente para lidar com certas realidades da avaliação dos investimentos. Neste contexto, a análise das opções reais tem ganhado espaço cada vez maior. Um dos setores pioneiros para o uso da nova ferramenta foi o setor de petróleo e gás, por possuir características estilizadas que permitem aplicações interessantes da nova abordagem. Dentre tais peculiaridades, pode-se citar o elevado grau de risco, a longa maturidade dos empreendimentos, pesadas economias de escala e grande especificidade dos equipamentos, que conferem enorme irreversibilidade para os investimentos.

Com a progressiva utilização do novo instrumental, vários estudiosos acabaram deixando de lado alguns aspectos importantes da teoria dos recursos não renováveis [CAIRNS (1998)], dentre os quais a finitude dos estoques, cuja conseqüência mais importante é o crescimento dos custos operacionais à medida que o recurso é extraído. Esta propriedade da função de custos, conhecida na literatura como "Efeito Jevons", pode ter conseqüências importantes sobre a avaliação dos investimentos na exploração de petróleo. O instrumental das opções reais 
também possibilita a análise dos impactos de política sobre a decisão de investir, dentre as quais a tributação: como é de praxe no marco regulatório do setor em vários países [OTTO (1998)], os governos tendem a oferecer à iniciativa privada os direitos de exploração e produção em troca de compensações financeiras, conhecidas como Benefícios Governamentais.

O objetivo deste capítulo é introduzir os conceitos fundamentais da análise de opções reais, sobretudo quando aplicada ao setor de petróleo e gás, e apresentar um panorama sobre o estado da arte. A seção 1 é introdutória do tema e a seção 2 traz uma revisão da literatura mais relevante. Por fim, na seção 3, apresentamos um modelo genérico de opções reais, com vistas a abarcar algumas flexibilidades possíveis de um projeto de investimento.

\subsection{Introdução}

A avaliação da viabilidade econômica dos investimentos conta com uma antiga e extensa literatura. Há uma diversidade grande de abordagens, cada uma das quais enfatizando diferentes elementos que pesam sobre a decisão de investir, seja em nível micro, seja em nível macroeconômico. Agrupá-las e identificar seus elementos em comum representam um grande desafio para qualquer estudo, já que cada teoria conta com diferentes métodos e diferentes abordagens.

Apesar da dificuldade, DIXIT \& PINDYCK (1994) estabelecem duas classificações para o conjunto de teorias de investimento, tendo em vista o critério sugerido para a tomada de decisão de investir: a Teoria Ortodoxa e a Nova Teoria.

A Teoria Ortodoxa, derivada do pensamento neoclássico, baseia a avaliação dos investimentos no princípio do Valor Presente Líquido (VPL), definido como o valor presente dos fluxos de caixa futuros produzidos por um projeto, descontado o investimento inicial. Em termos matemáticos, se $R_{t}$ forem as receitas esperadas no instante $t, C_{t}$ os custos, $r$ a taxa de desconto (suposta constante) e $I$ o investimento inicial, o VPL de um projeto de investimento é dado por: 


$$
V P L=-I+\frac{\left(R_{1}-C_{1}\right)}{1+r}+\frac{\left(R_{2}-C_{2}\right)}{(1+r)^{2}}+\ldots+\frac{\left(R_{T}-C_{T}\right)}{(1+r)^{T}}=-I+\sum_{t=1}^{T} \frac{R_{t}-C_{t}}{(1+r)^{t}}
$$

O VPL procura estabelecer uma regra objetiva de decisão para avaliar se um empreendimento é viável ou não: se o VPL for positivo, o projeto deve ser aceito enquanto um VPL negativo sugeriria um investimento inviável ${ }^{1}$. O princípio básico do critério do VPL é estabelecer uma comparação entre ganhos e perdas futuras trazidos a um único instante de tempo e, a partir daí, avaliar se a decisão de investir deve ser empreendida ou não.

A Teoria Ortodoxa obteve grande hegemonia na análise de investimentos e, até hoje, constitui a base para muitos critérios de tomada de decisão, notadamente quando alguns pré-requisitos são preenchidos, tais quais baixa incerteza e possibilidade de recuperação dos gastos em investimento.

Ao longo do tempo, o pensamento econômico produziu teorias mais sofisticadas com vistas a explicar o investimento, a maior parte baseada no princípio da maximização do VPL ou do lucro. O resultado mais importante deste conjunto de teorias, conhecidas como teorias neoclássicas do investimento, é o de que o agente deve investir até o ponto em que a produtividade marginal do capital é igual à taxa de juros, dado que esta representa o custo de oportunidade para aplicação de recursos produtivos. Obedecendo a este princípio, o agente estaria maximizando o lucro de sua firma. A principal conseqüência deste princípio é o resultado de que o volume de investimentos varia inversamente com o nível da taxa de juros.

Segundo DIXIT \& PINDYCK (1994) e PINDYCK (1991), apesar do grande

\footnotetext{
${ }^{1}$ Uma variante da regra do VPL é a regra da Taxa Interna de Retorno (TIR), isto é, a taxa $r$ que produz $V P L=0$. Se a TIR for superior à taxa de juros, o investimento deve ser levado adiante. A TIR também é conhecida como Eficiência Marginal do Capital.
} 
sucesso e da relativa facilidade operacional, a teoria ortodoxa do investimento falha em três aspectos fundamentais:

Em primeiro lugar, é muito difícil incorporar a incerteza no modelo. A análise do valor presente requer uma estimativa de todo o fluxo de caixa do projeto e quanto mais distante for este no futuro, menor a confiança que se deposita nas estimativas, as quais podem se tornar muito subjetivas dependendo do horizonte do projeto a que se referem. Isso prejudica a avaliação do investimento pelo princípio do valor presente. A fragilidade fundamental da incorporação da incerteza na abordagem do VPL é a definição de uma taxa de desconto adequada. Em particular, JACOBY \& LAUGHTON (1992) avaliam que as inter-relações simultâneas entre fluxo de caixa esperado, taxa de desconto ajustada ao risco, estratégia ótima e resultados obtidos são pouco identificáveis nesta linha de modelos e, quando o grau de risco do projeto é variável ao longo do tempo, a taxa de desconto correta sequer pode ser calculada.

Outro problema ocasionado pela análise do VPL é a suposição implícita de reversão plena de todos os investimentos, ou seja, a possibilidade de recuperação dos gastos em caso de interrupção do andamento do projeto. Trata-se de uma hipótese pouco realista, já que em boa parte dos setores industriais verifica-se a presença de investimentos irreversíveis ${ }^{2}$ (ou sunk costs), isto é, uma vez tomados, não podem ser recuperados em caso de desistência. A irreversibilidade dos investimentos decorre da especificidade dos equipamentos em certa indústria [DIXIT \& PYNDICK (1994); PINDYCK (1988)]. Por exemplo, uma plataforma de petróleo não possui outras utilidades a não ser servir à extração de recursos do subsolo e mesmo que haja um mercado secundário para estes equipamentos, ele tende a ser limitado. Além disso, como ocorre no Brasil, a agência reguladora pode determinar que, em caso de desistência, todos os equipamentos devem ser revertidos à União. A irreversibilidade acarreta um enorme custo de oportunidade, tornan-

\footnotetext{
${ }^{2}$ Para uma abordagem matemática do conceito de irrreversibilidade, ver HENRY (1974).
} 
do o investimento uma decisão "única e para sempre" de modo que, uma vez tomada, a firma abre mão de adiar o gasto e esperar por novas informações. Esta característica tem influência significativa sobre a avaliação do projeto e, portanto, sobre a decisão de investir.

Uma terceira limitação do VPL como método de avaliação de investimentos é a pouca margem para o controle do timing do projeto. Assume-se, ainda que implicitamente, que as decisões de investimento são inflexíveis, isto é, de natureza "agora ou nunca", negligenciando possíveis ganhos na administração da sucessão das etapas do projeto. Mesmo que o critério do valor presente indique a inviabilidade de um investimento hoje, a simples possibilidade de adiamento de sua execução, no intuito de aguardar condições econômicas mais favoráveis, afeta sua avaliação, podendo torná-lo viável. Na prática, os empreendedores possuem uma boa margem para administrar a seqüência temporal das fases de um projeto e, muitas vezes, o agente pode ganhar mais se esperar antes de investir, à medida que novas informações se tornem disponíveis.

Estas três limitações tornam a análise de valor presente pouco útil para a avaliação dos impactos de políticas sobre os investimentos, pois acarretam as seguintes implicações: a) considera-se que o investimento possui um caráter de "agora ou nunca", descartando a flexibilidade de gerenciamento do timing do projeto de acordo com as condições da economia; b) assume-se que os gastos podem ser revertidos, o que representa uma hipótese pouco realista, sobretudo em setores com equipamento específico, como o de petróleo; c) o tratamento da incerteza é precário, limitando-se a incorporar um prêmio de risco à taxa de desconto dos fluxos futuros.

Desta forma, a avaliação dos efeitos de política (como a tributação), sob uma análise de valor presente não permite incorporar todas as interações entre as diversas dimensões do valor do projeto. A teoria das opções reais contribui para melhorar a maior parte das deficiências relatadas.

Pelo fato da incerteza, da irreversibilidade das decisões e da possibilidade de 
Tabela 1.1: Comparação entre opções sobre ações e opções reais

\begin{tabular}{||c||c||}
\hline \hline Opção de ações & Opção Real \\
\hline \hline Preço da ação & Valor Presente do Projeto \\
\hline Preço de Exercício & Custo do Investimento \\
\hline Maturidade & Prazo em que há oportunidade de investimento \\
\hline Volatilidade do preço da ação & Volatilidade do valor presente do projeto \\
\hline Dividendo da Ação & Lucros e Dividendos do Projeto \\
\hline
\end{tabular}

adiamento serem características importantes dos investimentos, uma nova vertente teórica vem se desenvolvendo nos últimos vinte anos, procurando englobar tais elementos nos modelos de avaliação de investimentos: trata-se da teoria das opções reais ${ }^{3}$, uma ferramenta útil para incorporar a irreversibilidade, o controle do tempo, e a incerteza na avaliação do projeto e na estratégia ótima de investir. Esta abordagem traça um paralelo entre o investimento e as usuais opções sobre ações, no qual a oportunidade de investimento é encarada como uma opção americana de compra em que o preço do ativo fundamental é o valor presente esperado do projeto. O investimento, portanto, é associado ao exercício da opção o que, assim como nos derivativos, só deve ser realizado se as condições forem propícias $^{4}$.

A comparação com o mercado de ações é direta. A tabela 1.1 resume os parâmetros das opções financeiras e o que elas significam no caso de um projeto de investimento genérico, de acordo com a fase em que se encontra. Ela

\footnotetext{
${ }^{3}$ Bons panoramas desta vertente teórica encontram-se presentes em PINDYCK (1991); DIXIT \& PINDYCK (1994); TRIGEORGIS (1995, 1996a); BRENNAN \& TRIGEORGIS (2000); SCHWARTZ \& TRIGEORGIS (2001). Uma abordagem mais aplicada pode ser encontrada em COPELAND \& ANTIKAROV (2002).

${ }^{4}$ MOSZKOWICZ (2003) chama a atenção para um aspecto interessante: a teoria usual do VPL falha em avaliar as diversas flexibilidades do projeto na medida em que foi originalmente desenvolvida para investimentos passivos em títulos, cujos rendimentos são dados pelos cupons, previamente conhecidos. Assim, projetos de investimento que admitem grandes flexibilidades gerenciais e temporais tendem a ser desfavorecidos. A avaliação por opções reais ganhou força à medida que os instrumentos derivativos e suas avaliações foram se sofisticando no mercado financeiro.
} 
Tabela 1.2: Opção de Compra e Opções sobre reservas não desenvolvidas

\begin{tabular}{||l||l||l||}
\hline \multirow{2}{*}{\multicolumn{1}{||c||}{ Call }} & \multicolumn{1}{c||}{ Opção Real sobre: } \\
\cline { 2 - 3 } & \multicolumn{1}{c||}{ Exploração } & \multicolumn{1}{c||}{ Desenvolvimento } \\
\hline \hline Preço da ação & Valor reserva não-desenvolvida & Valor reserva desenvolvida \\
\hline Preço de exercício & Gastos em exploração & Gastos no desenvolvimento \\
\hline Maturidade & Prazo de exploração & Prazo de desenvolvimento. \\
\hline Volatilidade & Volatilidade do valor da reserva & $\begin{array}{l}\text { Volatilidade do valor da reserva } \\
\text { desenvolvida }\end{array}$ \\
\hline Dividendos da Ação & Receita líquida da produção menos exaustão \\
\hline \hline
\end{tabular}
Fonte: SUNNEVAG (1998)

mostra a correspondência de parâmetros entre as opções sobre ações e as opções reais, para um projeto de investimentos de ordem geral. Em muitas ocasiões, um empreendimento é composto de diversas etapas, o que requer o refinamento e a subdivisão destes parâmetros. Neste caso, os conceitos estilizados dos mercados de opções são mais facilmente identificáveis. Um projeto petrolífero, por exemplo, é dividido em duas fases principais ${ }^{5}$ : Exploração e Desenvolvimento/Produção. Na primeira, são efetuados gastos na descoberta e avaliação de reservas; na segunda, investe-se na infraestrutura necessária para a produção do recurso e seu aproveitamento econômico propriamente dito. No final da exploração, o agente deve tomar a decisão de investir ou não no desenvolvimento da jazida. Deste modo, ele se depara com uma opção de usufruir os benefícios econômicos do projeto em troca do investimento.

A tabela 1.2 resume os parâmetros da opção financeira para um projeto petrolífero, de acordo com a fase em que se encontra. Ao fim do período exploratório, o agente tomará a decisão de exercer ou não sua opção de investimento e, para isso, ele deve levar em conta uma série de parâmetros que afetam o valor do projeto. Em primeiro lugar, deve avaliar se o investimento necessário para desenvolver a reserva é compatível com o valor da reserva desenvolvida, pois quanto

\footnotetext{
${ }^{5}$ A rigor, três fases, pois a fase de desenvolvimento é distinta da de produção. Entretanto, é comum englobar as duas últimas em uma só.
} 
maior aquele em relação a este, menos provável é a decisão de investir; em segundo lugar, o agente deve ponderar o tempo total permitido para o desenvolvimento, da mesma forma que no caso da opção de compra; além disso, a volatilidade do valor do ativo subjacente também é um fator que deve ser incorporado, pois a incerteza afeta o valor da opção. Por fim, assim como os dividendos exercem influência na precificação das calls, o lucro do projeto também deve ser analisado na decisão de investimento.

Apesar da analogia pretender ser direta, há alguns problemas na transposição dos parâmetros de um caso para o outro. Diferentemente do mercado financeiro em que o valor do ativo subjacente é uma variável facilmente observável e também quantificável, a avaliação do ativo real é mais complicada, pois requer a estimação do valor presente de todos os seus fluxos futuros. Desta forma, apesar de fornecer um instrumental mais acurado para a estimação do valor do projeto, a análise das opções reais não elimina o problema de predizer o fluxo de caixa futuro. Além disso, como ocorre com o caso do petróleo, é necessário muitas vezes supor que exista um mercado para o ativo, como o caso das reservas desenvolvidas. Por fim, nem sempre o preço de exercício (no caso o investimento) é conhecido de antemão, pois está sujeito a um conjunto de incertezas.

McCORMACK et al. (2001) listam outras diferenças entre as opções sobre ações e as opções sobre ativos reais, como as reservas não-desenvolvidas:

a) o exercício de uma opção de compra fornece ao seu detentor o ativo subjacente, que possui um preço de mercado prontamente observável, ao passo que exercer uma opção real (por exemplo, desenvolver uma reserva) resulta em uma série de fluxos de caixa ao longo de vários anos. Este fluxo é muito sensível a flutuações de preço e de custos;

b) o valor do projeto varia de acordo com a taxa de produção, a qual tende a ser decrescente devido à exaustão dos poços;

c) a qualidade das reservas é variável de acordo com as condições geológicas de sua localização, de modo que seu valor pode não ser totalmente conhecido; 
d) o custo do desenvolvimento (preço de exercício) pode não ser independente do fluxo de caixa futuro (valor do projeto), sobretudo se houver disputa para compra de equipamentos; por outro lado, é possível que os fluxos de caixa sejam endógenos ao gasto em investimento.

e) a estimação da volatilidade pode ser complexa, pois em geral a variância do preço do petróleo não é a mesma da do valor do empreendimento;

f) enquanto o exercício da opção sobre ações implica na obtenção imediata do ativo fundamental, a decisão de converter reserva não-desenvolvida em reserva desenvolvida requer algum tempo para se concretizar (time to build), pois os investimentos precisam estar concluídos para que o projeto gere receitas;

g) opções sobre ações usam a taxa de juros livre de risco para sua avaliação, devido a questões de arbitragem. No caso do desenvolvimento de reservas, os fluxos de caixa futuro podem embutir um risco político, o que requer a adição de um prêmio para que se possa depreender uma avaliação ajustada ao risco.

Deste modo, a utilização da análise de opções para a avaliação de reservas requer uma série de adaptações e/ou hipóteses simplificadoras, com vistas a acomodar estas especificidades.

A lógica fundamental da análise das opções reais é o reconhecimento de que diversas flexibilidades agregam valor do projeto, interferindo no processo de investimento. No exemplo de PINDYCK (1991):"The option value of waiting creates an opportunity cost, and this must be added to the current direct cost of destroying the wilderness area when doing a cost-benefit analysis of the parking lot" (p. 1143). O critério do valor presente líquido, neste caso, se torna incompleto para avaliar os determinantes da decisão de investir, podendo conduzir a decisões contraditórias com o critério de opções reais.

Considere, a título de exemplo, a flexibilidade gerada pela opção de adiar a decisão de investir. O investimento contém um importante custo de oportunidade, que consiste em esperar pela chegada de novas informações. Este custo de oportunidade deve ser levado em consideração na forma da adição de um valor 


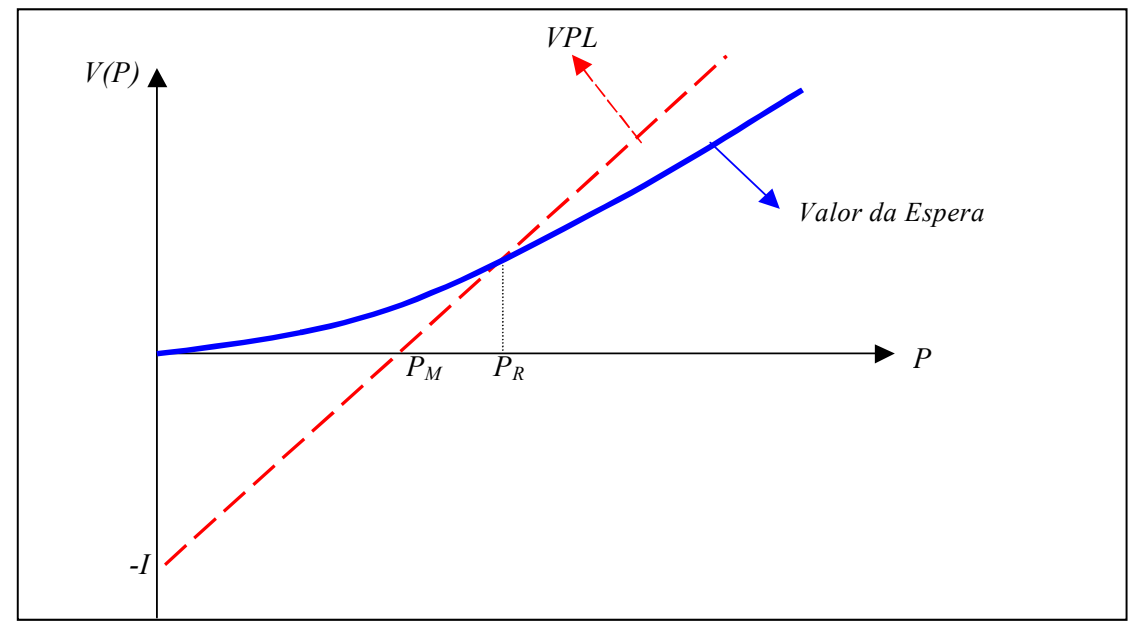

Figura 1-1: Valor da Espera X Valor da Reserva

ao projeto ou, em termos equivalentes, de um valor de espera.

A figura 1-1 ilustra o ponto. A curva pontilhada representa o Valor Presente Líquido, que é linear em relação ao preço. Sob este critério, o investimento deve ser empreendido quando o preço for igual ou superior a $P_{M}$ (também conhecido como preço marshalliano); a curva cheia é o valor da espera, que representa o custo de oportunidade de adiar o investimento, que também depende do nível de preços, já que quanto maior este, mais vantajoso é o projeto. O investimento só deve ser realizado se o valor presente líquido superar o valor da espera, que ocorre quando $P>P_{R}$. Este é chamado de "preço de gatilho" (trigger price) ou preço limite. Note que $P_{M}<P_{R}$, ou seja, decisões de investimento baseadas no critério do VPL podem conduzir a erros de avaliação.

Apesar de suas dificuldades e de suas potenciais limitações, a análise de opções reais representa um poderoso instrumento para avaliação de investimentos considerando as mais diversas flexibilidades possíveis, as quais agregam valor ao projeto. Exemplos típicos são:

Opção de fechamento (shutdown): quando a firma se depara com condições econômicas desfavoráveis, como queda abrupta de preços ou elevação proibiti- 
va dos custos, ela pode optar por paralisar temporária ou definitivamente suas atividades. No caso de uma empresa extrativa, por exemplo, o produtor pode interromper a extração durante o período de baixa no preço; por outro lado, o abandono ocorre quando as condições de custo inviabilizam a continuidade do empreendimento. A possibilidade de abandonar o projeto é avaliada como uma opção de venda cujo preço de exercício é seu valor residual.

Opção de ampliação ou expansão: se houver uma melhora imprevista nas condições de demanda, pode ser vantajoso para a firma ampliar suas operações, investindo em capacidade adicional. Ela é avaliada como uma opção de compra americana cujo preço de exercício é o investimento nas instalações complementares.

Opção de adiamento: quando há incerteza sobre as condições econômicas, o agente pode julgar mais vantajoso adiar o investimento, à espera da chegada de mais informações. Isso ocorre porque existe um custo de oportunidade de realizar um gasto definitivo e irrecuperável, que consiste em esperar por melhores condições. Em particular, conforme aponta McCOMARCK et al. (2001), a análise de opções reais é a mais adequada para a decisão de converter reservas não desenvolvidas em reservas desenvolvidas, tendo em vista a forte irreversibilidade dos gastos no processo de desenvolvimento das reservas.

\subsection{Revisão Bibliográfica}

Conforme já dissemos anteriormente, o setor de petróleo e gás apresenta uma série de características (sunk costs, incerteza, longa maturidade) que o tornam um campo fértil para a utilização do instrumental das opções reais. Desta forma, o desenvolvimento das técnicas se deu de forma praticamente simultânea à sua aplicação nesta área, de modo que ambas as literaturas possuem um profundo grau de entrelaçamento. Uma resenha detalhada da literatura pode ser encontrada em PINDYCK (1991). 
TOURINHO (1979), em seu trabalho seminal, foi um dos pioneiros na utilização das opções reais na avaliação de recursos naturais. Ele analisa o paradoxo da extração, isto é, o resultado de que nunca será ótimo extrair um recurso se não houver prazo para isso. Isso acontece pois o valor da reserva no solo e o preço do recurso extraído não podem crescer simultaneamente à taxa de juros, para eliminar oportunidades de arbitragem . Ele propõe e analisa duas soluções para o paradoxo: introdução de custos de manutenção de reservas no solo e custos crescentes para extração. Uma de suas conclusões mais importantes é de que o aumento da incerteza contribui para elevar o investimento ótimo em exploração.

Boa parte dos desdobramentos posteriores da teoria resultou da combinação de TOURINHO (1979) com os trabalhos de PADDOCK et al. (1988), McDONALD \& SIEGEL (1984) e MAJD \& PINDYCK (1987). Ao mesmo tempo, é possível identificar duas grandes vertentes metodológicas mas que, em essência, conduzem aos mesmos resultados: análise em tempo contínuo e por árvore de informações.

A análise em tempo contínuo pressupõe a evolução do ativo fundamental de acordo com um processo composto, em geral, por um termo de tendência e por incrementos estocásticos, com vistas a incorporar a incerteza no valor. Em termos gerais, assume-se que o valor da reserva $V$ evolui de acordo com um processo estocástico pré-definido:

$$
d V=\alpha(V, t) d t+\sigma(V, t) d Z
$$

onde $\alpha(V, t)$ e $\sigma(V, t)$ são parâmetros que governam o valor do ativo e $d Z$ são incrementos de Wiener. A incorporação de (1.2) no critério de maximização do agente resulta em uma equação diferencial cuja solução determina o valor da reserva como função dos parâmetros relevantes.

A abordagem da árvore de informações pressupõe que o valor do ativo, em cada instante de tempo, assume um conjunto de valores possíveis ${ }^{6}$. A cada estado,

\footnotetext{
${ }^{6}$ Quando o número de estados no período seguinte a cada nó é igual a dois, trata-se de uma
} 




Figura 1-2: Esquematização-tempo discreto

associa-se uma probabilidade. O diagrama abaixo ilustra a idéia para uma árvore de informações binomial, inspirada na metodologia desenvolvida por COX, ROSS \& RUBINSTEIN (1979) para o caso de opções sobre ações ${ }^{7}$.

Cada nó representa um estado no qual a incerteza foi resolvida. No instante $t_{1}$, há dois estados possíveis: o projeto pode assumir valor $V^{+}$com probabilidade $p$ e $V^{-}$com probabilidade $1-p$. O valor de $V$ é obtido retroativamente, observandose a lucratividade em cada estado de $t_{1}$. A vantagem da teoria das opções reais em relação à avaliação tradicional é o estudo de como as diversas flexibilidades operacionais, combinadas com a evolução de $V$, afetam o valor do projeto e da decisão de investir.

MCDONALD \& SIEGEL (1984) analisam o valor das flexibilidades em um contexto mais geral, incorporando a opção de interrupção temporária sem custos das atividades (shutdown), assumindo preço e custos estocásticos e correlacionados entre si. Utilizando uma fórmula aproximada para call européia (isto é, que só pode ser exercida no vencimento), os autores realizam exercícios de estática comparativa que avaliam alterações em parâmetros (incerteza, taxa de juros, custo, convenience yield) sobre o valor do projeto. Suas principais conclusões são: a)

árvore binomial.

${ }^{7}$ Quando $\Delta t=t_{1}-t_{0} \rightarrow 0$, a análise da árvore de informações equivale ao tempo contínuo. 
aumentos na variância do preço podem elevar ou reduzir o valor do projeto $^{8}$; b) não há necessidade de se prever preços, já que o uso de preços futuros observados elimina a necessidade de ajuste para o risco sistemático; c) para um projeto com estoque de capital dado, é possível que fluxos de lucro incertos em futuro distante tenham valor corrente maior que fluxos imediatos. Tais resultados diferem, em termos econômicos, das conclusões usuais de Black \& Scholes.

Outra contribuição significativa na análise das flexibilidades é o de BRENNAN \& SCHWARTZ (1985), que incorpora os efeitos de três flexibilidades em um projeto extrativo genérico: operar o projeto, paralisar temporariamente e abandonar, ilustrando como elas afetam o valor da jazida. Assume-se, ainda, que a taxa de extração depende do preço do produto, através de um problema de controle ótimo com reservas homogêneas e infinitas, com custos conhecidos.

Ao longo do tempo, a literatura sobre a ferramenta de opções reais evoluiu através da incorporação dos fatos estilizados e flexibilidades que conferem valor ao investimento. MAJD \& PINDYCK (1987) avaliam os efeitos do time to build, isto é, incluindo o investimento seqüencial em unidades produtivas heterogêneas. O tempo necessário para que as instalações sejam concluídas antes que o projeto passe a gerar fluxos de renda é incorporado através de uma velocidade máxima à qual suas etapas são realizadas. A idéia é que o time to build representa uma flexibilidade temporal do projeto cujo controle permite respostas ótimas à chegada de novas informações. Além disso, na medida em que o investimento só começa a gerar lucros quando está terminado, o adiamento da conclusão das instalações representa um custo de oportunidade composto pelo adiamento dos fluxos de receita. A conclusão dos autores é que o time to build majora o efeito da incerteza sobre o valor do projeto e sobre a decisão de investir ${ }^{9}$.

\footnotetext{
${ }^{8} \mathrm{Um}$ aumento na variabilidade do preço do produto aumenta a esperança de lucros futuros (para dado estoque de capital), mas pode reduzir o valor presente de tais lucros. O resultado líquido depende da medida como o fluxo de caixa do projeto covaria com os fluxos de outros ativos da economia.

${ }^{9}$ Em particular, o time to build eleva o valor limite (trigger value) acima do qual a decisão de
} 
DIXIT (1992) analisa um fenômeno interessante que pode ser explicado pela teoria das opções reais, cuja análise pelo método do fluxo de caixa descontado é precária: trata-se da histerese, isto é, a inércia das decisões em relação as condições econômicas. Em termos mais precisos, a entrada de uma firma em um mercado (ou seja, uma decisão de investimento) não é atrativa quando o preço está acima do custo médio, mas quando o preço está suficientemente acima do custo médio. O grau em que o preço deve estar acima do custo médio para induzir a entrada depende da combinação da incerteza com a irreversibilidade. Do mesmo modo, é possível observar a permanência de firmas em um mercado por um período significativo de tempo mesmo com receitas abaixo dos custos, em virtude dos custos de saída produzidos pelos investimentos irreversíveis. Nos termos da análise de opções reais, a histerese ocorre pelo valor da espera gerado pela incerteza e pela irreversibilidade (vide figura 1-1), bem como pelos custos de entrada/saída.

PINDYCK (1988) analisa a opção de crescimento no contexto da escolha da capacidade operacional, em que o valor do investimento inclui a opção de adicionar capacidade instalada se as condições de mercado forem favoráveis. Sua conclusão é de que, na presença de irreversibilidade, a capacidade escolhida é sempre menor do que sob VPL e o valor da firma pode ser fortemente atribuído às possibilidades de crescimento. Em outras palavras, a opção de incorporar capital adiciona valor e a irreversibilidade leva a firma a manter menos capacidade como uma proteção contra quedas não antecipadas na demanda. Como conseqüência, o investimento ocorre em "surtos", quando a demanda cresce acima de níveis históricos.

PADDOCK et al. (1988) foram um dos pioneiros no emprego das opções reais na avaliação de reservas de petróleo, tendo identificado características im-

investir é tomada. KULATILAKA (1995a) atribui às seguintes características o time to build: a) investimento sequencial ao longo do tempo; b) máxima taxa de incorporação de capital; c) não há retorno até os investimentos estarem concluídos. 
portantes que nortearam os trabalhos posteriores. Ele chama a atenção para algumas falhas da análise de VPL (algumas já apontadas acima), em particular o problema da não-homogeniedade de avaliação de uma reserva por diferentes firmas, na medida em que cada uma apresenta diferentes distribuições esperadas de preço e diferentes graus de aversão ao risco. A análise de opções reais, na medida em que assume um processo estocástico para o valor da reserva (ou para o preço) permitiria superar esta deficiência, além das demais apontadas por DIXIT \& PINDYCK (1994).

Em particular, PADDOCK et al (1988) discutem a necessidade de se incorporar um modelo de equilíbrio de mercado para o ativo subjacente, ao contrário do que acontece com opções de ações, cujos dividendos normalmente são dados. No caso de opções sobre reservas, é necessário combinar o ganho de capital produzido pela posse do recurso com a lucratividade decorrente da sua extração, ou seja, no equilíbrio, o resultado líquido de manter uma reserva desenvolvida (lucro mais ganhos de capital) deve compensar o proprietário do custo de oportunidade de investir na sua extração. Para isso, é fundamental que haja um mercado para reservas desenvolvidas, ou seja, um conjunto de reservas que possuem estruturas fiscais e de custos análogas para efeitos de avaliação dos recursos.

Um tópico presente na literatura foi a relevância do valor incorporado pela irreversibilidade e pelas flexibilidades. BJERKSUND \& EKERN (1990) levantaram a discussão e, através de um modelo aplicado à extração de recursos nãorenováveis, analisam diversas flexibilidades e concluem que o efeito da flexibilidade temporal do investimento (possibilidade de adiar a decisão) é significativo, mas o efeito adicional da opção de abandono ou da flexibilidade operacional sobre o valor do projeto é pequeno. Mesmo assim, aconselham que elas não sejam ignoradas, pois podem induzir a decisões de investimento equivocadas.

Apesar das flexibilidades adicionarem valor aos projetos, TRIGEORGIS (1993) chama a atenção para a não-aditividade das opções, isto é, as flexibilidades, na medida em que interagem entre si, agregam valor de forma não aditiva. Por ex- 
emplo, o valor incremental de uma opção de abandono é diferente na presença e na ausência de opção de paralisação. Em particular, mostra-se que o valor incorporado por uma opção adicional, na presença de outras flexibilidades, é menor que o seu valor isolado, além de ser decrescente no número de opções presentes. Se $F_{i}$ for o valor da flexibilidade (opção) $i$, tem-se, em geral:

$$
F_{1}+F_{2}+\ldots+F_{n} \leq F_{(1, \ldots, n)}
$$

$$
\lim _{n \longrightarrow \infty} F_{n+1}=0
$$

onde $F_{(1, \ldots, n)}$ é o valor conjunto das $n$ opções. Desta forma, a desconsideração de uma opção específica tende a não acarretar erros de avaliação quanto maior o número de flexibilidades presentes no projeto.

Esta constatação acarreta uma série de dificuldades para a avaliação por opções reais, dentre as quais o fato de que o exercício de uma opção afeta, necessariamente, o valor das opções remanescentes ${ }^{10}$. De acordo com TRIGEORGIS (1993), só é possível separar os valores das opções quando não existe interação entre elas e isso é tanto mais provável quanto menos o exercício de uma afetar o valor de outra. Segundo ele, as opções tendem a ser mais aditivas quando: a) as opções envolvidas são de tipo oposto (compra vs. venda); b) as maturidades são próximas (ou então são de tipo européia); c) quando as opções estão "out of money" (cujo exercício não é vantajoso). Nestes casos, as regiões de exercício não se sobrepõem, garantindo a aditividade. Apesar desta advertência, a grande maioria dos trabalhos em opções reais tende a utilizar a propriedade da aditividade,

\footnotetext{
${ }^{10}$ Além disso, não há muito consenso sobre a importância das flexibilidades. KULATILAKA \& MARKS (1988) mostram que é possível que a presença de uma tecnologia flexível versus uma tecnologia rígida pode reduzir o valor da firma, ao invés de elevá-lo.
} 
que só é válida para casos muito específicos. TRIGEORIS (1996) aplica o seu modelo de 1993 para o caso de contratos de leasing, nos quais há a tríplice opção de cancelar antecipadamente, estender sua duração ou comprar o ativo ao final do contrato. Utiliza-se uma abordagem numérica de árvore binomial, ilustrando como as interações entre as opções contratuais alteram o valor do leasing.

KULATILAKA (1995b) também aborda o problema da interatividade dos valores das opções presentes em um projeto. Os valores incrementais de cada opção podem ser crescentes ou decrescentes quando um projeto já possui outras flexibilidades operacionais. Sua conclusão é de que a opção de esperar para investir vale menos na presença da opção de paralisação temporária e/ou crescimento, implicando em uma relação de substitubilidade ${ }^{11}$ entre elas; por outro lado, a opção de paralisar vale mais na presença de opção de crescimento, identificando uma relação de complementaridade entre ambas.

Na linha da árvore de informações, registram-se as contribuições de JACOBY \& LAUGHTON (1992), LAUGHTON (1998a), SALAHOR (1998), BRADLEY (1998), LAUGHTON (1998b) dentre outras. LAUGHTON (1998a) chama a atenção para a melhor adequação da nova teoria para a presença de não-linearidades nos fluxos de caixa do projeto, as quais podem ser provocadas, na maioria dos casos, pela presença de opções operacionais. Os três últimos trabalhos compõem uma série que aplica o modelo de opções reais (chamado Modern Asset Pricing - MAP) para diferentes situações, como tradeoff entre investimento de capital e custos operacionais, tradeoff entre custos e produção potencial em jazidas de gás [SALAHOR (1998)], análise de não-linearidades produzidas por regimes fiscais progressivos [BRADLEY (1998)] e flexibilidades no tempo de exploração, desenvolvimento e abandono de campos desenvolvidos de petróleo [LAUGHTON (1998b)].

Os modelos de avaliação de opções reais ganharam enorme popularidade nos

\footnotetext{
${ }^{11} \mathrm{Ou}$ seja, a presença de opção de paralisar tenderia a reduzir o valor da opção de esperar, facilitando o investimento.
} 
últimos dez anos, com aplicações para uma ampla variedade de situações e setores além de óleo e gás. Exemplos de resenhas e aplicações de opções reais são KEMMA (1993), TRIGEORGIS (1995, 1996a).

Apesar de sua ampla utilização, WEEDS (2002) aponta alguns problemas com a abordagem das opções reais. Segundo sua análise, nem sempre o valor da espera é algo mensurável, na medida em que as empresas podem se deparar com restrições de ordem estratégica, sobretudo quando se considera a interação competitiva com outras firmas. Por exemplo, as oportunidades de investimento podem não estar abertas por tempo considerável, tendo em vista a possibilidade de ocupação por uma rival. Um exemplo típico é o caso do desenvolvimento de novas tecnologias: embora se aplique com freqüência a ferramenta das opções reais nesta situação (já que o valor da espera pode ser significativo), a disputa por patentes pode restringir as opções da firma, que pode se ver compelida a acelerar o investimento. Neste caso, a análise se degenera para o caso "agora ou nunca", reduzindo-se a avaliação a algo próximo do valor presente líquido. Na sua opinião, as opções reais são mais úteis quando associadas a uma análise de rivalidade, como, por exemplo, a teoria dos Jogos. Apesar destas advertências, as opções são amplamente utilizadas na análise de investimentos na indústria do petróleo, já que sua natureza (regime de concessões de direitos de exploração) o livra da maior parte de tais restrições.

Em síntese, as aplicações da teoria das opções reais são múltiplas. A tabela 1.3 [TRIGEORGIS, 1995] resume algumas utilizações mais comuns, de acordo com as características do projeto.

Outros exemplos de aplicações das opções reais compreendem poluição [EDLESON \& REINHARDT, 1995], desenvolvimento de terras [QUIGG, 1995; CAPOZZA \& LI, 1994], mercado imobiliário [GRENADIER, 1996], restrições produtivas e estoques intermediários [CORTAZAR \& SCHWARTZ, 1993], construção de ferrovias [EMERY \& McKENZIE, 1996], dentre outros. 
Tabela 1.3: Aplicações mais comuns de opções reais

\begin{tabular}{l|l|l}
\hline \hline \multicolumn{1}{c|}{ Opção } & \multicolumn{1}{c|}{ Exemplos } & \multicolumn{1}{c}{ Referências } \\
\hline \hline Investir & Indústria extrativa (Opção de & Tourinho (1979) \\
& desenvolver jazidas) & Paddock et al. (1988) \\
\hline Time to build & Farmacêutica & Majd \& Pindyck (1987) \\
& Geração de Energia & Trigeorgis (1993) \\
\hline Alteração da escala & Extrativa & Brennan \& Schwartz (1985) \\
de produção (expandir, & Construção civil & Pindyck (1988). \\
contrair, etc.) & Duráveis de Consumo & McDonald \& Siegel (1984) \\
\hline Opção de abandono & capital intensivas (transportes) & Myers \& Majd (1990) \\
\hline \hline
\end{tabular}

No que se refere aos aspectos regulatórios, o setor de petróleo também apresenta algumas especificidades. Por um lado, ele partilha de muitas características dos chamados "Serviços de Utilidade Pública" [AZEVEDO et. Al, 1998], as quais demandam intervenção estatal: a) a presença de economias de escala associadas a elevados custos fixos conferem uma característica de monopólio natural, sobretudo de caráter regional. Esta característica é particularmente sensível no setor extrativo, tendo em vista a questão do common pool; b) os ativos são específicos ao setor (plataformas, dutos, etc.), levando à presença de "custos irrecuperáveis"; c) há uma certa separação entre atividades de geração (extração) e distribuição; d) o transporte do petróleo tem um perfil, ao menos parcial, de redes, na forma de dutos, de modo que o acesso por outras firmas pode requerer o uso de instalações das participantes; e) trata-se de um insumo energético de demanda generalizada, que apresenta certa inelasticidade, pelo menos no curto prazo. Por outro lado, há certas especificidades que fogem ao trade-off usual entre Regulação por Custo de Serviço vs. Limite de Preços [LAFFONT \& TIROLE (1993)]. A mais evidente delas é que o preço do serviço é uma commodity, de modo que não faz muito sentido estabelecer controles de preço, sob pena de inviabilização da empresa. Além disso, o custo marginal de produção de petróleo, embora pequeno em relação ao custo fixo, é crescente ao longo do tempo, devido ao esgotamento progressivo das jazidas. Estas duas características tornam a indústria do petróleo bastante 
peculiar quanto a seu marco regulatório.

$\mathrm{Na}$ verdade, o problema regulatório fundamental dos setores de recursos extrativos é a garantia da extração eficiente: pelo fato de não haver renovação de seu estoque na natureza, a extração no presente pode produzir perdas de bem estar para as gerações futuras. Assim, o regulador benevolente tem a preocupação em investir as rendas dos recursos não renováveis em ativos que diversifiquem a economia rumo a atividades menos dependentes do recurso [POSTALI (2002), cap.1]. Por isso, dentre os objetivos regulatórios primordiais do setor mineral, incluindo petróleo e gás, são:

a) Garantia de direitos de propriedade definidos, evitando externalidades na produção decorrentes do common pool, com a conseqüente a extração predatória e ineficiente dos recursos. O principal instrumento para o alcance desta meta é a definição da exclusividade da União no usufruto dos recursos do subsolo, conferindo a uma agência regulatória o poder de conceder direitos de exploração à iniciativa privada;

b) Garantia da extração da renda do recurso (renda de Hotelling) em favor da sociedade, com o objetivo de evitar a queda no bem estar futuro. O instrumento regulatório básico para esta meta é o pagamento de compensações financeiras ao Governo pela extração privada do petróleo (no Brasil, estas compensações são chamadas de Benefícios Governamentais) como royalties, bônus de acesso, imposto sobre a renda, aluguel de áreas, etc. Este será o elemento no qual focalizaremos este trabalho na aplicação do ferramental das opções reais.

Sob a ótica das opções reais, os critérios de neutralidade da tributação do setor de petróleo e gás devem ser modificados. Na literatura tradicional [e.g.: GARNAUT \& C. ROSS (1983)] argumenta-se que um imposto é neutro quando não é capaz de alterar nem o sinal esperado do valor presente líquido nem a ordem de lucratividade dos projetos. Quando adotamos este critério, observa-se que um tributo incidente sobre a renda possui efeitos distorcivos virtualmente nulos sobre a decisão de investir, diferentemente dos royalties, cuja base de incidência 
é a receita, que pode alterar tanto o valor presente líquido quanto a trajetória de extração.

Desta forma, estamos interessados em avaliar se as conclusões sobre neutralidade que obtivemos anteriormente são afetadas pela introdução destes novos critérios de avaliação, ou seja, quando se incorpora o efeito das flexibilidades no valor do investimento.

\section{$1.3 \quad$ Modelo Genérico}

Cada um dos trabalhos acima descritos analisa uma flexibilidade presente no projeto e seu impacto sobre o valor e sobre a decisão de investir ${ }^{12}$. Conforme a interpretação de KULATILAKA (1995a), é possível generalizar as abordagens anteriores no conceito de "modos de operação" e a escolha entre os mesmos. Assim, os modos podem ser "investir" versus "esperar para investir", "uso do insumo A" versus "uso do insumo B", ou "paralisar" versus "operar" versus "abandonar". O modelo genérico apresentado a seguir baseia-se nos trabalhos de KULATILAKA (1995a, 1995b), KULATILAKA \& MARKS (1988) e KULATILAKA \& TRIGEORGIS (1994) e tem o objetivo de mostrar como cada uma das flexibilidades pode ser interpretada como um caso particular deste caso mais geral, no qual as opções são entendidas como modos de operação à disposição do investidor, o qual toma sua decisão com base nas condições econômicas vigentes.

Suponha um projeto de investimento genérico no qual há $M$ modos possíveis de operação, cada um deles indexado por $m \in\{0,1, \ldots, M\}$. Seja $\theta=$ $\left(\theta_{1}, \theta_{2}, \ldots, \theta_{N}\right)$ o vetor de variáveis de estado que determinam o valor do projeto, isto é:

\footnotetext{
${ }^{12}$ CARVALHINHO (2003) analisa o valor das flexibilidades para contratos de fornecimento de gás natural para a indústria.
} 


$$
V(\theta, t, m)=V\left(\theta_{1}, \theta_{2}, \ldots, \theta_{N}, t, m\right)
$$

A expressão (1.3) estabelece que o valor do projeto no instante $t$ depende do modo de operação $m$ e de uma realização de $\boldsymbol{\theta}$. Cada uma das $i$ variáveis de estado pode ser modelada por um processo estocástico genérico na forma:

$$
\frac{d \theta_{i}}{\theta_{i}}=\alpha\left(\theta_{i}, t\right) d t+\sigma_{i} d Z_{i t}
$$

onde $\alpha\left(\theta_{i}, t\right)$ é a taxa de retorno instantânea de $\theta_{i}, i=1, \ldots, N, \sigma_{i}$ sua volatilidade instantânea e $d Z_{i t}$ um processo de Wiener padrão. As variáveis $\theta_{i}$ estão correlacionadas entre si por uma matriz de correlações $\Sigma$.

Em cada instante de tempo, há uma função lucro condicionada ao modo de operação $m, \Pi(\theta, m, t)$. Em caso de ausência total de flexibilidade, ou seja, quando o modo de operação é fixo, o valor do projeto no instante inicial será dado por:

$$
V\left(\theta_{0}\right)=E_{0}\left[\sum_{t=0}^{T} \delta^{t} \Pi\left(\theta_{t}\right)\right]
$$

onde $E_{0}$ é o operador esperança risco-neutro e $\delta$ é o fator de desconto livre de risco.

Quando o projeto é flexível no sentido de permitir a migração de um modo de operação para outro a um certo custo (o qual chamaremos de custo de transferência), o valor do projeto não pode ser representado apenas por (1.5), já que envolve uma série de opções embutidas pela possibilidade de substituir o modo de operação com vistas a otimizar a lucratividade. Suponha que $V\left(\theta_{t}, m, t\right)$ rep- 
resente o valor do projeto quando a firma otimiza o processo produtivo (isto é, opera no modo que maximiza o seu valor) e $c_{m b}$ o custo de migração do modo de operação $m$ para o modo de operação $b$. O valor do investimento em cada instante $t$, condicionado ao modo de operação $m$, pode ser obtido por programação dinâmica através de uma representação de Bellman na forma:

$$
V\left(\theta_{t}, m, t\right)=\max _{b}\left\{\left[\Pi\left(\theta_{t}, b, t\right)-c_{m b}\right]+\delta E_{t}\left[V\left(\theta_{t+d t}, b\right)\right]\right\}
$$

A expressão (1.6) deve ser resolvida pelos procedimentos usuais de programação dinâmica para se obter os valores $V\left(\theta_{t}, m, t\right)$ para todo $m$ e $t$. Sua interpretação é intuitiva: em cada período, a firma avalia a possibilidade de migrar do modo de operação $m$ para o modo de operação $b$, incorrendo nos custos $c_{m b}$ a fim de apurar o lucro $\Pi(\theta, b, t)$, obtendo no período subseqüente uma função valor $V\left(\theta_{t+d t}, b, t+d t\right)$. Como $\theta_{t+d t}$ é desconhecido em $t$, é necessário tomar sua esperança $E_{t}$ e descontá-la a $\delta$.

É interessante observar como a presença dos custos de transferência tornam a análise não trivial, já que não basta escolher o modo de operação que maximiza o lucro $\Pi(\theta, m, t)$ em cada período. É necessário fazer uma análise adiante no tempo, incorporando os custos de migrar de um modo para outro ${ }^{13}$.

A solução de (1.6) pode ser complicada, pois envolve a obtenção de uma equação diferencial parcial sujeita a condições de contorno que expressam soluções particulares. Com vistas a mostrar a idéia da resolução, trabalharemos com uma aproximação discreta $(d t=1)$, ilustrando o processo de solução por indução retroativa. Em cada período, deve-se obter simultaneamente o valor do projeto e o modo de operação ótimo.

\footnotetext{
${ }^{13}$ Conforme salienta KULATILAKA (1995a) e DIXIT (1992), estes custos são os responsáveis pelos fenômenos de histerese, isto é, a inércia de se insistir em um modo de operação apesar das eventuais perdas.
} 
No instante final $t=T$, o valor residual do $\operatorname{projeto}^{14}$ é $V_{R}\left(\theta_{T}\right)$ para todo $m$ : $V\left(\theta_{T}, m, T\right)=V_{R}\left(\theta_{T}\right)$. No instante $t=T-1$, o modo ótimo de operação é aquele que maximiza o lado direito de (1.6). Como se supõe que o valor residual independe do modo de operação, deve-se escolher aquele que propicia o máximo lucro líquido dos custos de transferência. Desta forma, para $m, b \in\{1, \ldots, M\}$ :

$$
V\left(\theta_{T-1}, m, T-1\right)=\max _{b}\left\{\left[\Pi\left(\theta_{T-1}, b, T-1\right)-c_{m b}\right]+\delta E_{T-1}\left[V_{R}\left(\theta_{T}\right)\right]\right\}
$$

Ou seja, no instante $T-1$ deve-se resolver para $M$ funções $V\left(\theta_{T-1}, m, T-1\right)$ a fim de obter a tecnologia que maximiza $V$.

No instante $T-2$, a análise é mais complicada, pois chega-se a este período já sob um modo de operação dado. Assim, deve-se maximizar o lucro líquido dos custos de transferência mais o valor esperado descontado do projeto ao fim do período, o qual depende agora do modo de operação neste período. Desta forma, o modo $b$ é escolhido pela solução de:

$$
V\left(\theta_{T-2}, m, T-2\right)=\max _{b}\left\{\left[\Pi\left(\theta_{T-2}, b, T-2\right)-c_{m b}\right]+\delta E_{T-2}\left[V\left(\theta_{T-1}, b, T-1\right)\right]\right\}
$$

A dificuldade de se calcular (1.8) reside no termo expectacional, o segundo termo entre as chaves. No passo anterior, resolveu-se para a função $V\left(\theta_{T-1}, b, T-\right.$ 1) para cada modo possível de operação de modo que, no instante $T-2$, repete-se o procedimento tomando-se a esperança desta função condicionada a $\theta_{T-1}$. Para isso, é necessária a especificação de um processo evolutivo para $\theta$.

O processo recursivo prossegue em $T-3$ e o modo de operação $b$ neste período

\footnotetext{
${ }^{14}$ Este valor pode ser entendido como uma espécie de valor de abandono ou "valor de sucata". Note que $V_{R}\left(\theta_{T}\right)$ pode ser igual a zero.
} 
é escolhido através da solução de:

$V\left(\theta_{T-3}, m, T-3\right)=\max _{b}\left\{\left[\Pi\left(\theta_{T-3}, b, T-3\right)-c_{m b}\right]+\delta E_{T-3}\left[V\left(\theta_{T-2}, b, T-2\right)\right]\right\}$

Dessa forma, sucedendo o processo recursivo retroativamente, podemos encontrar a solução $V\left(\theta_{0}, m, t=0\right)$ para cada um dos $m$ modos de operação possíveis. O modo escolhido deverá ser aquele que maximiza a função $V($.$) , para uma dada$ realização do vetor $\theta=\theta_{0}$.

Como se disse anteriormente baseado em KULATILAKA (1995), as opções presentes em um projeto podem ser interpretadas como casos particulares dos modos de operação. Considere os três exemplos a seguir.

\subsubsection{Opção de investimento}

Considere a situação em que os administradores de um projeto têm a opção de investir até um instante terminal $T$ (por exemplo, no desenvolvimento de uma reserva de recurso natural não-renovável). Uma vez efetuado, o investimento é irreversível, de modo que é necessário incorporar seu custo de oportunidade. O investimento irá alterar o fluxo de caixa do projeto (no exemplo, o recurso é extraído e vendido, permitindo um lucro П). À luz da terminologia acima, tem-se: $m, b=1,2$, onde modo $1=$ não investir $;$ modo $2=$ investir $; c_{12}=I$ é o investimento desembolsado; a irreversibilidade significa que $c_{21}=+\infty$; a manutenção do mesmo modo de operação não acarreta custos adicionais, ou seja, $c_{11}=c_{22}=0$. Considera-se, ainda, que ao final do período $T$, o investidor perde totalmente os direitos sobre o projeto, isto é, $V_{R}\left(\theta_{T}\right)=0$. No instante $T$, o máximo lucro proporcionado pelo projeto será igual ao seu valor, já que ele perde totalmente valor no instante seguinte: 


$$
\begin{aligned}
V\left(\theta_{T}, 1, T\right) & =\max _{2}\left[\Pi\left(\theta_{T}, b, T\right)-I\right]=V\left(\theta_{T}, 2, T\right)-I \\
V\left(\theta_{T}, 1, T\right) & =V\left(\theta_{T}, 2, T\right)-I
\end{aligned}
$$

A condição acima estabelece que, no instante terminal, o valor do projeto sem o investimento (modo 1) deve ser igual ao seu valor após o investimento (modo 2) líquido do custo de transferência $\left(c_{12}=I\right)$ com vistas a tornar o agente indiferente entre investir ou não. Trata-se da chamada condição de contato (value matching condition) e caracteriza uma solução para o problema. O valor inicial do projeto é obtido pelo procedimento retroativo descrito. A decisão de investir ou não no instante inicial é obtida pela comparação de $V\left(\theta_{0}, m, 0\right), m=1,2$, em cada um dos dois modos possíveis: se $V\left(\theta_{0}, 2,0\right)>V\left(\theta_{0}, 1,0\right)$, o investimento é realizado.

\subsubsection{Opção de abandono}

Considere agora um projeto em funcionamento com a possibilidade de interrupção definitiva de suas atividades em caso de condições econômicas desfavoráveis. Neste caso, temos: modo 1 = operar; modo 2 = abandonar; o custo de abandonar é dado por $c_{12}=k$; novamente, trata-se de uma decisão irreversível, ou seja, $c_{21}=+\infty$; Considere que o projeto pode ser vendido no mercado secundário ao valor $S$, de modo que $\Pi\left(\theta_{T}, 2, T\right)=S$.

Assim, pelo mesmo procedimento do item anterior, tem-se:

$$
V\left(\theta_{T}, 1, T\right)=\max _{2}[S-k]=S-k
$$

Por (1.11), o abandono só será vantajoso se o valor do projeto em cada instante de tempo for inferior ao seu valor residual líquido do custo de abandono ${ }^{15}$. Note

\footnotetext{
${ }^{15}$ Isso acontece porque estamos assumindo que, no instante final, o valor residual independe
} 
que, se o custo de abandono for muito alto, o investidor pode preferir manter-se operando mesmo com prejuízo ${ }^{16}$.

\subsubsection{Opção de expansão}

Considere agora que o investidor possui a opção de expandir sua capacidade diante de condições econômicas propícias. Considere que a firma esteja obtendo um lucro $\Pi_{1}$ em condições normais e que, após a expansão, este lucro seja acrescido por um fator $\varepsilon$, de modo que $\Pi_{2}=(1+\varepsilon) \Pi_{1}$. Assim, tem-se os seguintes parâmetros: Modo 1 = manter capacidade; Modo $2=$ aumentar capacidade; $c_{12}=K$ e $c_{21}=+\infty$, indicando a irreversibilidade da decisão. No instante final, tem-se:

$$
V\left(\theta_{T}, 1, T\right)=\max _{2}\left\{(1+\varepsilon) \Pi_{1}-K\right\}=\Pi_{1}
$$

dado que, sob o modo de operação 1, o lucro no instante final será o próprio valor do projeto. Deste modo, no instante $T$, a ampliação da capacidade só será vantajosa se $(1+\varepsilon) \Pi_{1}-K>\Pi_{1}$, isto é, $\Pi_{1}>K / \varepsilon$. Por indução retroativa, o agente obtém $V\left(\theta_{0}, 1,0\right)$ e $V\left(\theta_{0}, 2,0\right)$ e a decisão de expandir ou não é tomada comparando-se os dois valores.

\subsection{Síntese do capítulo}

O objetivo deste capítulo foi rever a bibliografia fundamental da teoria das opções reais, com uma síntese das contribuições mais significativas. Argumentou-se que as flexibilidades presentes em um projeto de investimentos não podem ser ignoradas, dado que incorporam valor a ele e, portanto, podem alterar a decisão

de uma realização de $\theta$. Se $S$ depender de $\theta$, então a decisão ótima no instante inicial deve ser obtida novamente pelo processo de indução retroativa.

${ }^{16} \mathrm{~A}$ análise para opção de paralisação temporária é análoga quando se supõe que $S$ é o custo fixo, o qual constitui o "lucro" quando a atividade está suspensa. 
de investir. Conforme a abordagem da subseção anterior, cada uma das opções (abandono, fechamento, investimento, etc.) pode ser interpretada como um modo de operação particular e a possibilidade de transferência entre os mesmos deve ser levada em consideração na avaliação do investimento.

Conforme argumenta KEMNA (1993), as principais idéias por trás da teoria das opções reais (OR), sobretudo do ponto de vista operacional, são as seguintes:

a) Os mesmos princípios fundamentais regem as teorias do VPL e de OR e ambas são complementares entre si, e não substitutas. Elas devem ser usadas em combinação quando há decisões futuras que influenciam o risco do fluxo de caixa. A técnica do VPL é apropriada para uma classe ampla de projetos sob gerenciamento passivo (sobretudo quando não existe opção de esperar);

b) A teoria das OR é uma combinação apropriada das análises de fluxo de caixa descontado e árvore de decisão. É particularmente útil para analisar um investimento multifásico com gerenciamento ativo e, apesar do VPL ser suficiente para a avaliação de um grande leque de projetos, ele sub-avalia os benefícios possibilitados pela espera.

No capítulo seguinte, caracterizamos as propriedades de $\theta$ para o caso de investimentos em petróleo. Argumentamos que o preço é a principal variável determinante do valor e, a partir de um estudo da sua série histórica, procuramos justificar o processo de difusão utilizado no restante do trabalho. 


\section{Capítulo 2}

\section{A trajetória do Preço do Petróleo}

No capítulo anterior, dissemos que a escolha do processo estocástico do preço do petróleo é importante para aferir o impacto da incerteza sobre a decisão de investir. Assim, é necessário escolher um movimento para os preços que reflita com boa precisão a dinâmica do mercado de petróleo. O objetivo deste capítulo é discutir alguns processos estocásticos empregados pela literatura de opções reais na avaliação de investimentos. Procura-se identificar os prós e os contras de uma seleção deles, bem como suas características e dificuldades operacionais.

Este capítulo se divide em três partes; na seção 2.1, descrevemos os principais processos estocásticos; na seção 2.2, empreendemos alguns testes de raiz unitária; na seção 2.3, estimamos a meia vida dos preços anuais do petróleo, com vistas a justificar o argumento de que o movimento browniano geométrico, a despeito de sua menor verossimilhança, pode representar uma aproximação adequada para a avaliação dos investimentos em petróleo.

\subsection{Processos Estocásticos do preço do petróleo}

A discussão sobre o processo mais adequado para modelar o preço do petróleo é longa e está ligada às características deste mercado. Os primeiros trabalhos 
na área, seguindo as aplicações para precificação de opções, [PADDOCK et al. (1988); BRENNAN \& SCHWARTZ (1985); McDONALD \& SIEGEL (1985)] modelavam o preço de commodities como um Movimento Browniano Geométrico na forma:

$$
d P=\alpha P d t+\sigma d Z
$$

onde $\alpha$ é a taxa de crescimento esperada, $\sigma$ o desvio padrão instantâneo, $Z$ um processo de Wiener, tal que $E(d Z)=0$ e $\operatorname{Var}(d Z)=d t$. Os retornos do ativo têm distribuição normal de forma que $d \ln P \sim N(\alpha d t, \sigma d t)$.

O movimento browniano geométrico possui algumas propriedades úteis, permitindo a ocorrência de soluções fechadas para vários casos de avaliação de ativos: em primeiro lugar, a taxa esperada de crescimento do preço é constante, dada por $E(d P / P)=\alpha d t$. O desvio padrão instantâneo, $\sigma$, também é constante, ou seja, a variabilidade do preço esperado aumenta conforme o horizonte temporal cresce. Se os preços sobem (caem) mais do que o previsto em um determinado instante de tempo, todas as previsões futuras são majoradas (reduzidas) na mesma proporção. Assim, o MBG implica em um alto grau de variabilidade dos preços previstos, contendo um elevado nível de incerteza.

Muitos autores, como LAUGHTON e JACOBY (1995) e SCHWARTZ (1997) argumentam que o preço do petróleo seria modelado com mais acurácia por um processo de reversão à média. A especificação mais convencional deste processo, também conhecido como Processo de Ornstein-Uhlenbeck, é dada por:

$$
d P=\eta(\bar{P}-P) d t+\sigma d Z
$$

em que $\eta$ representa a velocidade de reversão ao nível de equilíbrio de longo prazo, que pode representar a tendência histórica do preço, associada aos custos 
Figura 2-1: Processo Ornstein-Uhlembeck Geométrico

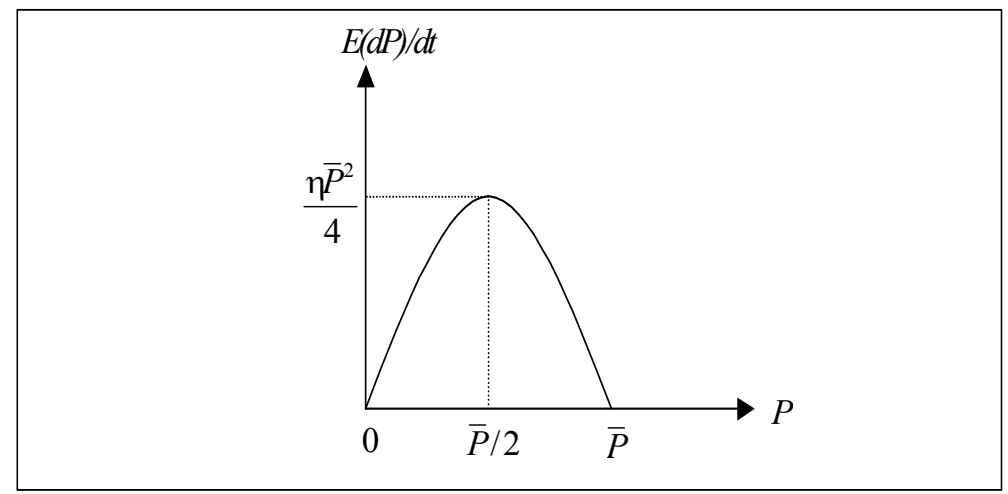

marginais de produção. Quanto maior $\eta$, maior a velocidade de reversão.

Entretanto, (2.2) pode não ser adequado para representar o valor de uma commodity, já que ele pode acarretar em preços negativos. Para contornar este problema, DIXIT \& PINDYCK (1994) propõem uma variação deste processo, no qual os retornos do ativo tenderiam à reverter a um valor histórico (também chamado de Ornstein-Uhlenbeck Geométrico - OUG), de acordo com a seguinte especificação:

$$
d P=\eta(\bar{P}-P) P d t+\sigma P d Z
$$

Agora, tem-se que a variação percentual esperada em $P$ é dada por $E[(d P / P)] / d t=$ $\eta(\bar{P}-P)$ e a variação de preço absoluta esperada é $E(d P) / d t=\eta(\bar{P}-P) P=$ $\eta \bar{P}-\eta P^{2}$. Destas expressões, pode-se extrair duas conclusões: a) quanto mais próximo (distante) o preço anual estiver do preço de equilíbrio de longo prazo, menor (maior) a variação percentual esperada do preço; b) a variação absoluta esperada de $P$ é uma parábola com raízes em $P=0$ e $P=\bar{P}$ e vértice em $P^{*}=\bar{P} / 2$, conforme ilustrado na figura $2-1$.

Diferente do MBG, em que variações imprevistas de preço levam à revisão de 
todas as estimativas na mesma proporção, o processo OUG impõe um limite superior para a as variações esperadas, sendo máxima quando o preço é equidistante do zero e de seu valor de equilíbrio. Quando $P>\bar{P}, E(d P) / d t<0$. Por esta razão, os movimentos de reversão à média embutem um grau de variabilidade menor que o movimento browniano geométrico, permitindo-o gravitar em torno de seu valor de equilíbrio de longo prazo, $\bar{P}$, com maior ou menor freqüência de acordo com a velocidade de reversão, $\eta$.

A lógica de um modelo desta natureza reside na constatação de que a oferta e a demanda do recurso tendem a se ajustar gradativamente a desequilíbrios de preço: quando o preço de uma commodity é maior que certa média ou equilíbrio de longo prazo, a oferta irá crescer gradativamente, pois produtores de custo mais elevado tendem a ingressar no mercado, pressionando o preço para baixo. Inversamente, preços mais baixos tendem a expulsar produtores menos eficientes, desencadeando um movimento paulatino de alta nos preços. A questão fundamental é que as respostas aos desequilíbrios de preço não são instantâneas: do ponto de vista da oferta, há uma defasagem temporal entre a decisão de ingressar no mercado e o ingresso efetivo, devido ao "time to build", já que a conclusão dos investimentos requer certo tempo; do lado da demanda, verifica-se uma inércia decorrente das diferenças de elasticidade de curto e de longo prazo $^{1}$, já que os consumidores têm certos custos em se adaptarem a novos patamares de preço (como, por exemplo, substituir meio de transporte, alterar processos produtivos que dependem deste insumo, etc.)

Ao contrário do MBG, o processo de reversão à média não pressupõe uma taxa esperada de crescimento constante. Este processo ganha certo grau de realismo na medida em que a taxa de crescimento (drift) passa a responder aos desvios do preço à vista em relação à média. Se o preço à vista for superior ao equilíbrio, a tendência à reversão derruba a taxa de crescimento, podendo torná-la negativa.

\footnotetext{
${ }^{1} \mathrm{O}$ petróleo combustível é um exemplo de bem cuja elasticidade de demanda é grande no longo prazo e baixa no curto prazo.
} 
Quanto maior a velocidade de reversão $(\eta)$, maior a variabilidade do drift.

As evidências a longo prazo mostram que, de fato, a modelagem por reversão à média é mais precisa para a dinâmica deste mercado. Desta forma, a utilização deste processo estocástico seria mais realista que um movimento browniano geométrico e induziria a uma maior precisão na avaliação das reservas.

Conforme o entendimento de DIAS (2001), os processos de movimento browniano geométrico (2.1) e de reversão à média (2.2) - (2.3) representam casos extremos em relação ao grau de incerteza e de previsão: enquanto o primeiro contém uma variabilidade alta (maior risco), o segundo é compatível com um maior grau de previsibilidade (menor risco). Há modelos com graus de previsão intermediários que talvez expressem melhor a medida da incerteza do projeto. DIAS \& ROCHA (1999) e DIAS (2001) apresentam um sumário dos mesmos. Eis alguns deles:

Modelo de Dois Fatores [GIBSON \& SCHWARTZ (1990)]: no qual o preço segue um movimento browniano geométrico e o seu convenience yield evolui de acordo com um movimento de reversão à média, da seguinte forma:

$$
\begin{gathered}
d P=\mu P d t+\sigma_{1} P d Z_{1} \\
d \delta=k(\alpha-\delta) d t+\sigma_{2} d Z_{2}
\end{gathered}
$$

em que $Z_{1}$ e $Z_{2}$ são processos de Wiener correlacionados entre si. Como uma das variáveis de estado, o convenience yield, não é diretamente observada, ela deve ser estimada a partir da relação entre o preço à vista e o preço futuro do petróleo. O movimento que descreve o convenience yield foi motivado, segundo os autores, por evidências de forte tendência de reversão à média em preços futuros 
de 2 a 6 meses. Essa modelagem é compatível com a relação inversa entre o nível dos estoques e o convenience yield. Este pode ser entendido, em analogia com a taxa de dividendos das ações, como o benefício líquido ao proprietário de manter uma unidade adicional do recurso, de modo que quanto mais abundante este, menor o convenience yield. Na avaliação dos autores, apesar do modelo ter sido desenvolvido para a avaliação de derivativos de petróleo, ele pode ser facilmente estendido para a avaliação de ativos reais, incluindo decisões de desenvolvimento e produção de óleo, gás e de outros recursos.

Modelos de Dois Fatores de $2^{o}$ tipo: Apesar de captar melhor os movimentos de ajuste entre oferta e demanda, o modelo anterior requer a estimação de uma variável que não é diretamente observada. SCHWARTZ \& SMITH (2000) fazem uma distinção entre preço de curto prazo e preço de longo prazo e desenvolvem um modelo de dois fatores que contém reversão à média no primeiro e movimento browniano geométrico no segundo, com o objetivo de incorporar a incerteza no preço de equilíbrio. Suas conclusões são análogas ao anterior e os autores mostram que, dada uma combinação de parâmetros apropriada, os dois modelos são equivalentes, com a vantagem de prescindir do conceito de convenience yield, já que as noções de variações de preço de curto prazo e de longo prazo são bem mais intuitivas, levando a resultados mais transparentes.

Esta classe de modelos procura explorar melhor a interdependência entre os preços de curto prazo e de equilíbrio de longo prazo. O preço à vista do recurso segue um processo de reversão à média para um nível de equilíbrio que também é estocástico. PILIPOVIC (1997), seguida por SCHWARTZ \& SMITH (2000), modelam o preço de longo prazo na forma de um MBG, na forma:

$$
d P=\eta(E-P) d t+\sigma_{P} d Z_{P}
$$




$$
d E=\mu_{E} E d t+\sigma_{E} E d Z_{E}
$$

onde $E$ é o preço de equilíbrio de longo prazo. A vantagem desta modelagem é incorporar a inter-relação entre ambos os preços, enfatizando a incerteza no patamar de longo prazo. Uma interpretação interessante desta estrutura é que os desvios de curto prazo em relação ao valor de equilíbrio resultam de fenômenos de inércia, histerese e time to build no ajuste dos estoques aos valores das reservas, enquanto o preço de longo prazo representaria o movimento decorrente de fatores tecnológicos e exaustão global dos recursos.

Apesar de se tratar de um modelo bastante útil para avaliar o mercado de petróleo, já que a tendência à exaustão tende a produzir deslocamentos no nível de equilíbrio de longo prazo, a modelagem do preço de equilíbrio como um movimento browniano geométrico pode incorporar um nível excessivo de incerteza sobre esta variável (já que o MBG representa o grau máximo de variabilidade e imprevisibilidade dentre os modelos mencionados), o que pressuporia uma falta de conhecimento grande sobre estoques globais e tecnologias alternativas. Em vista disso, PINDYCK (1999) modela o preço de equilíbrio $E$ na forma de um movimento com reversão à média, que contém um grau de variabilidade menor que o $\mathrm{MBG}^{2}$. Entretanto, se levarmos em conta os resultados da teoria dos recursos não-renováveis [HOTELLING (1931)], espera-se que o preço de equilíbrio apresente um drift resultante do progressivo esgotamento tendencial do petróleo.

Modelo de Três Fatores [SCHWARTZ (1997)]: análogo ao modelo de dois fatores, em que se adiciona um processo estocástico de reversão à média para a

\footnotetext{
${ }^{2} \mathrm{Na}$ verdade, a escolha do processo adequado para o equilíbrio de longo prazo depende do conjunto de informações que se supõe disponível para os agentes. Se os agentes possuem um grau de conhecimento amplo sobre os fatores que determinam os estoques de longo prazo (reservas, tecnologia, planos de investimento, etc.), é de se supor que o preço de equilíbrio contenha uma baixa incerteza. Por outro lado, se houver grande assimetria de informações sobre estes dados, a variabilidade prevista tende a ser alta.
} 
taxa de juros (como em VASICEK, 1977), de modo a incorporar a incerteza sobre esta variável. SCHWARTZ (1997) compara três tipos de modelos: a) um fator (preço) com reversão à média; b) dois fatores (preço e convenience yield) com reversão à média e c) três fatores, incluindo a volatilidade na taxa de juros, em uma extensão do modelo de GIBSON \& SCHWARTZ (1990). Seu argumento é de que a volatilidade da taxa de desconto influencia significativamente o valor dos ativos reais. Sua conclusão é de que a desconsideração dos processos de reversão à média pode atrasar desnecessariamente a decisão de investimento.

Embora tais modelos, sob algumas condições, apresentem solução analítica para o valor da opção, há duas dificuldades para sua utilização: uma das variáveis de estado, o convenience yield, não é diretamente observável, sendo necessária sua estimação. SCHWARTZ (1997) estima a sua realização utilizando filtro de Kalman a partir de dados de preço futuro e spot de petróleo e de alguns metais. Mesmo que esta dificuldade seja superada, os derivativos disponíveis no mercado precificam contratos para no máximo seis meses, quando os investimentos são de longa maturidade.

Modelo Unifatorial de Saltos com Reversão à Média [DIAS \& ROCHA (1998)]: o modelo estabelece que o preço do recurso evolui revertendo à média, mas pode sofrer variações abruptas com uma certa probabilidade, de acordo com informações atípicas (guerras, cortes imprevistos na produção, etc.) das quais os agentes tomam conhecimento. Tais informações tendem a produzir saltos (positivos ou negativos) no preço do petróleo, os quais são modelados como um processo de Poisson. Exemplos de saltos positivos são conflitos, guerras e greves; saltos negativos são produzidos, por exemplo, por anúncios de descobertas ou de novas tecnologias. O preço tende a convergir para seu equilíbrio de longo prazo à medida que os efeitos das informações atípicas se dissipam. Sua formulação é dada por: 


$$
\frac{d P}{P}=\eta(\bar{P}-P) d t+\sigma_{P} d Z_{P}+(\theta-1) d q
$$

onde $d q=1$ com probabilidade $\lambda d t$ e $d q=0$ com probabilidade $1-\lambda d t$. $\lambda$ é o parâmetro de chegada de Poisson e $\theta$, o tamanho do salto, é uma variável aleatória com distribuição normal. Supõe-se que $d Z_{P}$ e $d q$ são processos independentes. Desta forma, tem-se $E[d P / P]=[\eta(\bar{P}-P)+\lambda E(\theta-1)] d t$, ou seja, a variação esperada do preço depende dos parâmetros de salto ${ }^{3}$.

O processo de saltos com reversão à média procura englobar os dois fatos estilizados mais notórios do preço de uma commodity, quais sejam, a reversão à média e as variações abruptas inesperadas. Entretanto, há várias dificuldades operacionais com o modelo, notadamente a necessidade de estimar vários parâmetros (um problema que cresce com o aumento do número de fatores determinando o valor da reserva). Além disso, são necessários dados sobre eventos raros de grande magnitude, o que pode ser difícil de se verificar na prática ${ }^{4}$.

HILLARD \& REIS (1998) desenvolvem um modelo de três fatores com saltos no preço do ativo, estendendo o modelo de três fatores de SCHWARTZ (1997). Através de simulações numéricas, procuram avaliar o erro de avaliação produzido por um modelo de um fator em relação aos demais. Suas conclusões mostram que, quando o convenience yield inicial é próximo do de longo prazo e/ou a velocidade de reversão é baixa, o valor da opção em um modelo de um fator (com $\delta$ constante) não é significativamente diferente da avaliação sob dois fatores (com $\delta$ estocástico).

Ainda com relação à influência dos saltos na avaliação das reservas, MILLER

\footnotetext{
${ }^{3}$ DIAS \& ROCHA (1998) propõem um processo de Poisson compensado, que consiste em subtrair do drift o termo $\lambda k$ para tornar a variação esperada de preço independente dos parâmetros de salto.

${ }^{4}$ Uma outra dificuldade pode advir da impossibilidade da construção de um portfólio livre de risco, o que inviabiliza a abordagem dos ativos contingentes. DIXIT \& PINDYCK (1994).
} 
\& ZHANG (1996) constróem um modelo que supõe um MBG com saltos de Poisson positivos em tempos de paz e negativos em tempos de guerra ${ }^{5}$, de modo que existiriam dois processos estado-contingentes governando o preço do petróleo. Sua conclusão é de que quanto maior o parâmetro de Poisson $(\lambda)$, menor o impacto do salto sobre o valor da jazida, ou seja, eventos transitórios tendem a não afetar as decisões de investir. Por outro lado, a inclusão dos saltos de Poisson tende a elevar a variância dos preços e, conseqüentemente, atrasar os investimentos. Neste contexto, um aumento do preço pode não induzir necessariamente o desenvolvimento se houver expectativa de mudança de regime (ou seja, se os agentes avaliarem que a elevação da cotação do barril decorre da expectativa de guerra e não de fundamentos de mercado). Mas este atraso pode ser compensado se o salto positivo esperado for suficientemente elevado. Deste modo, o efeito "permanente" do salto sobre o valor da reserva tende a ser bem menor do que a variação de preços efetiva (em torno de $\frac{1}{4}$, para valores simulados para o período da Guerra do Golfo).

Em suma, os casos intermediários descritos acima compreendem a introdução de um processo paramétrico para os fatores que influenciam a trajetória do preço do petróleo (e, conseqüentemente, o valor do investimento), como o convenience yield, a taxa de juros, o preço de equilíbrio ou mesmo a variância instantânea (que também pode ser incerta, modelada de acordo com um processo de OrnsteinUhlenbeck), com vistas a tornar a avaliação mais acurada. No limite, todos os parâmetros podem ser incertos, evoluindo de acordo com um processo estocástico pré-definido (para o caso de taxas de juros estocásticas, INGERSOLL \& ROSS, $1992)^{6}$. Os principais custos das extensões nesta direção são o crescimento signi-

\footnotetext{
${ }^{5}$ Este cenário é bastante compatível com a trajetória do preço do barril nos períodos da Guerra do Golfo (1991) e na Guerra do Iraque (2003), quando o preço mostrava-se bastante pressionado nos meses que antecediam aos conflitos conforme informações sobre este eram divulgadas. Quando ambas as guerras começaram, o preço do petróleo imediatamente passou a apresentar trajetória descendente, à medida que as expectativas de solução da crise se consolidavam.

${ }^{6}$ Os resultados do modelo de INGERSOLL \& ROSS (1992) sugerem que a volatilidade da
} 
ficativo do número de parâmetros que precisam ser estimados e a necessidade de métodos numéricos na maioria dos casos.

É desnecessário dizer que cada um dos casos intermediários apresenta graus de dificuldades maiores de implementação e de estimação. De fato, uma observação visual da trajetória do preço do petróleo permite corroborar as análises de autores que julgam mais apropriado modelá-lo de acordo com um movimento de reversão à média. Entretanto, conforme procuramos argumentar, sua velocidade de reversão é baixa o suficiente no sentido de permitir uma aproximação para movimento browniano geométrico. A subseção a seguir propõe um estudo quantitativo da série do preço internacional do petróleo.

\section{$2.2 \quad$ Testes de Raiz Unitária}

O objetivo desta seção é estudar a trajetória do preço do petróleo com vistas a identificar algumas propriedades que justifiquem a utilização do movimento browniano geométrico para avaliar as jazidas e inferir o impacto das políticas sobre a decisão de investir.

O gráfico ${ }^{7}$ 2-2 dispõe o preço internacional do petróleo (anual), em valores constantes de 1999. Apesar dos dados serem anuais, é possível identificar duas variações abruptas nesta variável: nos anos 70, por ocasião da combinação dos choque do petróleo de 1973 e de 1979; na década dos 60 do século XIX, que coincide com o advento da tecnologia do motor à explosão. Embora haja possíveis quebras estruturais, não se pode afirmar a priori que haja uma tendência

taxa de juros pode ser um fator mais importante do que o seu nível para os investimentos. O seu modelo incorpora taxas de juros estocásticas com fluxos de caixa futuros conhecidos com certeza. Mesmo neste caso, há um custo de oportunidade de investir e o uso da regra usual do valor presente líquido pode levar a um viés de aceitação dos projetos. Segundo seus resultados, o investimento só deve ser feito quando a taxa de juros se encontra abaixo de certo patamar $r^{*}$, inferior à taxa interna de retorno do projeto (TIR) A diferença entre $r^{*}$ e a TIR é maior quanto maior a volatilidade da taxa de juros.

${ }^{7}$ Até 1944, trata-se de uma média dos preços nos EUA; de 1945 a 1985, tipo árabe-light; de 1986 a 1999, tipo Brent. Fonte: British Petroleum/EIA. 




Figura 2-2: Preço do petróleo, em \$ 1999.

estocástica.

Tomemos os dois casos extremos de Movimento Browniano Geométrico e Reversão à Média. PINDYCK (1999) reconhece que a modelagem por MBG é menos completa que a de reversão. Todavia, a taxa de reversão à média é muito baixa, implicando em uma meia vida longa. Além disso, o próprio nível de equilíbrio do preço é variável e depende dos estoques e das condições de escassez, informações que nem sempre estão disponíveis para todos os agentes em todos os instantes de tempo. Seu argumento tem como base o fato de que só é possível rejeitar a raiz unitária em longos períodos de tempo (cerca de 127 anos). Desta forma, a utilização de MBG, embora menos realista, não induziria a erros significativos de avaliação ${ }^{8}$.

PINDYCK (1999) recupera a teoria dos recursos não renováveis de Hotelling para mostrar que, mesmo assumindo reversão à média, a tendência e o nível do preço do petróleo são estocásticos, elevando o seu grau de variabilidade e

\footnotetext{
${ }^{8}$ Em suas próprias palavras: "These numbers suggest that for irreversible investment decisions for which energy prices are the key stochastic state variables, the GBM assumption is unlikely to lead to large errors in the optimal investment rule" (PINDYCK, 1999, p. 25).
} 
imprevisibilidade. O nível e a tendência do preço são estimados por um Filtro de Kalman. Analisando séries históricas de óleo cru, gás natural e carvão, o autor conclui que o nível do preço do petróleo é não estacionário, de modo que uma modelagem de reversão à uma média estocástica apresenta melhor desempenho em termos de previsão. Entretanto, no caso de opções reais, o critério de tomada de decisão de investir pode ser mais importante que a avaliação da reserva em si, de modo que uma aproximação por MBG não conduzirá, segundo PINDYCK, a erros de avaliação.

Além disso, de acordo com o argumento de DIXIT (1992), retomado por ZHANG (1997), o MBG apresenta uma vantagem em relação aos demais modelos, já que ele permite capturar melhor o efeito conjunto da incerteza e da irreversibilidade na decisão ótima de investir. Como a irreversibilidade dos gastos em desenvolvimento só é relevante para a decisão de investimento na medida em que existe incerteza sobre as condições futuras do valor do barril do petróleo e o MBG contém o maior grau de variabilidade do preço, este processo permite construir o cenário mais desfavorável para o investidor tomar sua decisão, o que pode ser mais adequado para um agente avesso ao risco. O processo de reversão à média e suas variantes, por sua vez, tornam a irreversibilidade menos proeminente para a avaliação da jazida.

Inspirando-se em PINDYCK (1999), pode-se mostrar como um modelo elementar de extração de recursos não renováveis pode conduzir a grande variabilidade de tendência e no patamar aos quais o preço do petróleo reverte.

Conforme a definição de HOTELLING (1931), a renda do recurso $\lambda$ (também chamada de valor sombra ou custo de uso) é dada por:

$$
\lambda_{t}=P_{t}-C_{t}
$$

onde $P_{t}$ é o preço do recurso e $C_{t}$ seu custo marginal. Pela regra de Hotelling 
, a renda do recurso de crescer à taxa de juros com vistas a garantir a extração ótima, isto é:

$$
\lambda_{t}=\lambda_{0} e^{r t}
$$

Conforme o efeito Jevons, o custo marginal irá crescendo conforme ocorre a exaustão da jazida, ou seja:

$$
C_{t}=C_{0} e^{\phi t}
$$

Substituindo (2.9) e (2.11) em (2.10):

$$
P_{t}=C_{0} e^{\phi t}+\left(P_{0}-C_{0}\right) e^{r t}
$$

Considere uma curva de demanda linear na forma $Q=A-B P$, onde $A$ e $B$ são parâmetros positivos. A condição de igualdade entre oferta e demanda requer que o total produzido seja igual ao estoque inicial do recurso $S_{0}$, de modo que:

$$
\int_{0}^{T} Q(t) d t=\int_{0}^{T}(A-B P) d t=S_{0}
$$

onde $T$ é o instante terminal de extração, suposto exógeno ${ }^{9}$. Podemos encontrar a solução analítica da expressão acima. Isolando $P_{0}$, e substituindo em (2.2) tem-se:

\footnotetext{
${ }^{9} \mathrm{~A}$ rigor, o término da extração é endógeno à condição de transversalidade $\lambda(T)=0$, isto é, no instante final, a jazida deve ter valor econômico nulo. Assumimos de forma simplificada a exogeneidade da condição terminal para viabilizar a solução do restante do modelo.
} 


$$
P_{t}=C_{0}\left(e^{\phi t}-e^{r t}\right)+\left[\frac{A}{B} r T-\frac{C_{0}}{\phi}\left(r e^{\phi T}-\phi e^{r T}+\phi-r\right)-\frac{r}{B} S_{0}\right] \frac{e^{r t}}{e^{r T}-1}
$$

Conforme sugere a intuição, quanto maior o estoque inicial de recurso, menor o preço. Um deslocamento na demanda (aumento de $A$ ) resulta em aumento no preço do petróleo; um aumento da elasticidade da curva (aumento em $B$ ) tende a deprimi-lo.

A expressão (2.14) fornece uma idéia dos fatores que impactam no nível dos preços. Em primeiro lugar, o estoque de recursos. Novas descobertas tendem a produzir redução do nível de preços. Desta forma, quaisquer incertezas quanto aos estoques disponíveis ou quanto ao volume das reservas recuperáveis tendem a produzir variações no valor do barril.

Incertezas quanto ao parâmetro $A$, isto é, quanto ao nível da demanda, tendem a afetar o valor do barril. Quanto mais volátil e sujeita a choques a demanda, maior a variabilidade do nível de preços.

Por fim, a elasticidade de demanda tende a produzir impactos nos preços. Como se pode observar em (2.14), quanto mais elástica a demanda (menor $A / B$ ), mais deprimido tende a ser o preço. Este parâmetro pode ser associado a fatores tecnológicos ligados a substitutos do petróleo, ou seja, as incertezas sobre a evolução das pesquisas de combustíveis alternativos tendem a afetar o valor do barril na medida em que alteram a elasticidade esperada da demanda.

Desta forma, portanto, o preço do petróleo está sujeito a uma série de incertezas ligadas a assimetrias de informação relativas a custos, estoques, reservas recuperáveis, reservas prováveis, tecnologias alternativas e volumes demandados. É a interação de todas estas incertezas que pode provocar grande oscilação no preço do barril do petróleo, tornando-o sensível a um conjunto enorme de variáveis, as quais nem sempre estão disponíveis para todos os agentes.

Conforme salienta PINDYCK (1999), não apenas o nível, mas também a 
inclinação do preço do petróleo será estocástica. Derivando (2.14) com relação a $t$ :

$$
\frac{d P_{t}}{d t}=C_{0}(\phi-r) e^{\phi t}+r P_{t}
$$

Ou seja, a inclinação do preço também será estocástica, sujeita às mesmas fontes de incerteza do nível de preços. Após substituições recursivas, observa-se facilmente que:

$$
\frac{d^{n} P_{t}}{d t^{n}}=C_{0}\left(\phi^{n}-r^{n}\right) e^{\phi t}+r^{n} P_{t}
$$

Desta forma, se a demanda, as elasticidades e os estoques disponíveis ${ }^{10}$ forem estocásticos, o nível, a inclinação e os demais momentos de ordem $n$ serão variáveis na proporção $r^{n}$. Observe que para valores pequenos de $r$ e de $\phi$ (menores que 1), o impacto tende a ser decrescente em ordens de derivação superiores. Nas palavras de PINDYCK (1999: 13):

"For most depletable resources, one would expect demand, extraction, costs, and reserves all to fluctuate continuously and unpredictably over time. Whether or not the processes that these variables follow are stationary is an open matter. But in either case, we would expect price to revert to a trend line with a level and slope that likewise fluctuate over time".

E, mais adiante (p. 25):

"These numbers suggest that for irreversible investment decisions for which energy prices are the key stochastic state variables, the GBM assumption is unlikely to lead to large errors in the optimal investment rule."

A todos estes fatores influenciando o preço e sua inclinação (estoques, custos,

\footnotetext{
${ }^{10}$ Pode-se considerar também a taxa de juros
} 
tecnologia alternativa, demanda) somam-se as instabilidades inerentes ao mercado de petróleo, como decisões políticas (OPEP), guerras, dentre outras.

A presença de uma tendência estocástica na série do preço pode ser avaliada através de um teste de raiz unitária. A não rejeição desta hipótese nula não significa que o movimento browniano geométrico seja o processo correto de modelagem, mas traz indícios de uma reversão lenta à média. Por outro lado, se a série for estacionária, há evidência de que o componente de reversão à média é relevante.

A idéia pode ser expressa assim: se assumirmos que o processo gerador de dados do preço do petróleo tem a forma

$$
P_{t}=\rho P_{t-1}+\varepsilon_{t}
$$

onde $\varepsilon_{t}$ é um termo aleatório. A estacionariedade da série requer que $\rho<1$. Seja $T$ o número de anos da série. A variância assintótica de $\rho$ é dada por $\sigma^{2}(\rho)=\left(1-\rho^{2}\right) / T$. Para que a hipótese nula de que $1-\rho=0$ seja rejeitada a um nível de significância de 5\%, o valor absoluto da estatística $\tau$ deve ser pelo menos 1,9422, ou seja:

$$
\frac{1-\rho}{\sqrt{1-\rho^{2}}} T^{1 / 2} \geq 1,94
$$

$\mathrm{Ou}:$

$$
T \geq 1,94^{2} \frac{1-\rho^{2}}{(1-\rho)^{2}}
$$

Com base em (2.19), a tabela 2.1 sintetiza o tamanho mínimo da série necessário 
Tabela 2.1: Coeficiente autorregressivo, meia vida e tamanho da série

\begin{tabular}{c|c|c}
\hline \hline$\rho$ & $T$ (anos) & $H$ (anos) \\
\hline \hline 0,95 & 148 & 13,51 \\
0,90 & 72 & 6,58 \\
0,85 & 47 & 4,26 \\
0,50 & 12 & 1,00 \\
0,30 & 8 & 0,57 \\
\hline
\end{tabular}

para rejeitar a hipótese nula da raiz unitária e a Meia Vida $(H)^{11}$ estimada para o preço do petróleo para alguns valores assumidos de $\rho$. Como podemos observar, o tamanho mínimo da série para rejeitar a raiz unitária em uma série cujo coeficiente do $\mathrm{AR}(1)$ é 0,95 é de 148 anos, implicando uma meia vida em torno de 13 anos; um coeficiente de 0,85 irá requer uma amostra de 47 anos para a rejeição da raiz unitária, o que significa uma meia vida em torno de 4 anos. Por outro lado, se a série possuir um coeficiente autorregressivo menor, em torno de 0,3, requer-se apenas 8 anos para acusar a estacionariedade, implicando em uma meia vida de apenas 7 meses. Ou seja, quanto maior o tamanho da série necessário para rejeitar a raiz unitária, maior a meia vida, indicando lenta reversão à média.

A tabela 2.2 resume alguns resultados de testes de raiz unitária de PhillipsPerron, de acordo com a periodicidade escolhida. Todas as periodicidades estão modeladas com intercepto e sem tendência, pois foi a única especificação capaz de rejeitar a raiz unitária a um nível de significância de $5 \%^{12}$.

Na tabela 2.3 reportamos resultados do teste de raiz unitária $\operatorname{KPSS}^{14}$, cuja hipótese nula é a estacionariedade. Para cada um dos sub-períodos considerados, reportamos a estatística LM. O número de lags do teste foi selecionado de

\footnotetext{
${ }^{11} \mathrm{O}$ conceito de meia vida foi derivado da Física, indicando o tempo necessário para que um elemento perca metade de sua massa radioativa. Aqui indica o tempo necessário para que o preço do petróleo volte à metade de seu valor original, após um desvio. A fórmula para a meia vida do coeficiente do AR (1) é dado por: $H=\ln (0.5) / \ln (\rho)$.

${ }^{12} \mathrm{O}$ teste $\mathrm{ADF}$ apresentou resultados análogos para a mesma especificação, quando aumentado para um mínimo de 6 defasagens.

${ }^{14}$ Ver KWIATKOWSKY et. al (1992).
} 
Tabela 2.2: Teste de Raiz Unitária de Phillips-Perron

\begin{tabular}{c|c}
\hline \hline Período & Estatística $\tau^{13}$ \\
\hline \hline $1861-1999$ & $-3,20^{* *}$ \\
$1880-1999$ & $-2,60^{*}$ \\
$1900-1999$ & $-2,38$ \\
$1910-1999$ & $-2,08$ \\
$1920-1999$ & $-2,35$ \\
$1950-1999$ & $-1,50$ \\
\hline
\end{tabular}

Tabela 2.3: Teste KPSS

\begin{tabular}{c|c|c|c}
\hline \hline Período & Lags & \multicolumn{2}{|c}{ Estatística KPSS } \\
\hline \hline & & Nível & Tendência \\
\cline { 3 - 4 } $1861-1999$ & 4 & 0,377 & $0,344^{* * *}$ \\
$1880-1999$ & 4 & $0,415^{*}$ & $0,244^{* * *}$ \\
$1900-1999$ & 4 & $0,523^{* *}$ & $0,214^{* *}$ \\
$1910-1999$ & 3 & $0,698^{* *}$ & $0,224^{* * *}$ \\
$1920-1999$ & 3 & $0,761^{* * *}$ & $0,190^{* *}$ \\
$1950-1999$ & 3 & $0,614^{* *}$ & $0,164^{* *}$ \\
\hline
\end{tabular}

$(* * *)$ Significativo a $1 \% ;(* *)$ Significativo a $5 \% ;(*)$ Significativo a $10 \%$;

( ) Sugestão Newey-West.

acordo com a sugestão de Newey-West. Confirmando os resultados anteriores, a estacionariedade ao redor do nível só não é rejeitada para a amostra total de 139 anos; para a sub-amostra de 1880 a 1999, rejeitamos a estacionariedade (nível) a $10 \%$ de significância. A estacionariedade em torno da tendência é rejeitada em todos os sub-períodos analisados.

Tais resultados, além de confirmar as observações de PINDYCK (1999), mostram que só é possível rejeitar a raiz unitária em um período secular, o que, apesar do baixo poder desta classe de testes, sugere uma reversão à média bastante lenta (ou uma dissipação lenta de choques). Considerando que o horizonte temporal de um investimento no setor de óleo e gás se situa entre 20 e 30 anos, a utilização de um modelo de MBG para o preço não parece induzir a erros significativos de avaliação, a despeito de sua maior simplicidade e de seu menor grau de realismo. Além disso, as conclusões de SCHWARTZ \& SMITH (2000) sugerem que, para 
muitos casos de investimentos de longo prazo, é possível avaliar os projetos sem grandes erros de avaliação considerando a modelagem do nível de preços de equilíbrio como um MBG, interpretado como um caso particular do modelo de dois fatores ${ }^{15}$.

Conforme se pode observar pela figura 2-2, a série de preços do petróleo contém pelo menos dois movimentos abruptos que podem sugerir quebras estruturais, o que pode explicar resultados que não rejeitam a raiz unitária em períodos mais ou menos curtos. Conforme as conclusões de PERRON (1989), o poder dos testes de raiz unitária se reduz quando uma quebra estrutural presente na série é ignorada. Para averiguar o ponto, aplicamos o teste de LEE \& STRAZICICH (2003) para duas quebras estruturais. A vantagem deste método é a determinação das quebras de forma endógena, as quais são incorporadas sob a hipótese nula. De forma resumida, a especificação do teste é dada por:

$$
\begin{aligned}
y_{t} & =\delta^{\prime} Z_{t}+\epsilon_{t} \\
\epsilon_{t} & =\beta \epsilon_{t-1}+v_{t}
\end{aligned}
$$

tal que $v_{t} \sim N\left(0, \sigma^{2}\right)$. $Z_{t}$ é um vetor de variáveis exógenas que definem o tipo de quebra, de acordo com duas hipóteses possíveis:

Modelo A: Define duas quebras de intercepto de modo que $Z_{t}=\left[1, t, D_{1 t}, D_{2 t}\right]$, onde $D_{j t}=1$ para $t \geq T_{B j}+1, j=1,2$ e zero caso contrário. $T_{B j}$ são os instantes de tempo em que ocorrem as quebras, definidas a partir da combinação de quebras que minimiza a estatística $L M \tau$ que testa a hipótese nula $H_{0}: \beta=1$

\footnotetext{
${ }^{15}$ Sobre isso, SCHWARTZ \& SMITH (2000), dizem: "Although these extensions may improve the performance of the model in terms of its ability to describe the stochastic evolution of spot and futures prices, we must balance our desire for fidelity in the price models with need for parsimony in the models used to evaluate complex real or financial options. Given the difficulty of valuing options on several state variables and the fact that price is typically one of many relevant uncertainties in real options applications, the more complex models may not be suitable for use in these applications".
} 
contra a hipótese alternativa $H_{A}: \beta<1$. As formas funcionais das hipóteses são dadas por:

$$
\begin{aligned}
& H_{0}: \quad y_{t}=\mu_{0}+d_{1} B_{1 t}+d_{2} B_{2 t}+y_{t-1}+v_{1 t} \\
& H_{A}: y_{t}=\mu_{1}+\gamma t+\delta_{1} D_{1 t}+\delta_{2} D_{2 t}+v_{2 t}
\end{aligned}
$$

onde $v_{1 t}$ e $v_{2 t}$ são erros estacionários. As dummies de quebra $B_{1 t}$ e $B_{2 t}$ são necessárias para evitar que a distribuição das estatísticas do teste dependam das magnitudes das quebras $d_{1}$ e $d_{2}$ [PERRON (1989)]. Sendo $L$ o operador defasagem, a equação do teste é representada por:

$$
y_{t}=\alpha+\gamma t+\theta_{1} B_{1 t}+\theta_{2} B_{2 t}+\Psi_{1} D_{1 t}+\Psi_{2} D_{2 t}+\beta y_{t-1}+\sum_{i=1}^{S} k_{i} \Delta L^{i} y_{t}+v_{t}
$$

Modelo C: Define duas quebras de intercepto e duas de tendência, ou seja, $Z_{t}=\left[1, t, D_{1 t}, D_{2 t}, D T_{1 t}, D T_{2 t}\right]$ onde $D T_{j t}=t$ para $t \geq T_{B j}+1, j=1,2$ e zero caso contrário. As formas funcionais das hipóteses são dadas por:

$$
\begin{aligned}
& H_{0}: \quad y_{t}=\mu_{0}+d_{1} B_{1 t}+d_{2} B_{2 t}+\delta_{1} D_{1 t}+\delta_{2} D_{2 t}+y_{t-1}+v_{1 t} \\
& H_{A}: \quad y_{t}=\mu_{1}+\gamma t+\delta_{1} D_{1 t}+\delta_{2} D_{2 t}+\gamma_{1} D T_{1 t}+\gamma_{2} D T_{2 t}+v_{2 t}
\end{aligned}
$$

e sua equação testável é expressa por: 


$$
\begin{aligned}
y_{t}= & \alpha+\gamma t+\theta_{1} B_{1 t}+\theta_{2} B_{2 t}+\Psi_{1} D_{1 t}+\varphi_{1} D T_{1 t}+\varphi_{2} D T_{2 t}+\Psi_{2} D_{2 t}+ \\
& +\beta y_{t-1}+\sum_{i=1}^{S} k_{i} \Delta L^{i} y_{t}+v_{t}
\end{aligned}
$$

Os autores do teste destacam como o processo gerador de dados (2.20) e (2.21) incorpora as quebras sob $H_{0}$ e $H_{A}$ de forma consistente. As distribuições das estatísticas dos testes são obtidas a partir de simulações e estão presentes em LEE \& STRAZICICH $(2003)^{16}$. A vantagem deste teste para os demais, além da incorporação das quebras na hipótese nula, é a que sua eventual rejeição permite concluir pela hipótese alternativa de estacionariedade na tendência. Desta forma, é possível averiguar se as não rejeições da raiz unitária para sub-períodos nos testes ADF, PP e KPSS são efeito da redução do poder do teste em função da desconsideração de possíveis quebras.

A tabela 2.4 resume os resultados do teste para a série de preços de petróleo, considerando os sub-períodos em questão. O número de lags ótimo foi selecionado pela significância em $10 \%$ da última defasagem (estatística $t^{*}=1,645$ ), iniciando em 8. Obtêm-se evidências de que as conclusões dos testes convencionais decorrem da desconsideração das quebras estruturais. Em relação às quebras de intercepto (Modelo A), verificam-se os mesmos resultados dos testes anteriores, qual seja, a não rejeição da raiz unitária (com quebras) para sub-períodos menores. O modelo de quebra de tendência e intercepto, por sua vez, é mais robusto a todos os períodos considerados, permitindo concluir pela estacionariedade do preço do petróleo. É interessante observar, para o modelo C, como o ano de 1973 sempre constitui uma quebra estrutural, coincidindo com o choque do petróleo.

\footnotetext{
${ }^{16}$ Para o modelo $\mathrm{A}$, os valores críticos são assintóticos; para o modelo $\mathrm{C}$, os valores críticos dependem da razão $\lambda_{j}=T_{B j} / T$.
} 
Tabela 2.4: Teste de raiz unitária com duas quebras - Lee Strazicich 2003

\begin{tabular}{l|l|l|l|l|l}
\hline \hline Período & Modelo & \# de lags & Quebras & $\beta-1$ & Estat. $\tau$ \\
\hline \hline 1861-1999 & $\mathrm{A}$ & 8 & $1974 / 1981$ & $-0,286$ & $-5,019^{* *}$ \\
& $\mathrm{C}$ & 8 & $1881 / 1973$ & $-0,519$ & $-6,806^{* *}$ \\
\hline $1880-1999$ & $\mathrm{~A}$ & 1 & $1974 / 1986$ & $-0,323$ & $-4,724^{* *}$ \\
& $\mathrm{C}$ & 8 & $1973 / 1983$ & $-1,111$ & $-8,456^{* *}$ \\
\hline $1900-1999$ & $\mathrm{~A}$ & 0 & $1974 / 1986$ & $-0,196$ & $-3,221$ \\
& $\mathrm{C}$ & 8 & $1973 / 1983$ & $-1,001$ & $-7,310^{* *}$ \\
\hline $1910-1999$ & $\mathrm{~A}$ & 6 & $1987 / 1989$ & $-0,220$ & $-3,935^{* *}$ \\
& $\mathrm{C}$ & 8 & $1973 / 1983$ & $-1,053$ & $-7,203^{* *}$ \\
\hline \multirow{1}{1920-1999}{} & $\mathrm{A}$ & 7 & $1983 / 1987$ & $-0,146$ & $-2,743$ \\
& $\mathrm{C}$ & 6 & $1973 / 1992$ & -0.621 & $-6,346^{*}$ \\
\hline $1950-1999$ & $\mathrm{~A}$ & 5 & $1983 / 1987$ & $-0,249$ & $-3,070$ \\
& $\mathrm{C}$ & 8 & $1973 / 1983$ & $-1,583$ & $-8,319^{* *}$ \\
\hline \hline
\end{tabular}

$(*)$ Significativo a $5 \%,(* *)$ Significativo a $1 \%$

Mesmo com os resultados do teste de LEE \& STRAZICICH, é possível identificar uma reversão lenta à média. Além disso, conforme a observação dos próprios autores, uma quebra estrutural sob a hipótese nula pode ser interpretada como um choque permanente de grande magnitude, o que confirma a alta instabilidade nos preços do petróleo, apoiando mais uma vez o uso do Movimento browniano geométrico como uma aproximação aceitável.

\subsection{Reversão à Média e Meia Vida}

Conforme argumentou-se, a utilização do movimento browniano geométrico em substituição ao movimento de reversão à média acarreta em menor erro de avaliação quanto mais lenta for a velocidade de reversão à média (ou, de modo equivalente, quanto maior a meia vida da reversão). A série de preços de petróleo acima descrita permite estimar a meia vida média no período de 1862 a 1999, em anos. Considere uma variante da equação (2.1) acima, na qual o logaritmo natural do 
preço do petróleo segue um processo de Ornstein-Uhlenbeck ${ }^{17}$ :

$$
d \varkappa=\eta(\bar{\varkappa}-\varkappa) d t+\sigma d Z
$$

Em que $\varkappa=\ln P_{t}$. Sabemos que $E(d \varkappa)=\eta(\bar{\varkappa}-\varkappa) d t$.Assim, uma maneira de estimar os parâmetros $\bar{\varkappa}$ e $\eta$ é através da regressão:

$$
\Delta x_{t}=\alpha+\beta x_{t-1}+\varepsilon_{t}
$$

onde $x_{t}=\ln P_{t}$ e $\Delta x_{t}=x_{t}-x_{t-1}$. O preço de equilíbrio e o parâmetro de reversão são dados pelas fórmulas:

$$
\begin{gathered}
\hat{\eta}=-\ln (1+\hat{\beta}) \\
\bar{\varkappa}=\frac{\hat{\alpha}+\sigma_{\varepsilon}^{2}}{\hat{\eta}}
\end{gathered}
$$

onde $\sigma_{\varepsilon}$ é o desvio-padrão dos resíduos da regressão. A meia vida pode ser calculada pela fórmula ${ }^{18}$ :

\footnotetext{
${ }^{17}$ Esta modelagem é mais vantajosa não apenas por reduzir as magnitudes, mas também por evitar valores negativos para o preço.

${ }^{18}$ Esta é a fórmula para o cálculo da meia vida ajustada para tempo discreto. Embora o conceito de meia vida seja próprio de processos em tempo contínuo, o ajuste foi necessário para evitar um viés de discretização muito acentuado, já que nossos dados são anuais. A meia vida para tempo contínuo é dada por $\ln 2 / \eta$.
} 
Tabela 2.5: Coeficientes Ornstein-Uhlenbeck

\begin{tabular}{c|c}
\hline \hline$\hat{\beta}$ & $-0,1398(0,049)^{* *}$ \\
\hline$\hat{\alpha}$ & $0,3905(0,1406)^{* *}$ \\
\hline$\hat{\eta}$ & 0,1506 \\
\hline$P$ & $\$ 19,64$ \\
\hline$H$ & 4,24 anos \\
\hline \hline Estat. $J$ & $0,019\left[\chi^{2}(2)=2,59\right]$ \\
\hline \hline
\end{tabular}

$$
H=-\frac{\ln 2}{\ln (1-\eta)}
$$

A estimação de (2.25) foi feita pelo Método dos Momentos Generalizados (GMM) utilizando-se como instrumento a segunda, a terceira e a quarta defasagens do preço do petróleo, especificação que permitiu não rejeitar a hipótese de que os resíduos são um ruído branco. A tabela 2.5 sintetiza as estimativas obtidas, para os dados anuais (início do ano) do preço internacional, de 1861 a 1999. As estatísticas entre parênteses são os desvios-padrão.

As estimativas mostram uma velocidade de reversão baixa, implicando em uma meia vida de cerca de quatro anos, com um preço de equilíbrio estimado em $\$ 19,64$ para o período considerado. Desta forma, quando existe um desequilíbrio entre o preço do petróleo e seu valor de longo prazo, o desvio se reduz à metade em um prazo de cinco anos. Isso significa que, embora não se possa rejeitar uma estrutura de reversão à média, dado que $\eta$ é significante a $1 \%$, o uso de um movimento browniano geométrico constitui uma aproximação razoável para a avaliação das reservas e das decisões de investir. Conforme salienta PINDYCK (1999, 2001) quanto menor a velocidade de reversão, menos o valor do ativo irá depender do preço de equilíbrio de longo prazo, de forma que este pode ser omitido da análise sem provocar erros significativos de avaliação. 
Tabela 2.6: Coeficientes Ornstein-Uhlenbeck Geométrico

\begin{tabular}{c|c}
\hline \hline$\hat{\gamma}$ & $0,0951(0,038)^{*}$ \\
\hline$\hat{\theta}$ & $-0,0051(0,002)^{* *}$ \\
\hline$\hat{\eta}$ & 0,0051 \\
\hline$P$ & $\$ 18,34$ \\
\hline \hline Estat. $J$ & $0,017\left[\chi^{2}(2)=2,29\right]$ \\
\hline \hline (*) Significante a $5 \% ;(* *)$ Si gnificantes a 1\%.
\end{tabular}

Considere agora o processo Ornstein-Uhlenbeck Geométrico, como proposto por DIXIT \& PINDYCK (1994). Uma possível maneira de se estimar seus parâmetros é através da especificação:

$$
\Delta x_{t}=\gamma+\theta P_{t-1}+v_{t}
$$

onde $x_{t}=\ln P_{t}$ e $v_{t}$ é um ruído branco. Trata-se de uma versão, determinística e em tempo discreto, da equação (1.3). A tabela 2.6 reporta as estimativas ${ }^{19}$ obtidas.

Diferentemente do caso anterior, a meia vida deste processo de reversão não é constante. Para derivar a fórmula, é necessário primeiro encontrar a solução da seguinte equação à diferença não-linear:

$$
P_{t}-P_{t-1}=\eta P_{t-1}\left(\bar{P}-P_{t-1}\right)
$$

Trata-se de uma classe conhecida como equação logística discreta, cuja solução exige ferramentas de cálculo não triviais, envolvendo, em geral, aproximações analíticas, o que dificulta sobremaneira o cálculo da meia vida. Desta forma, a fim de derivar uma fórmula para $H$, utilizamos a versão contínua e determinística

\footnotetext{
${ }^{19}$ Novamente, utilizamos o GMM , cujos instrumentos são a segunda, a terceira e a quarta defasagens do preço.
} 
da equação (mesmo incorrendo em possíveis viés de discretização), expressa por:

$$
d P=\eta P(\bar{P}-P)
$$

A solução desta equação diferencial é dada por:

$$
P=\frac{\bar{P}}{1+k \eta e^{-\eta \bar{P} t}}
$$

onde $k=\frac{P_{0}-\bar{P}}{P_{0}}$. De $(2.29)$, observa-se que $\lim _{t \rightarrow \infty} P_{t}=\bar{P}$, constituindo a estimativa do equilíbrio de longo prazo. Para derivar a fórmula da meia vida, subtrai-se $\bar{P}$ de ambos os lados de (2.29) e tomamos $P-\bar{P}=\frac{1}{2}\left(P_{0}-\bar{P}\right)$, o que, depois de certo trabalho algébrico, resulta em:

$$
H=\frac{\ln \left(1+\frac{\bar{P}}{P_{0}}\right)}{\eta \bar{P}}
$$

Se tomarmos os valores do preço de equilíbrio e da velocidade de reversão à média constantes, a meia vida, ou seja, o tempo que o desvio do preço do petróleo em relação ao equilíbrio histórico se reduz à metade, irá depender de $\bar{P}$ e do preço no período em questão, $P_{0}$. Quanto mais distante um do outro, menor é a meia vida, isto é, mais rápido há a convergência para o equilíbrio.

A figura 2-3 apresenta as meias vidas estimadas, em anos, para o período de 1982 a 1999, da nossa série. O tempo de meia vida oscila muito no período considerado, variando de um mínimo de 2 anos e um máximo de 13 anos, com uma média de 8 anos. Estes valores podem estar majorados pelo viés de discretização, mas ilustram como o preço do petróleo apresenta uma velocidade lenta de reversão 
Figura 2-3: Meias vidas estimadas, em anos

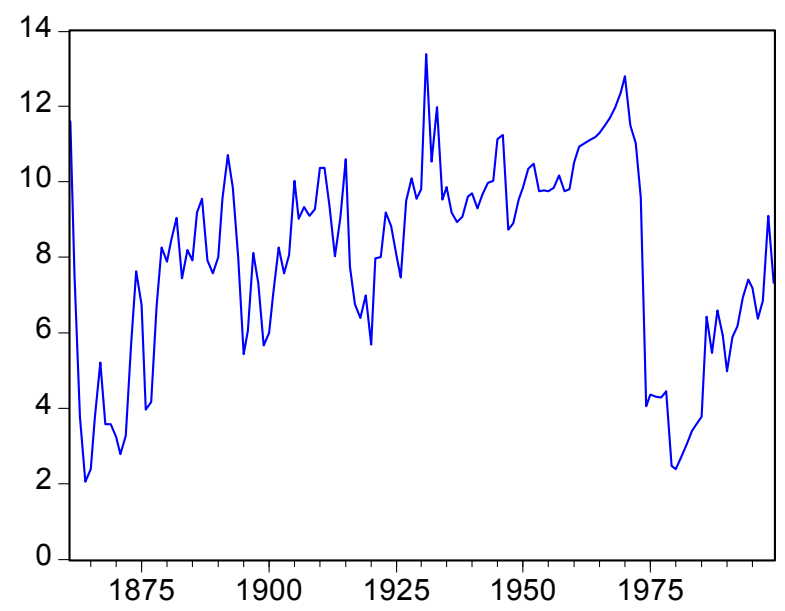

à média ${ }^{20}$. Isso significa que ele leva em média 8 anos para que o desvio em relação ao equilíbrio de longo prazo se reduza à metade. É claro que o modelo apresenta limitações, já que pressupõe uma velocidade de reversão e um preço de longo prazo constantes no período de mais de cem anos, o que é uma hipótese altamente questionável. Entretanto, de acordo com este raciocínio, os períodos de instabilidade ou de desequilíbrio podem ser identificados por uma redução da meia vida muito abaixo de sua média, como no decênio de 1974 a 1984 ( $H$ médio de 3,54 anos), período influenciado pelos choques do petróleo nos anos 70 .

O interessante a observar é que a meia vida varia inversamente com o nível de preço, conforme se pode observar pela fórmula (2.30). Pode-se estimar a meia vida de equilíbrio tomando $P=\bar{P}$ em (2.30), resultando em $H=7,4$ anos. Quanto maior o preço histórico - isto é, maior a escassez - menor a meia-vida de equilíbrio. Deste modo, existe a possibilidade de que o preço do petróleo apresente uma instabilidade crescente com o progressivo esgotamento das reservas globais.

\footnotetext{
${ }^{20}$ No caso do processo Ornstein-Uhlenbeck puro, a meia vida quando utilizada a fórmula em tempo contínuo é de 4,6 anos, contra 4,24 anos da fórmula em tempo discreto, uma diferença de $8,4 \%$.
} 


\subsection{Síntese do Capítulo}

O objetivo deste capítulo foi analisar uma série secular de preço de petróleo com vistas a identificar algumas de suas propriedades de longo prazo. A definição de um processo para esta variável tem conseqüências importantes sobre a avaliação das reservas e sobre a decisão de investir. Tanto a intuição quanto as evidências sugerem que o preço deste recurso evolui de acordo com um movimento de reversão à média, em virtude da dinâmica do mercado, qual seja, as defasagens temporais entre variações de preço e as oscilações na oferta e na demanda. $O$ nosso objetivo foi avaliar se a utilização de um movimento browniano geométrico implica em grandes erros de avaliação.

Os testes de raiz unitária convencionais empregados na série de preço anual só são capazes de rejeitar a hipótese nula de não-estacionariedade para um período secular, de modo que, se considerarmos um horizonte de tempo em torno de 30 anos, típico de investimentos no setor de petróleo, não há grandes erros em se desconsiderar o elemento de reversão à média do processo de evolução do preço. O teste KPSS confirma os resultados, não permitindo rejeitar a estacionariedade em torno de um nível apenas para a série completa, de 1861 a 1999.

Quando incluem-se quebras estruturais na hipótese nula, nos moldes do teste LEE \& STRAZICICH (2003), o padrão de não rejeição da raiz unitária se mantém para sub-períodos mais curtos quanto se testa a quebra de intercepto; por outro lado, quando incluem-se quebras na tendência, a raiz unitária com duas quebras é rejeitada em todos os subperíodos, o que nos permite inferir que a não rejeição nos testes anteriores pode ser consequiência da presença de quebras estruturais, que reduziu a potência dos testes usuais. Neste caso, a significância das quebras atesta que o preço do petróleo está sujeito a mega choques de lenta dissipação, elevando o grau de incerteza quanto ao seu comportamento futuro. Nota-se, em particular, que o ano de 1973 do primeiro choque do petróleo sempre configura uma quebra. 
Estes resultados mostram que, embora processos que contenham reversão à média (como o Ornstein Uhlembeck, aritmético ou geométrico) sejam mais acurados para representar a realidade da evolução do preço das commodities, a aproximação por um movimento browniano geométrico não acarreta erros significativos de avaliação, na medida em que a velocidade de reversão à média é baixa, implicando em pouca dependência do valor da reserva em relação ao preço de equilíbrio de longo prazo do petróleo. Além disso, conforme os argumentos de PINDYCK (1999), a tendência ao qual o preço do petróleo reverte é estocástica, sujeita a uma série de informações nem sempre disponíveis perfeitamente. A não rejeição da raiz unitária para sub-períodos inferiores a um século mostra que os choques demoram um longo período para serem dissipados, resultando em grande variabilidade de previsão de preços, tal como no MBG.

Esta maior imprevisibilidade de preços, compatível com o MBG, representa a grande vantagem da adoção deste processo para a avaliação de reservas, pois permite incorporar melhor a interação entre a irreversibilidade dos investimentos e a incerteza: na medida em que o efeito dos sunk costs só é relevante na presença de incerteza, uma decisão de investir tomada sob movimento browniano também teria sido tomada com movimento de reversão à média [SCHWARTZ (1997)]. Trata-se do "princípio da má notícia" [DIXIT (1992)], ou seja, a tendência do investidor de avaliar sempre pelo pior cenário possível.

Por esta razão e também por uma questão de facilidade operacional, utilizaremos um modelo de movimento browniano geométrico para a modelagem do preço do ativo fundamental. Além disso, como os nossos propósitos são comparar os efeitos de política e não estimar os valores das reservas, a escolha deste processo evolutivo não irá afetar qualitativamente a análise. 


\section{Capítulo 3}

\section{O Modelo}

No capítulo anterior, procuramos argumentar que o uso do movimento browniano geométrico na avaliação das reservas não é incompatível com as evidências empíricas, representando boa aproximação da a realidade, além de possuir vantagens operacionais que ficarão evidentes logo mais. Pretendemos agora utilizar o método das opções reais para avaliar a regra de investimento em cada uma de suas duas etapas fundamentais. Por se tratar de um caso de opção composta, a análise deve ser feita de forma retroativa, do futuro para o presente.

O nosso objetivo é avaliar de que forma a estrutura de benefícios governamentais na indústria de petróleo (royalties e imposto sobre a renda) são distorcivos no sentido de afetar a regra de investimento, à luz da teoria das opções reais descrita anteriormente. Em uma análise tradicional de valor presente líquido, a literatura [e.g.: MAYO (1979), CAMPBELL \& LINDNER (1985), DASGUPTA et al. (1980), GARNAUT \& C. ROSS (1983), FRASER (1993), FRASER \& KINGWELL (1997), FRASER (1998)] demonstra que os royalties apresentam um potencial distorcivo sobre o investimento, ao passo que o imposto sobre a renda do recurso possui um perfil virtualmente neutro. Agora, pretendemos investigar em que medida tais conclusões se mantêm ou não.

O modelo desenvolvido a seguir se baseia nas contribuições citadas anterior- 
mente sobre avaliação de investimentos em petróleo e gás, com base em opções reais [TOURINHO (1979); PADDOCK et al. (1988)], com a inclusão de flexibilidades que conferem valor ao projeto [McDONALD e SIEGEL (1985)] e a metodologia de DIXIT (1989), presente também em PINDYCK $(1988,1991)$ e DIXIT \& PINDYCK (1994). Considerando que investimentos em projetos de extração de petróleo compreendem duas fases principais, a de exploração e a de desenvolvimento/produção, o contexto do modelo pode ser situado entre o término da fase exploratória, quando a incerteza de ordem geológica foi dissipada, e a declaração de desenvolvimento, quando o investidor anuncia o interesse em prosseguir com o projeto, construindo a infraestrutura necessária para extrair o recurso. Trata-se, portanto, de um modelo de investimento em dois estágios ${ }^{1}$ : de posse da reserva não-desenvolvida, o agente deve avaliar se é ótimo ou não exercer a opção de transformá-la em reserva desenvolvida. A título de simplificação, assumimos que, uma vez realizado, o investimento no desenvolvimento é concluído imediatamente, isto é, estamos ignorando o tempo de construção (time to build ${ }^{2}$ ). Entretanto, depois de efetuado, o investimento não pode ser revertido, de modo que é necessário incorporar o custo de oportunidade de desenvolver a reserva.

Apesar da irreversibilidade, o modelo pode ser estendido para a presença de opção de paralisação da produção, com ou sem custos. Mostraremos como a existência desta flexibilidade adiciona valor ao investimento, contribuindo para elevar a disposição de investir e como a incorporação do efeito Jevons, através dos parâmetros de evolução do custo de produção, afeta a regra de investimento.

Este capítulo está dividido em 3 partes. No item 3.1, obtemos o processo de evolução do valor unitário de uma reserva desenvolvida, considerando duas situações: quando o investidor não tem a opção de paralisar a produção e quando

\footnotetext{
${ }^{1}$ Aqui não entendido como time to build.

${ }^{2}$ MAJD \& PINDYCK (1987) incorporam o time to build em sua análise, mas o relaxamento desta hipótese não traz diferenças qualitativas nos resultados. A inclusão do tempo de instalação apenas acentua o efeito da incerteza.
} 
esta opção existe; no item 3.2, obtém-se o valor da reserva não-desenvolvida; por fim, no item 3.3, obtemos os preços-custos críticos de desenvolvimento e de interrupção.

\subsection{Valor Unitário da Reserva Desenvolvida}

Supõe-se que o valor unitário da reserva desenvolvida, $V(P, C, t)$ seja governado por duas variáveis de estado, o preço e o custo operacional de produção, os quais seguem os quais seguem movimento browniano geométrico:

$$
\begin{aligned}
& d P=\alpha P d t+\sigma_{P} P d Z_{P} \\
& d C=\phi C d t+\sigma_{C} C d Z_{C}
\end{aligned}
$$

onde $\alpha$ e $\phi$ são os crescimentos esperados do preço e do custo; $d Z_{P}$ e $d Z_{C}$ são processos de Wiener tal que $E\left(d Z_{P} d Z_{C}\right)=\rho d t, E\left(d Z_{P}\right)=E\left(d Z_{C}\right)=0$, $E\left(d Z_{P}\right)^{2}=E\left(d Z_{C}\right)^{2}=d t ; \rho$ é o coeficiente de correlação entre as variações de $P$ e $C . \sigma_{P}$ e $\sigma_{C}$ são os desvios padrão instantâneos de cada processo.

A dependência do valor da reserva em relação ao preço parece trivial, dada a amplitude dos trabalhos na área. A inclusão do custo, porém, pode despertar dúvidas sobre o uso desta variável de estado no valor do depósito, já que o usual seria utilizar o seu tamanho físico. Esta discussão está ligada a um antigo debate, retomado por CAIRNS $(1990,1994)$, entre os enfoques de HOTELLING (1931) e GRAY (1914), sobre a avaliação de recursos exauríveis. Mesmo correndose o risco de abusar da linguagem, pode-se dizer que o primeiro fornece uma abordagem mais "macroeconômica", com ênfase na trajetória da renda do recurso e nas condições de equilíbrio intertemporal da extração, vinculada à sua finitude. Uma abordagem que foi posta de lado foi a de GRAY (1914), de conteúdo mais "microeconômico", voltado para as diferenças de qualidade entre as jazidas e sua 
extração ótima. Segundo seus resultados, as jazidas mais abundantes devem ser exploradas primeiro, em um esquema análogo às terras ricardianas. As diferenças qualitativas entre as jazidas são expressas por diferenças nos custos unitários de extração e, à medida que as reservas de pior qualidade começam a ser exploradas, tais custos tendem a crescer, refletindo as dificuldades crescentes de produção. Deste ponto de vista, a abordagem de GRAY (1914), embora menos conhecida e voltada para os custos, representa uma alternativa à análise de HOTELLING (1931), que privilegia o estoque físico dos recursos. Neste contexto, a inclusão dos custos na avaliação da jazida constitui um retorno à metodologia mais remota de Gray.

Na análise aqui proposta, a taxa de crescimento dos custos unitários é dada por $\phi$, um parâmetro associado a uma propriedade em geral ignorada, mas importante, da função custo de produção: o efeito estoque (também conhecido como efeito Jevons ${ }^{3}$ ). À medida que a reserva vai sendo extraída, o custo unitário ${ }^{4}$ de produção tende a crescer, pois fica cada vez mais difícil extrair o recurso remanescente em virtude da queda da pressão nos poços. Ou seja, assumindo que o custo unitário é inversamente proporcional ao tamanho físico da reserva, se $\phi$ for a taxa de decaimento das reservas $S$, temos ${ }^{5}$ :

$$
S_{t}=S_{0} e^{-\phi t}
$$

Como $C_{t}$ e $S_{t}$ são inversamente proporcionais:

\footnotetext{
${ }^{3}$ Ver OSMUNDSEN (1998) para as implicações do efeito estoque sobre a função custo. Em CHERIAN et al. (2000), esta propriedade se chama "custos cumulativos".

${ }^{4} \mathrm{~A}$ rigor, o custo marginal. Mas assumimos que o custo marginal é igual ao custo médio variável.

${ }^{5}$ Trata-se, portanto, de uma forma de unificar as análises de HOTELLING (1931) e GRAY (1914). CAIRNS (1994) propõe um retorno à abordagem deste último com vistas a uma melhor modelagem da heterogeneidade das jazidas, bem como da endogeneidade das descobertas.
} 


$$
C_{t} S_{t}=C_{0} S_{0}
$$

De (3.3):

$$
\begin{aligned}
C_{t} S_{0} e^{-\phi t} & =C_{0} S_{0} \\
C_{t} & =C_{0} e^{\phi t}
\end{aligned}
$$

Ou seja, o parâmetro que expressa a taxa de decaimento da reserva pode ser interpretado como a própria taxa de crescimento dos custos unitários. Assim, a incorporação do efeito estoque é importante para avaliar a disposição de investir dos agentes, já que se trata de uma particularidade da função de custos no setor extrativo [OSMUNDSEN (1998)]. Além disso, como estamos trabalhando em termos unitários, o crescimento da função custo constitui uma forma alternativa de expressar o progressivo esgotamento da reserva em relação ao usual estoque inicial do recurso. Desta forma, ao invés de tratarmos de quantidade, voltamos a análise para a qualidade da reserva, que pode ser indicada pelo montante de investimento necessário para desenvolver uma unidade da mesma.

A figura 3-1 ilustra a idéia. A produção cresce gradativamente até $t_{D}$, instante em que a fase de desenvolvimento é concluída. Neste período, a produção atinge seu ponto máximo - platô - quanto, a partir de então, entra em declínio gradativo em decorrência do esgotamento da jazida. A contrapartida deste fenômeno é o crescimento dos custos unitários a partir de $t_{D}$, conforme visualizado no diagrama ${ }^{6}$.

\footnotetext{
${ }^{6}$ Detalhes da dinâmica dos custos e da produção na indústria do petróleo podem ser encontrados no material do prof. Dr. Saul B. Suslick, do Instituto de Geociências da Unicamp, intitulado "Evolução dos custos na Indústria de Petróleo", Março/2000, disponível em $<$ www.ige.unicamp.br $/{ }^{\sim}$ suslick/custos1web.pps $>$.
} 
Figura 3-1: Produção e Custos Unitários no tempo

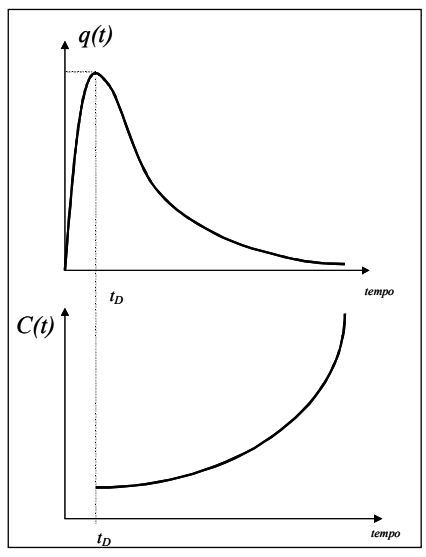

O parâmetro $\phi$ expressa a relação entre a produção e o total de reservas, um importante indicador prático do ritmo de extração e, portanto, do tempo disponível do recurso. Como a variação da reserva é dado pela quantidade extraída $y$, tem-se $y=-d S / d t=\phi S$, por (3.3). Desta forma, $\phi^{-1}=S / y$. Trata-se de um indicador que avalia em termos práticos a disponibilidade futura de petróleo e pode ser tratado como uma variável de decisão. Em geral, é medida em anos.

Outra vantagem em incorporar diretamente a evolução dos custos reside em flexibilizar a usual regra do " $1 / 3$ " 7 . Trata-se de uma regra de avaliação (também conhecida como equação Business ${ }^{8}$ ) que compreende a multiplicação de um fator $q$ sobre o preço do barril com vistas a encontrar o valor da unidade de reserva, a qual depende linearmente do preço spot do petróleo. Em resumo, supõe-se que $V=q P-I$, onde $V$ é o valor unitário da reserva desenvolvida, $P$ o preço e $I$ o investimento por barril. O fator $q$ sintetiza todas as características geológicas da reserva - qualidade, tipo, etc. PADDOCK et al (1988) utilizam o valor de $q=1 / 3$, o qual se tornou referência nos trabalhos posteriores. Além disso, esta abordagem não incorpora explicitamente a evolução dos custos, assumindo-se que

\footnotetext{
${ }^{7}$ PADDOCK et al. (1988), DIAS (2001), MOSZKOWICZ (2003).

${ }^{8}$ MOSZKOWICZ (2003).
} 
este possui correlação unitária com os preços. Conforme mostramos adiante, a especificação do processo dos custos permite assumir correlação imperfeita entre estas variáveis, o que é mais compatível com a realidade.

Assume-se que a taxa esperada de crescimento do preço é dada por $\alpha$. Tratase de um parâmetro crucial para a avaliação da reserva. Em geral, os modelos de avaliação de ativos preferem trabalhar com o conceito de convenience yield $\delta$, que depende inversamente da taxa de crescimento do valor do ativo. O convenience yield é análogo à taxa de dividendos das ações e pode ser interpretado como o benefício líquido de se estocar uma unidade marginal do recurso ${ }^{9}$. Por esta razão, no contexto em questão, ele pode ser entendido como o custo de oportunidade de adiar o desenvolvimento da reserva, mantendo em aberto a opção de investir ${ }^{10}$.

Apesar de não assumirmos uma taxa de crescimento estocástica, a nossa escolha em trabalhar diretamente com $\alpha$ está relacionada com os dois métodos alternativos para a avaliação de investimentos sob incerteza: a abordagem da programação dinâmica e a abordagem do ativo replicante ${ }^{11}$. Ambas têm como objetivo obter a equação diferencial que descreve o valor do ativo (ou da opção de investir).

A programação dinâmica consiste em comparar o valor do ativo se o investimento ocorresse hoje com a oportunidade de se esperar um período para investir (chamado de valor de continuação). Considerando um modelo discreto de dois períodos de opção de investir, o investidor só irá desembolsar uma despesa $I$ de

\footnotetext{
${ }^{9}$ No mercado financeiro, a taxa de dividendos, em equilíbrio, é igual à diferença entre a taxa de juros livre de risco e a taxa de crescimento do ativo fundamental. Se não houver dividendos, ambas devem ser iguais na ausência de arbitragem. No caso de ativos reais, não existe uma razão para que o valor do ativo cresça à taxa de juros. Assim, o convenience yield costuma ser associado a uma "taxa de dividendos" mas, na verdade, ele está ligado à diferença entre a taxa de juros e a taxa de crescimento do valor. Pelo fato de haver uma cunha entre ambas, há um benefício em estocar o ativo.

${ }^{10}$ Assumimos que o produtor é pequeno a ponto de tomar como dado o preço do petróleo. PINDYCK (1988) generaliza o processo para o caso da presença de uma equação de demanda da firma na forma de $P=q(t)-\gamma Q$, onde $q(t)$ segue um MBG. Se o produtor é price taker, $\gamma=0$.

${ }^{11}$ DIXIT \& PINDYCK (1994)
} 
investimento no instante atual se os lucros percebidos forem maiores do que estes lucros no futuro, que representam o valor de continuação, trazidos a valor presente a uma taxa de desconto $r$. Dessa forma, o valor do ativo $A$ no instante $t$ é igual a:

$$
A_{t}=\max \left\{V-I, \frac{1}{1+r} E\left(A_{t+1}\right)\right\}
$$

onde $V$ é o valor presente dos fluxos fornecidos pelo ativo e $E[$.] representa o operador esperança. Em termos contínuos, o mesmo problema pode ser expresso como função do retorno esperado da opção de investimento, na forma da equação de Bellman abaixo:

$$
r A(V, t)=\max _{Z}\left\{\pi(V, Z, t)+\frac{1}{d t} E[d A]\right\}
$$

onde $Z$ representa uma ação contida na variável de controle, como a decisão de investir $(Z=D)$ ou não $(Z=0)$. A solução de (3.6) resulta em uma equação diferencial que descreve o comportamento de $A$ de acordo com $V$.

Uma abordagem alternativa à programação dinâmica e que se sobressaiu ao longo da literatura, notadamente no ramo das finanças, é a técnica dos ativos replicantes, que consiste em replicar o valor do projeto em um portfólio livre de risco através de uma posição de compra no valor do projeto e uma posição de venda de $n$ unidades de $V$ :

$$
\Pi(V, t)=A(V, t)-n V
$$

Prova-se que, para eliminar o risco da carteira, $n$ deve ser igual à derivada de 
$A$ com relação a $V^{12}$. Isso significa que o portfólio é dinâmico de modo que $n$ deve ser ajustado continuamente para eliminar o risco diante das variações inesperadas de $V^{13}$. A condição de não arbitragem requer que este portfólio se valorize de acordo com a taxa de juros livre de risco.

A escolha da abordagem mais adequada depende de fatores de ordem prática e de qual o objetivo proposto. Cada uma delas apresenta vantagens e desvantagens, apesar dos ativos contingentes terem ganhado um espaço consideravelmente maior [DIAS (1996)].

Apesar da sua predominância, notadamente na avaliação de opções sobre ações, a abordagem do ativo replicável se depara com algumas limitações quando aplicada para a avaliação de ativos reais. A composição do portfólio livre de risco pressupõe a existência de um mercado em que o ativo em questão seja negociado, ou seja, para utilizar esta abordagem, é necessário encontrar um ativo cujo valor seja o mais correlacionado possível com o valor da reserva a fim de mimetizá-la na composição da carteira (3.7). Para a obtenção de um portfólio sem risco, por sua vez, é necessário que haja um mercado completo de modo que o valor do projeto seja perfeitamente correlacionado com um ativo negociável. A vantagem deste método é que a avaliação do projeto independe da preferência de risco do agente e a taxa de desconto (ajustada ao risco) pode ser determinada via CAPM [DIXIT \& PINDYCK (1994)].

Se o valor da reserva for governado por um único fator, o preço do petróleo, é perfeitamente possível assumir que o valor desta commodity no mercado assuma o papel de ativo replicante, conforme os modelos originais fazem. Todavia, a presença de uma segunda variável de estado complica o problema. No caso dos custos operacionais deste modelo, surge a dificuldade em encontrar um ativo que o replique. Além disso, os conceitos usuais associados a ativos, como convenience

\footnotetext{
${ }^{12}$ Quando $n=d A / d V$, o termo estocástico decorrente da equação de evolução do ativo fundamental desaparece.

${ }^{13} \mathrm{O}$ que equivale ao delta da opção sobre ações.
} 
yield, se tornam obscuros quando transpostos para os custos.

Por esta razão, e com vistas a fundamentar melhor o valor da reserva do ponto de vista teórico, adotamos aqui o procedimento da programação dinâmica para encontrar a equação diferencial que governa o valor da reserva. Esta abordagem prescinde da existência de um ativo negociável perfeitamente correlacionado com o valor do projeto, mas requer a adoção de uma taxa de desconto exógena. Ou seja, agora torna-se complicado empreender uma avaliação ajustada ao risco mas, conforme relatamos logo abaixo, a transposição de uma avaliação neutra ao risco para a ajustada ao risco não trará ganhos de entendimento para os nossos objetivos, já que os efeitos de variações no prêmio de risco podem ser analisados por mudanças na taxa de juros, $r$.

O objetivo do agente é maximizar o valor da reserva e os lucros por ela proporcionados. Como estamos avaliando uma unidade de reserva (um barril), não há variável de controle (quantidade extraída ${ }^{14}$ ), pelo princípio de Bellman, temos:

$$
r V(P, C, t) d t=L(P, C, t) d t+E_{0}(d V)
$$

A equação (3.8) estabelece a condição de ótimo do problema, que requer que o retorno da reserva à taxa livre de risco, $r V d t$, deve ser o igual aos lucros proporcionados pela jazida, $L$, mais a variação esperada em seu valor, em equilíbrio.

Cabe aqui abrir um parênteses para uma importante discussão a respeito da taxa de desconto apropriada. Em (3.8) utilizamos a taxa livre de risco, o que comporta duas interpretações possíveis: a) supõe-se que o investidor seja neutro ao risco; b) não há risco sistemático, de modo que todos os riscos do projeto são diversificáveis ${ }^{15}$. Na prática, é possível empreender uma avaliação ajustada

\footnotetext{
${ }^{14}$ Aqui, o único parâmetro associado à quantidade extraída é a taxa de decaimento das reservas, $\phi$, suposto exógeno.

${ }^{15}$ Ver HULL (1993).
} 
ao risco através da inclusão de um prêmio à taxa de juros, o qual pode ser calculado a partir de um modelo CAPM. Todavia, não estamos interessados em discutir o impacto de alterações no grau de aversão ao risco sobre o investimento, pois tal efeito pode ser analisado por mudanças diretas na taxa de desconto intertemporal. Deste modo, desenvolveremos uma avaliação livre de risco, pois uma análise ajustada ao risco apenas acarretaria uma dificuldade desnecessária. Deve-se ter em vista que uma avaliação livre de risco não está longe da realidade dos investimentos do setor de petróleo no estágio em que estamos concentrando a análise, ou seja, quando a fase de exploração está encerrada e o potencial das reservas já é conhecido. Um prêmio de risco seria mais coerente com a fase pré-exploratória, quando a incerteza geológica tende a ser grande. Quando o volume de recursos já é conhecido, a presença do risco sistemático seria decorrente da possibilidade de quebras unilaterais de contratos de concessão pelo governo (sovereing risk $^{16}$ ), colocando em risco a propriedade das jazidas. Esta incerteza é subjetiva e de difícil quantificação. Assumiremos que as instituições regulatórias são suficientemente sólidas de modo a permitir que este risco não exista. Assumese, pois, que os riscos de preço e custo são os únicos relevantes e plenamente diversificáveis, justificando o uso da taxa livre de risco ${ }^{17}$.

Feitas estas hipóteses, a função de lucro unitário $L$ é dado por:

$$
L=(1-R)[(1-\tau) P-C]
$$

onde $\tau$ é a alíquota de royalties, que incide sobre a receita, e $R$ é a alíquota

\footnotetext{
${ }^{16}$ GARNAUT \& C. ROSS (1983).

${ }^{17}$ Conforme salienta PINDYCK (1991), os resultados do efeito da incerteza sobre a decisão de investir prescindem de qualquer hipótese sobre as preferências do agente em relação ao risco ou sobre em que medida o risco do projeto é correlacionado com o portfólio de mercado. Sejam as firmas neutras ou avessas ao risco, alterações estocásticas em $P$ (ou $C$ ) podem ser completamente diversificáveis e o efeito da incerteza sobre a regra de investimento será sempre o mesmo, podendo diferir apenas na intensidade.
} 
de uma versão lato sensu do imposto sobre a renda do recurso ${ }^{18}$.

Podemos justificar melhor agora porque optamos por trabalhar diretamente com a taxa esperada de crescimento do preço, $\alpha$, ao invés do convenience yield, . SCHWARTZ \& SMITH (2000) optam por uma estratégia análoga. Segundo eles, o convenience yield pode ser definido como o fluxo de serviços acumulado nas mãos do proprietário do estoque físico. O problema da noção de convenience yield em opções reais é que o detentor do ativo não "embolsa" a taxa de dividendos, o que a faz soar um tanto artificial. Em SCHWARTZ \& SMITH (2000), variações na taxa de convenience yield são interpretadas como variações no preço de equilíbrio de longo prazo.

É importante neste ponto desenvolver uma pequena digressão sobre a analogia do convenience yield com a taxa de dividendos das ações. Apesar de se fazer uma comparação direta, PILIPOVIC (1997) estabelece a distinção precisa entre os dois conceitos. Enquanto a taxa de dividendos está ligada a uma ação e a seu preço spot, o convenience yield é uma propriedade da relação entre o preço spot de uma commodity e um valor de equilíbrio de longo prazo. A acumulação de estoque de um recurso só será vantajosa para o agente se for capaz de produzir um benefício líquido dos custos de estocagem. Este benefício está ligado ao potencial de ganhos de capital resultante dos desvios do preço à vista em relação a um referencial de equilíbrio de longo prazo. O convenience yield pode ser positivo ou negativo de acordo com o estado geral do mercado, isto é, com o volume de estoques e as condições de oferta e demanda de longo prazo. Por esta razão, se $\delta>0$, haverá um custo de oportunidade de não explorar o recurso e de manter em aberto a opção de desenvolver. PILIPOVIC (1997) propõe relacionar o convenience yield $(C y)$ ao desvio do preço spot $\left(P_{t}\right)$ em relação ao preço de equilíbrio de longo prazo $\left(E_{t}\right)^{19}$ :

\footnotetext{
${ }^{18} \mathrm{~A}$ equação é equivalente a um imposto sobre os lucros no qual a despesa com royalties pode ser deduzida: $(1-R)[P-C-\tau P]$

${ }^{19}$ Uma especificação alternativa seria $C y_{t}=\delta+\gamma(P-E) / E$.
} 


$$
C y_{t}=\delta+\gamma \ln \left(\frac{P_{t}}{E_{t}}\right)
$$

Como se pode verificar, o convenience yield só será constante se o preço à vista coincidir com o equilíbrio de longo prazo. Isso significa que a utilização de um modelo com $C y$ constante, como o MBG, deve pressupor um coeficiente $\gamma$ próximo de zero ou então uma proximidade contínua entre os preços à vista e de longo prazo. Por outro lado, o mercado de derivativos de petróleo disponibiliza contratos de tempo não superiores a seis meses, de modo que seu preço futuro pode não refletir com precisão o equilíbrio de longo prazo, tendo em vista a complexidade do mercado. O equilíbrio de longo prazo, por sua vez, pode ser incerto, por problemas de assimetria de informação quanto às variáveis que o determinam.

Em resumo, o convenience yield não pode ser analisado como uma taxa de dividendos de ações, na medida em que é necessário um modelo determinante das condições de equilíbrio do mercado [PADDOCK et. al, 1988].

Pelo Lema de Itô, e desconsiderando ordens de $d t$ iguais ou superiores a 2 :

$$
d V=\frac{\partial V}{\partial P} d P+\frac{\partial V}{\partial C} d C+\frac{1}{2} \frac{\partial^{2} V}{\partial P^{2}}(d P)^{2}+\frac{1}{2} \frac{\partial^{2} V}{\partial C^{2}}(d C)^{2}+\frac{1}{2} \frac{\partial^{2} V}{\partial P \partial C} d P d C+\frac{\partial V}{\partial t}
$$

A fim de simplificar a notação, fazemos $V_{X}=\partial V / \partial X$ e $V_{X X}=\partial^{2} V / \partial X^{2}$. Por hipótese, sabemos que $E_{0}\left(d Z_{P}\right)=E_{0}\left(d Z_{C}\right)=0$, que $E_{0}\left(d Z_{P}\right)^{2}=E_{0}\left(d Z_{C}\right)^{2}=d t$ e que $E_{0}\left(d Z_{P} d Z_{C}\right)=\rho d t$, temos a expressão para $E_{0}(d V)$ : 


$$
\begin{aligned}
& E_{0}(d V)=V_{P} P \alpha d t+V_{C} C \phi d t+\frac{1}{2} V_{P P} \sigma_{P}^{2} P^{2} d t+\frac{1}{2} V_{C C} \sigma_{C}^{2} C^{2} d t+ \\
& +V_{P C} P C \sigma_{P} \sigma_{C} d t+V_{t} d t
\end{aligned}
$$

Substituindo (3.12) em (3.8) e rearranjando:

$$
\begin{aligned}
& \frac{1}{2} V_{P P} \sigma_{P}^{2} P^{2}+\frac{1}{2} V_{C C} \sigma_{C}^{2} C^{2}+V_{P C} P C \sigma_{P} \sigma_{C}+\alpha V_{P} P+\phi V_{C} C+ \\
& +V_{t}+(1-R)[(1-\tau) P-C]-r V=0
\end{aligned}
$$

A expressão (3.13) é uma equação diferencial parcial e não tem solução analítica. Entretanto, podemos assumir uma hipótese derivada da dinâmica do estoque de reservas e permitir uma trajetória determinística para o termo $V_{t}$. Confome salienta DIXIT \& PINDYCK (1994, cap. 7), $V_{t}$ pode ser interpretado como a depreciação do projeto. Os projetos no setor de petróleo apresentam duas características fundamentais: são de longa duração e depreciam conforme o esgotamento da jazida. Assim, se supusermos que, uma vez iniciado, a condição de abandono será o esgotamento econômico do recurso, podemos substituir $V_{t}$ por $-\phi V$, ou seja, o valor da reserva se deprecia proporcionalmente à sua taxa de decaimento ${ }^{20}$.

Mesmo com essa substituição, a equação (3.13) possui solução complicada, podendo requerer métodos numéricos de grande complexidade, pelo fato da função objetivo $V$ ser governada por dois fatores $(P, C)$. O resultado da equação diferencial irá gerar um problema de "livre fronteira", isto é, precisamos saber todas as combinações de $P$ e $C$ que tornam ótimo investir ou não. Para esta classe de problemas, as soluções analíticas são raras e as soluções numéricas são quase

\footnotetext{
${ }^{20}$ Embora muitos modelos estabeleçam que a condição de transversalidade para problemas de extração seja o esgotamento físico da jazida $(S(T)=0)$, esta hipótese é inconsistente com as considerações de otimização de lucro, já que neste caso, teríamos $C(T) \longrightarrow+\infty$. Na realidade, a condição terminal deve ser $V(S(T))=0$. Ver OSMUNDSEN (1998).
} 
sempre ad hoc, desenvolvidas para cada caso particular ${ }^{21}$. Em sua essência, o problema não difere do caso em que apenas o preço é incerto só que, ao invés de obtermos um "preço crítico" acima do qual a decisão de investir se torna ótima, obtém-se uma "fronteira crítica" e o problema se complica devido à sua bi-dimensionalidade. Entretanto, se o preço e o custo seguem um movimento browniano geométrico, é possível reduzir o problema a apenas uma variável de estado, devido à propriedade de homogeneidade da função $V$. Ou seja, assumindo que $V(P, C)=C v(P / C)=C v(p)$, o objetivo do problema passa a ser determinar a função $v(p)$.

A definição da variável $p \equiv P / C$ e a propriedade da homogeneidade conduzem às seguintes relações ${ }^{22}$ :

$$
\begin{aligned}
V_{P} & =v^{\prime}(p) \\
V_{C} & =v(p)-p v^{\prime}(p) \\
V_{P P} & =v^{\prime \prime}(p) / C \\
V_{P C} & =-p v^{\prime \prime}(p) / C \\
V_{C C} & =p^{2} v^{\prime \prime}(p) / C
\end{aligned}
$$

Substituindo as relações acima em (3.13) e dividindo ambos os lados por $C$ temos:

$$
\frac{1}{2}\left(\sigma_{P}^{2}-2 \rho \sigma_{P} \sigma_{C}+\sigma_{C}^{2}\right) p^{2} v^{\prime \prime}(p)+(\alpha-\phi) p v^{\prime}(p)-r v(p)+(1-R)[(1-\tau) p-1]=0
$$

Vale ressaltar que este resultado de homogeneidade só é válido para o caso em

\footnotetext{
${ }^{21}$ DIXIT \& PINDYCK (1994)

${ }^{22}$ As notações $v \prime($.$) e v \prime \prime($.) significam a primeira e a segunda derivada com relação a $p$.
} 
que ambas as variáveis de estado seguem um MBG. Não é possível empreender esta transformação quando pelo menos uma delas segue um processo de reversão à média, tendo em vista que o drift se torna função do nível da variável. Isso dificultaria sobremaneira a avaliação do impacto da exaustão progressiva (ou crescimento dos custos) que estamos incorporando.

Um detalhe interessante a ser observado na equação acima é a variância de $p$, no primeiro termo de (3.15). Ela é dada por $\operatorname{Var}[P-C]=\operatorname{Var}(P)+\operatorname{Var}(C)-$ $2 \operatorname{Cov}(P, C)=\sigma_{P}^{2}+\sigma_{C}^{2}-2 \rho \sigma_{P} \sigma_{C}$. A presença de duas variáveis de estado governando o valor da reserva introduz uma nova variável chave para sua avaliação, o coeficiente de correlação instantânea entre elas, $\rho$, ou seja, a presença de incerteza nos custos pode, na verdade, reduzir a incerteza global do projeto, dependendo do sinal algébrico deste coeficiente.

A expressão (3.15) é uma equação diferencial ordinária que admite solução homogênea e particular. É possível verificar facilmente que a solução particular é dada por:

$$
v^{*}=(1-R)\left[\frac{(1-\tau) p}{r-\alpha+\phi}-\frac{1}{r}\right]
$$

A interpretação da solução particular é direta. Ela representa o valor fundamental do barril de petróleo, isto é, o seu valor presente:

$$
\begin{gathered}
V P=\int_{0}^{\infty}(1-R)[(1-\tau) P(t)-C(t)] S(t) e^{-r t} d t \\
=\int_{0}^{\infty}(1-R)\left[(1-\tau) P_{0} e^{\alpha t}-C_{0} e^{\phi t}\right] S_{0} e^{-\phi t} e^{-r t} d t \\
=(1-R)\left[\frac{(1-\tau) P_{0}}{r-\alpha+\phi}-\frac{C_{0}}{r}\right]
\end{gathered}
$$

desde que $r>(\alpha-\phi)$. Esta hipótese corresponde à exigência de que o convenience yield seja maior que zero $(\delta>0)$, quando se incorporam os custos cumulativos (usualmente, para custos constantes, teríamos $r>\alpha$ ). Se isso não 
ocorrer, o custo de oportunidade do investimento sempre excede seu benefício e a firma nunca irá instalar capacidade para extração [PINDYCK (1988)], o que equivale tornar negativo o valor da reserva desenvolvida ${ }^{23}$. A expressão acima é a (3.16) multiplicada por $C_{0}$. Ela pode ser interpretada, de acordo com DIXIT e PINDYCK (1994), como o valor fundamental do ativo que, no nosso caso, é o barril de petróleo.

A solução homogênea assume a forma funcional $v_{H}=A p^{\beta}$. Substituindo em (3.15), $\beta$ é dado pela solução da equação característica:

$$
\frac{1}{2}\left(\sigma_{P}^{2}-2 \rho \sigma_{P} \sigma_{C}+\sigma_{C}^{2}\right) \beta^{2}+\left[\alpha-\phi-\frac{1}{2}\left(\sigma_{P}^{2}-2 \rho \sigma_{P} \sigma_{C}+\sigma_{C}^{2}\right)\right] \beta-r=0
$$

A equação (3.17) é de segundo grau e admite duas soluções, $\beta_{1}>1$ e $\beta_{2}<0$, de forma que a solução homogênea da equação diferencial é dada por:

$$
v_{H}=A_{1} p^{\beta_{1}}+A_{2} p^{\beta_{2}}
$$

Assim, a solução total será $v=v^{*}+v_{H}$. As constantes $A_{1}$ e $A_{2}$ são determinadas pelas condições de transversalidade próprias de acordo com as flexibilidades admitidas pelo projeto.

Com vistas a ilustrar o valor da flexibilidade na avaliação do projeto de investimento, tomemos dois casos separados: quando o investidor não possui opção de parada temporária e quando o agente é capaz de interromper a produção temporariamente, caso as condições econômicas não sejam favoráveis.

\footnotetext{
${ }^{23}$ Conforme apontam HILLIARD \& REIS (1998), o convenience yield sintetiza as informações sobre as preferências do consumidor em relação ao risco e sobre a tecnologia de produção. Assim, $\delta=r-a+\phi$ pode ser considerado um convenience yield aumentado para incorporar o efeito do custo $\phi$. Esta análise também é consistente com DAVIS \& CAIRNS (1999), segundo a qual restrições tecnológicas impedem a verificação da regra de Hotelling strictu sensu.
} 


\subsubsection{Sem opção de paralisação temporária}

Consideremos, em primeiro lugar, um projeto de extração em que o investidor não possa interromper a extração no caso de condições econômicas desfavoráveis. Neste caso, se o preço do petróleo cair a zero, a reserva perderá valor, de modo que a primeira condição de transversalidade será $v(0)=0$ o que, em (3.18), requer $A_{2}=0$, dado que $\beta_{2}<0$.

A outra constante, $A_{1}$ é mais difícil de ser excluída e representa o componente de bolha de $v$ obtido quando $p \rightarrow \infty$. Segundo DIXIT \& PINDYCK (1994), é possível demonstrar que o primeiro termo de (3.18) representa justamente a possibilidade dos agentes avaliarem o ativo a um valor acima do seu fundamento se esperam revendê-lo posteriormente com ganho de capital.

Aplicando o Lema de Itô em $p^{\beta_{1}}$, utilizando a equação característica (3.17) e lembrando que $d p / p=d P / P-d C / C$, é possível demonstrar depois de algum trabalho algébrico que:

$$
E\left[d\left(p^{\beta_{1}}\right) / p^{\beta_{1}}\right]=r d t
$$

Em uma avaliação livre de risco, o primeiro componente de $v_{H}$ em (3.18) tem taxa de retorno igual à taxa de juros livre de risco $^{24}$. É interessante observar que independe de $\beta_{1}$ (só dependeria se a taxa de retorno fosse ajustada ao risco). Qualquer desequilíbrio nesta relação tenderá a produzir um movimento de compra (se $E\left[d\left(p^{\beta_{1}}\right) / p^{\beta_{1}}\right]>r d t$ ) ou de venda (caso contrário) do ativo avaliado em $p^{\beta_{1}}$, de modo que a maneira de excluir a bolha representada pelo primeiro componente de (3.18) é tomando $A_{1}=0$.

Desta forma, portanto, se excluirmos as bolhas especulativas, o valor fundamental de uma unidade da reserva será dada por $v^{*}$ em (3.16).

\footnotetext{
${ }^{24}$ É interessante observar como este resultado é uma versão moderna do antigo Princípio de Hotelling.
} 


$$
v(p)=(1-R)\left[\frac{(1-\tau) p}{r-\alpha+\phi}-\frac{1}{r}\right]
$$

A expressão (3.20) remete a uma controversa discussão sobre o valor fundamental das reservas e sua relação com a teoria de extração de recursos nãorenováveis de HOTELLING (1931), segundo a qual o valor unitário da reserva é dado pela diferença entre o preço e o custo marginal de extração (também conhecido como valor sombra). DAVIS \& CAIRNS (1999) procuram medir o grau de precisão do princípio de avaliação de Hotelling e em que medida ele fornece um limite superior ou inferior para o valor das reservas. Este princípio é fundamentado em uma análise de fluxo de caixa descontado e parte do pressuposto de que, no equilíbrio, o valor unitário da reserva deve crescer à taxa de juros devido à arbitragem dos agentes e ao progressivo esgotamento do recurso. Davis \& Cairns concluem que, na presença de incerteza, de restrições tecnológicas ou regulatórias para a extração do recurso, o princípio de Hotelling tende a sobreavaliar o verdadeiro valor da reserva e o crescimento do seu valor sombra tende a ser inferior à taxa de juros ${ }^{25}$. A análise das opções reais vai na direção oposta, isto é, a desconsideração das flexibilidades que conferem valor às reservas levam o princípio de Hotelling a subavaliá-las. DAVIS \& CAIRNS (1999) argumentam que o valor de tais flexibilidades é pequeno, insuficiente para invalidar seus resultados. Todavia, suas conclusões sobre a restrição tecnológica e valor da reserva supõem que elevações na taxa de extração não afetam a trajetória de custos.

\footnotetext{
${ }^{25}$ Vale observar que a exigência de que $r>\alpha-\phi$ é consistente com esta constatação, ou seja, se $\phi$ representa a restrição tecnológica e assumirmos que $\alpha-\phi$ é uma proxy para o crescimento da renda de Hotelling, a afirmação de DAVIS \& CAIRNS (1999) pode ser interpretada como uma consequência do fato do valor fundamental da reserva ser finito.
} 


\subsubsection{Com opção de paralisação temporária}

McDONALD \& SIEGEL (1985) abordam a avaliação de um projeto de petróleo quando há a opção de paralisação temporária ${ }^{26}$. O modelo é análogo ao desenvolvido aqui, exceto com relação à evolução da função custo e à avaliação do investimento, para o qual os autores utilizam uma aproximação da fórmula de Black \& Scholes para calls européias. A interpretação de McDonald \& Siegel é que, em cada instante de tempo, o detentor da opção paga o preço $C$ para obter $P$.

Suponhamos que o produtor possa paralisar, a um custo $E$ por barril, a operação sempre que as condições econômicas forem desfavoráveis, ou seja, o preço caia demasiadamente e/ou haja um declínio acentuado da demanda. Se houver opção de paralisar a produção, a função lucro (3.9) se torna ${ }^{27}$ :

$$
L=\max \{0,(1-R)[(1-\tau) P-C]\}
$$

A equação diferencial que governa o valor da reserva irá depender da função de lucro. Se a jazida estiver inoperante, desenvolvida ou não, apenas a parte homogênea da solução permanecerá, assumindo a forma funcional $v(p)=H_{1} p^{\beta_{1}}+$ $H_{2} p^{\beta_{2}}$, onde $H_{1}$ e $H_{2}$ são constantes a serem determinadas; por outro lado, em caso de operação, a solução de (3.15) será dada por:

$$
v(p)=B_{1} p^{\beta_{1}}+B_{2} p^{\beta_{2}}+(1-R)\left[\frac{(1-\tau) p}{r-\alpha+\phi}-\frac{1}{r}\right]
$$

As constantes podem ser determinadas pelas condições de transversalidade. Se a operação estiver paralisada (ou a jazida não-desenvolvida), o valor da reserva é a

\footnotetext{
${ }^{26}$ Ver também DIXIT (1989).

${ }^{27} \mathrm{Na}$ verdade, estamos normalizando os custos fixos para zero.
} 
opção de retomada das atividades (ou de desenvolver) ${ }^{28}$. Conforme os argumentos apontados anteriormente, se $p \longrightarrow 0, v(p) \rightarrow 0$, de modo que $H_{2}=0$; por outro lado, se o projeto estiver em operação, o valor da unidade de reserva pode ser interpretado como a opção de suspender, de forma que, se $p \rightarrow \infty$, é improvável que o investidor a exerça. Assim, como $\beta_{1}>0$, devemos ter $B_{1}=0$.

Em síntese, se houver opção de paralisação, o valor da reserva desenvolvida será dado por:

$$
v(p)=\left\{\begin{array}{cl}
B_{2} p^{\beta_{2}}+(1-R)\left[\frac{(1-\tau) p}{r-\alpha+\phi}-\frac{1}{r}\right] & \text { se opera } \\
H_{1} p^{\beta_{1}} & \text { se não opera }
\end{array}\right.
$$

É interessante observar, no caso de operação, como a opção de paralisar a extração adiciona uma cunha ao valor fundamental. Assim, a desconsideração de flexibilidades pode levar a uma sub-avaliação do projeto.

A determinação do modo de operação, isto é, se a jazida opera ou não, irá depender da razão $p \equiv P / C$ crítica. Sejam $p^{E}$ e $p^{S}$, respectivamente, as razões preço-custo críticas que determinam o desenvolvimento e a interrupção da atividade em caso desta estar operando. A decisão ótima da empresa conforme cada faixa de $p$ irá depender de seu modo de operação: se a reserva não foi desenvolvida, a variável de decisão será $p^{E}$, isto é, o valor crítico que determina o exercício da opção de desenvolver e, conseqüentemente, operar ${ }^{29}$; por outro lado, se a reserva está desenvolvida, a decisão será entre paralisar ou não a produção, determinada pelo valor crítico $p^{S}$ (preço de saída). A tabela 3.1 resume as decisões ótimas de acordo com o valor de $p$.

É interessante observar como $p^{S}$ e $p^{E}$ são diferentes entre si e a razão preçocusto neste intervalo caracteriza um fenômeno de histerese: mesmo que $p^{E}$ tenha

\footnotetext{
${ }^{28}$ Esta interpretação pressupõe a aditividade do valor, discutido por TRIGEORGIS (1993).

${ }^{29}$ Assume-se que não faz sentido desenvolver uma jazida para mantê-la inoperante.
} 
Tabela 3.1: Preço crítico e decisão ótima

\begin{tabular}{c|c|c}
\hline \hline$p \equiv P / C$ & Jazida Não Desenvolvida & Jazida Desenvolvida \\
\hline \hline$p<p^{S}$ & Permanece & Paralisada \\
$p=p^{S}$ & Permanece & Indiferente operar/paralisar \\
$p^{S}<p<p^{E}$ & Permanece & Operante \\
$p=p^{E}$ & Indiferente desenvolver ou não & Operante \\
$p>p^{E}$ & Desenvolve & Operante \\
\hline \hline
\end{tabular}

sido o preço-custo determinante da entrada, a firma só irá paralisar as atividades se este parâmetro cair abaixo de $p^{S}<p^{E}$. Do mesmo modo, o preço $p^{S}$ não é suficiente para induzir a entrada/desenvolvimento, requerendo que o mesmo atinja o patamar mínimo $p^{E}$.

A decisão de investir ou não depende da comparação dos valores das reservas desenvolvida e não desenvolvida. Assim, é preciso analisar como esta última evolui de acordo com os parâmetros do preço e do custo, o que será objeto da subseção a seguir.

\subsection{Valor Unitário da Reserva Não-Desenvolvida}

Seja $F(P, C, t)$ o valor unitário da reserva não-desenvolvida. Novamente, supomos que ele seja governado pelo preço e pelo custo, segundo os movimentos brownianos geométricos acima definidos. O valor da reserva não-desenvolvida pode ser interpretado como uma opção de compra cujo ativo fundamental é uma unidade de reserva desenvolvida e o preço de exercício são os gastos em investimento $I$. A princípio, incluir os custos operacionais no valor da reserva não-desenvolvida pode parecer estranho, mas deve-se ter em vista que se trata de uma variável indicativa da qualidade da jazida, conforme os argumentos anteriores, além das propriedades dinâmicas típicas dos recursos exauríveis [OSMUNDSEN (1998)].

A equação de Bellman resultante ${ }^{30}$ é:

${ }^{30} \mathrm{Na}$ verdade, para sermos rigorosos, deveríamos definir $F(V, t)$. Entretanto, como apontam 


$$
r F(P, C, t) d t=E_{0}(d F)
$$

Aplicando o Lema de Itô, obtemos a seguinte equação diferencial parcial:

$$
\frac{1}{2} F_{P P} \sigma_{P}^{2} P^{2}+\frac{1}{2} F_{C C} \sigma_{C}^{2} C^{2}+F_{P C} \sigma_{P} \sigma_{C} P C+F_{P} \alpha+F_{C} \phi+F_{t}-r F=0
$$

A equação (3.23) é análoga à equação (3.13), exceto pela inexistência do termo de lucro. Trata-se de uma equação diferencial parcial sem solução analítica, devido ao termo $F_{t}$, que estabelece a evolução do valor da reserva conforme o tempo passa. Isso acontece pois, na maioria dos casos, há um prazo máximo $(T)$ até o qual o investidor deve declarar seu interesse em desenvolver suas reservas, sob pena de perder a concessão. Todavia, conforme argumentam PADDOCK et al. (1988), se o tempo de exploração for superior a 5 anos, a diferença entre os preços críticos das opções com tempo limitado e perpetua é pequeno, de modo que o termo $F_{t}$ pode ignorado sem erros significativos de avaliação. Assim, partiremos para o caso extremo em que o investidor se depara com um tempo ilimitado para declarar o desenvolvimento da jazida ${ }^{31}$.

Outra dificuldade para a solução de (3.23) é a existência de duas variáveis de estado, $P$ e $C$, determinando o valor da reserva. Novamente, utilizamos o resultado de homogeneidade adotado para a reserva desenvolvida, ou seja, $F(P, C)=C f(P / C)=C f(p)$. Dados os resultados das derivadas de $f$ com relação a $p$, a equação diferencial se torna:

DIXIT e PINDYCK (1994), nesta situação o processo de difusão de $V$ se torna complicado, dificultando consideravelmente a solução da equação diferencial ligando $V$ a $F$. Uma solução alternativa mais simples é ligar diretamente $F$ aos parâmetros que governam $V$, usando sua solução como condições de contorno que definem o exercício ótimo

${ }^{31}$ No caso brasileiro, a Lei do Petróleo estabelece prazos de até 9 anos entre a obtenção da concessão de exploração e a declaração de comercialidade, o que se encaixaria na aproximação adotada. 


$$
\frac{1}{2}\left(\sigma_{P}^{2}-2 \rho \sigma_{P} \sigma_{C}+\sigma_{C}^{2}\right) p^{2} f^{\prime \prime}(p)+(\alpha-\phi) p f^{\prime}(p)-(r-\phi) f(p)=0
$$

A equação (3.24) é análoga à parte homogênea de (3.15), admitindo solução analítica na forma:

$$
f(p)=H_{1} p^{\beta_{3}}+H_{2} p^{\beta_{4}}
$$

$\operatorname{com} \beta_{3}>0$ e $\beta_{4}<0$ raízes do polinômio característico e $H_{1}$ e $H_{2}$ constantes a serem determinadas. Dado que quando $p \rightarrow 0$, é improvável que a reserva seja desenvolvida, $f(0)=0$, ou seja, $H_{2}=0$.

Duas novas condições de transversalidade são necessárias ${ }^{32}$ :

$$
F(P, C)=V(P, C)-I \Longrightarrow f(p)=v(p)-I / C
$$

$$
f^{\prime}(p)=v^{\prime}(p)
$$

A equação (3.26) é chamada condição de contato (value matching condition) e determina que a condição de ótimo para o exercício da opção de investimento é a igualdade entre o valor da reserva não-desenvolvida, $F$, e o valor da reserva desenvolvida, $V$, líquido do custo de investimento ${ }^{33}$. Ou seja, se $F(P, C)>V(P, C)-I$,

\footnotetext{
${ }^{32} \mathrm{~A}$ rigor, como estamos trabalhando com dois fatores, $P$ e $C$, seria necessária uma terceira condição: $f(p)-p f \prime(p)=v(p)-p v \prime(p)-I / C$, derivada da condição de smoothing past $F_{C}=V_{C}$. Entretanto, esta equação é redundante pois representa uma combinação das anteriores.

${ }^{33}$ Estamos ignorando o tempo de construção (time to build). Ou seja, supomos que a
} 
é melhor para o investidor esperar, pois o valor da reserva não desenvolvida supera o da desenvolvida subtraída do investimento. O desenvolvimento imediato, por sua vez, é ótimo quando ocorre o inverso. Assim, (3.26) estabelece a condição de continuidade para as funções $F$ e $V$ em seu ótimo.

A expressão (3.27) expressa a chamada condição de suavidade (smoothing past condition), que impõe que as duas funções sejam contínuas também em suas inclinações, evitando "quebras" no ponto de ótimo ${ }^{34}$.

\subsection{Preços Críticos de Investir e Paralisar}

Os valores críticos $p^{E}$ e $p^{S}$ são determinados pelas condições de transversalidade (contato e suavidade) em cada modo de operação. Considere, primeiro, a decisão de desenvolver ou não a reserva. Substituindo (3.21) e (3.25) (com $\left.H_{2}=0\right)$ em (3.26) e (3.27), temos:

$$
\begin{array}{r}
-H_{1}\left(p^{E}\right)^{\beta_{3}}+B_{2}\left(p^{E}\right)^{\beta_{2}}+(1-R)\left[\frac{(1-\tau) p^{E}}{r-\alpha+\phi}-\frac{1}{r}\right]-i=0 \\
-H_{1} \beta_{3}\left(p^{E}\right)^{\beta_{3}-1}+B_{2} \beta_{2}\left(p^{E}\right)^{\beta_{2}-1}+\frac{(1-R)(1-\tau)}{r-\alpha+\phi}=0
\end{array}
$$

onde $i \equiv I / C$. Esta última é uma variável difícil de conceituar, pois representa a razão entre o investimento para o desenvolvimento e o custo operacional do barril de petróleo. Se assumirmos que as diferenças de qualidade das reservas se traduzem em diferentes níveis de investimento $I$ para a obtenção de um proces-

passagem da fase de exploração para a de desenvolvimento/produção é instantânea, sendo necessário apenas o desembolso do Investimento I.

${ }^{34} \mathrm{O}$ apêndice $\mathrm{C}$ do cap. 4 de DIXIT \& PINDYCK (1994) fornece a demonstração matemática para ambas as condições. 
so operacional com custos semelhantes, $C$, é possível identificar a qualidade da reserva apenas com a comparação do índice $i$.

Se a firma estiver operando, ela deve considerar a decisão de paralisar as operações se as condições econômicas se tornarem adversas, isto é, o preço-custo cair abaixo de $p^{S}$. As condições de contato e de suavidade serão:

$$
\begin{gathered}
v\left(p^{S}\right)=f\left(p^{S}\right)-\varepsilon \\
v^{\prime}\left(p^{S}\right)=f^{\prime}\left(p^{S}\right)
\end{gathered}
$$

onde $\varepsilon \equiv E / C$, sendo $E$ o custo de paralisação. É interessante observar que, quando a reserva está desenvolvida, porém paralisada, ela irá terá a mesma solução geral que uma reserva não-desenvolvida, já que a diferença entre ambas se dá apenas devido ao termo de lucro nas equações diferenciais. Portanto, substituindo as soluções gerais acima:

$$
\begin{array}{r}
-H_{1}\left(p^{S}\right)^{\beta_{1}}+B_{2}\left(p^{S}\right)^{\beta_{2}}+(1-R)\left[\frac{(1-\tau) p^{S}}{r-\alpha+\phi}-\frac{1}{r}\right]+\varepsilon=0 \\
-H_{1} \beta_{1}\left(p^{S}\right)^{\beta_{1}-1}+B_{2} \beta_{2}\left(p^{S}\right)^{\beta_{2}-1}+\frac{(1-R)(1-\tau)}{r-\alpha+\phi}=0
\end{array}
$$

As equações (3.28), (3.29), (3.31) e (3.32) formam um sistema não linear com as incógnitas $H_{1}, B_{2}, p^{E}$ e $p^{S}$. Ele não tem solução analítica, devendo ser resolvido por métodos numéricos. Como ambas as constantes $H_{1}, B_{2}$ refletem opções de 
retomada e paralisação, respectivamente, elas devem ser positivas ${ }^{35}$.

Consideremos agora a situação em que não há opção de parada, ou seja, as equações (3.31) e (3.32) deixam de fazer parte do sistema e $B_{2}=0$ nas equações anteriores. Assim, se $p_{N O}^{E}$ for o preço de entrada crítico quando não há opção de interrupção, temos:

$$
\begin{gathered}
H_{1}\left(p_{N O}^{E}\right)^{\beta_{3}}=(1-R)\left[\frac{(1-\tau) p_{N O}^{E}}{r-\alpha+\phi}-\frac{1}{r}\right]-i \\
\beta_{3} H_{1}\left(p_{N O}^{E}\right)^{\beta_{3}-1}=\frac{(1-R)(1-\tau)}{r-\alpha+\phi}
\end{gathered}
$$

Após algum trabalho algébrico, tem-se:

$$
p_{N O}^{E}=\frac{\beta_{3}}{\beta_{3}-1}\left[\frac{r-\alpha+\phi}{1-\tau}\right]\left[\frac{1}{r}+\frac{i}{1-R}\right]
$$

Finalmente, com vistas a concluir as expressões para a análise dos impactos de $R, \tau$ e dos demais parâmetros sobre $p^{E}$, na análise de valor presente líquido, devemos ter $v\left(p_{V P L}^{E}\right)-i=V(P, C)-I=0$, já que neste caso não há possibilidade de atrasar (lembrando que a principal característica da análise de VPL é a característica "agora ou nunca" do investimento ${ }^{36}$ ). Assim, para o caso de valor presente líquido:

$$
p_{V P L}^{E}=\left[\frac{r-\alpha+\phi}{1-\tau}\right]\left[\frac{1}{r}+\frac{i}{1-R}\right]
$$

\footnotetext{
${ }^{35}$ Sobre esta interpretação, ver também PINDYCK (1988)

${ }^{36}$ Ver BJERKSUND \& EKERN (1990).
} 


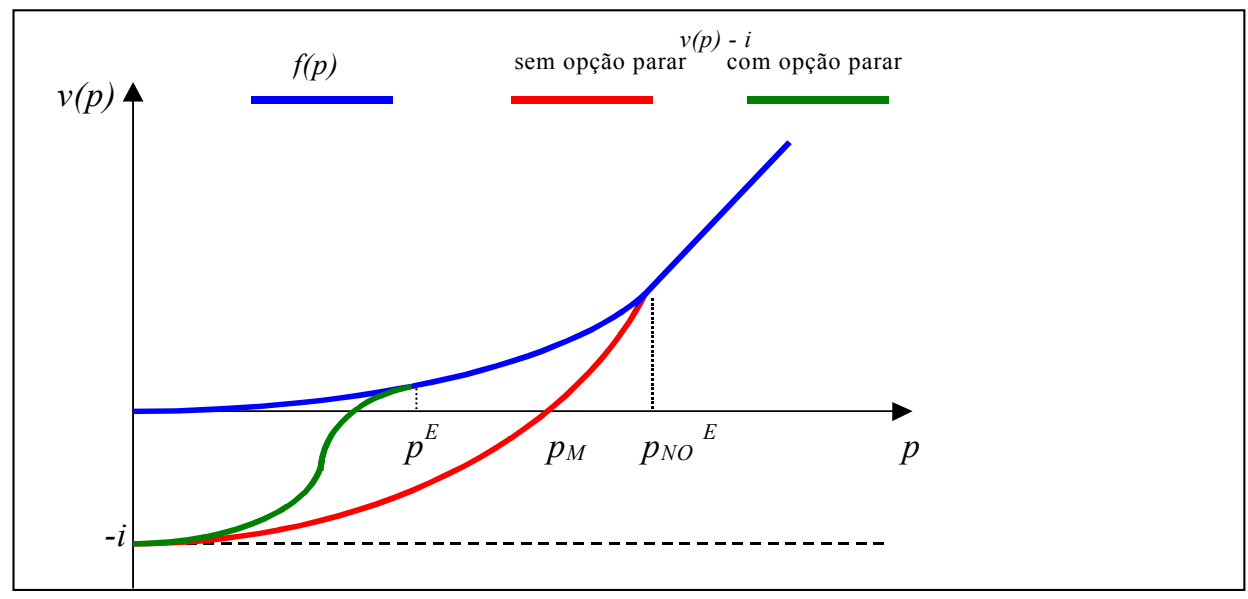

Figura 3-2: Valor da Reserva e Opção

Comparando as expressões (3.35) e (3.36), observamos que elas diferem pela presença do fator multiplicativo $\beta_{3} /\left(\beta_{3}-1\right)>1$ na análise de opções reais, dado que $\beta_{3}>1$. DIXIT \& PINDYCK (1994) chamam este termo de "múltiplo do valor da opção", o qual acrescenta uma margem sobre o valor crítico $p^{E}$ da regra do valor presente líquido. Este termo surge em decorrência da incerteza (representada nos parâmetros $\sigma_{P}$ e $\sigma_{C}$ ) e da irreversibilidade do investimento. Desta forma, a regra do VPL é incompleta ("míope") no sentido de não levar em conta tais propriedades. Outra forma de enxergar o ponto é notando pela equação característica de (3.24) que, em caso de certeza $\left(\sigma_{P}=\sigma_{C}=0\right), \beta_{3} \rightarrow \infty$ ou seja, $\beta_{3} /\left(\beta_{3}-1\right) \rightarrow 1$, de forma que a cunha entre ambas as avaliações se degenera. Portanto, em se tratando da falta da opção de parada, devemos encontrar uma razão preço-custo crítica maior para o caso da análise de opções do que para o VPL.

A figura 3-2 ilustra as avaliações de acordo com o critério e as flexibilidades assumidas. A curva azul representa o valor da reserva não-desenvolvida, isto é, o valor da opção de desenvolvimento. As curvas vermelha e verde indicam $v(p)-i$ na ausência e na presença de opção de paralisação, respectivamente. O 
critério de VPL estabelece o preço-custo crítico marshalliano tal que $v(p)-i=$ 0 , representado por $p^{M}$. As condições de transversalidade (value matching e smoothing past conditions) identificam o preço-crítico $p_{N O}^{E}$ para a ausência de flexibilidade de paralisação e $p^{E}$ para a presença, no encontro das curvas $v(p)-i$ e $f(p)$. Esta também pode ser interpretada como o valor da espera. Quando existe possibilidade de interrupção da produção, a tangência das curvas indica um valor de opção de espera menor (equivalente a um valor de opção de investir maior), indicando um preço limite inferior. Isso significa que a possibilidade de atrasos em investimentos é menor neste último caso.

Duas observações importantes sobre a figura. Em primeiro lugar, o valor da reserva com opção de interrupção é sempre maior que o seu valor em sua ausência e as distâncias entre as curvas verde e vermelha simbolizam o valor desta flexibilidade; em segundo lugar, a curva verde apresenta um ponto de inflexão correspondente ao ponto $p^{S}$, indicativo da fronteira entre a paralisação e o funcionamento [ver eq. 3.21].

Com base nesta modelagem, o nosso objetivo no capítulo seguinte, será avaliar quantitativamente como a estrutura tributária sobre o setor afeta a disposição de investir, desviando $p^{E}$ e $p^{S}$ de seus valores na ausência dos impostos. 


\section{Capítulo 4}

\section{Resultados}

Definidas as formas de obtenção da razão preço-custo crítica $p^{*}$ de acordo com a análise empreendida e as opções admitidas (VPL, ausência de opção de parada e presença de opção de parada com ou sem custos) passamos agora a analisar o impacto de algumas formas de benefício governamental sobre a decisão de investir. Para isso, desenvolvemos um exercício de estática comparativa para simular numericamente o impacto de variações nos parâmetros definidos sobre $p^{E}$ e $p^{S}$.

Antes de mais nada, é necessário parametrizar o modelo a fim de estabelecer valores de referência para cada exercício. Estimar os parâmetros ou calibrá-los a partir de dados empíricos não constituem objetivos deste trabalho, de modo que utilizamos números apresentados por outros trabalhos ou então assumimos alguns valores possíveis.

A tabela 4.1 resume os valores de referência utilizados na parametrização do modelo.

Assumiremos que a taxa de desconto é igual a $10 \%$ ao ano. Não estamos aqui muito preocupados em averiguar a verossimilhança deste valor ou mesmo se estamos ou não igualando-a à taxa de juros livre de risco, mas conforme demonstramos anteriormente, é necessário que $r>a-\phi$ para garantir que o valor da opção de investimento seja não nulo. 
Tabela 4.1: Parâmetros do Modelo

\begin{tabular}{c|c|c|}
\hline \hline Parâmetro & Valor & Fonte \\
\hline \hline$r$ & $10 \%$ & - \\
\hline$\alpha$ & $1,15 \%$ & Schwartz \& Smith (2000) \\
\hline$\phi$ & $10 \%$ & Dixit \& Pindyck (1994) \\
\hline$\sigma_{P}$ & $14,5 \%$ & Schwartz \& Smith (2000) \\
\hline$\sigma_{C}$ & $7 \%$ & - \\
\hline$\rho$ & $+0,9$ & Dias (1996) \\
\hline$i \equiv I / C$ & 1 & - \\
\hline$\tau$ & $5 \%$ & Lei $\mathrm{n}^{\circ} 9478 / 97$ (piso) \\
\hline$R$ & 0 & Decreto $\mathrm{n}^{\circ} 2705 / 98$ (piso) \\
\hline \hline
\end{tabular}

Estamos trabalhando diretamente com a taxa de crescimento esperada do preço do petróleo, $\alpha$, ao invés do convenience yield. Seguindo estimativas de Schwartz \& Smith utilizamos o valor de referência de 1,15\% a.a para este parâmetro.

A taxa de extração $\phi$ (igual à taxa de decaimento das reservas) é suposta exógena e igual a 10\% ao ano, valor considerado razoável por DIXIT \& PINDYCK (1994), equivalente a uma meia vida de cerca de 7 anos. Ao longo dos exercícios de simulação, iremos variá-la com vistas a identificar seu impacto sobre o preçocrítico. De acordo com o nosso argumento, quanto maior a taxa de extração, maior a velocidade de crescimento dos custos unitários em virtude do rápido esgotamento das pressões nos poços [ver CAIRNS (1998); DAVIS \& CAIRNS (1999); OSMUNDSEN (1998)].

O desvio padrão instantâneo do preço do petróleo, $\sigma_{P}$, pode ser estimado a partir de dados diários de preço de petróleo. Todavia, este não é o objetivo deste trabalho, de modo que assumiremos um valor de $\sigma_{P}=14,5 \%$ a.a. (semelhante ao adotado por DIXIT \& PINDYCK, 1994).

Conforme argumento de proporcionalidade exposto anteriormente, o efeito Jevons tem como conseqüência o crescimento do custo unitário à mesma taxa de decaimento das reservas. Assumimos ainda que há incerteza sobre os custos que, de um modo geral, estão ligados a mão de obra, manutenção de equipamentos, 
insumos químicos, energia e depreciação de máquinas ${ }^{1}$. Não temos uma série de custos para estimar este parâmetro. Todavia, como o investidor apresenta um certo domínio sobre o conjunto de informações determinantes de seus custos, espera-se que o desvio padrão instantâneo destes seja menor que o do preço do petróleo. Assim, assume-se que o desvio padrão dos custos, $\sigma_{C}$, é cerca de metade do desvio padrão do preço do petróleo, $\sigma_{P}$.

O coeficiente de correlação instantâneo entre as variáveis preço e custo, $\rho$, foi parametrizado tendo em vista a constatação de que existe uma forte correlação positiva entre o preço e o custo [DIAS (1996)]. A idéia por trás disso é que, quando o preço de petróleo está alto, a entrada de produtores marginais gera pressões sobre a demanda de equipamentos necessários à extração, elevando os custos com aluguel e manutenção de máquinas. Além disso, a elevação das contratações em um mercado de trabalho fortemente influenciado por sindicatos tende a gerar pressões de custo salarial. Neste sentido, a presença de uma correlação positiva entre preço e custo tenderá a reduzir o grau de risco do projeto. DIAS (1996) cita estimações em torno de $90 \%$ para este coeficiente, que adotaremos como referência.

A variável $i$ representa a razão entre o investimento necessário para desenvolver 1 barril de petróleo da reserva e o custo operacional $(I / C)$. Conforme argumentamos anteriormente, se supusermos que ambas as variáveis têm uma relação direta entre si, dependente da qualidade e da acessibilidade dos recursos do campo, podemos variar a razão $i$ e averiguar seu impacto sobre o preço-custo crítico $p^{*}$. Quanto maior $i$, pior a qualidade do campo. Há modelos de dois fatores [ver DIXIT \& PINDYCK, 1994, cap. 6] que não distinguem os gastos de desenvolvimento e de operação, de modo que adotaremos um valor de referência de $i=1$.

Por fim, as alíquotas de royalties e de imposto sobre a renda foram definidas

\footnotetext{
${ }^{1}$ Fonte; EIA/Department o Energy, USA.
} 
a partir da legislação brasileira (Lei nº9478/97 ou Lei do Petróleo). Os royalties devem variar entre $5 \%$ e $10 \%$ conforme as condições de risco e lucratividade esperadas para o projeto. Como referência para os exercícios de simulação com os demais parâmetros, adotamos a referência de 5\%, seu valor mínimo. As participações especiais, por sua vez, estão regulamentados no decreto n $^{\circ} 2705$ de 3/08/98 e estabelecem alíquotas progressivas de 0 a $40 \%$ conforme o volume de produção e tem como objetivo garantir uma participação maior da União em projetos mais lucrativos. A base de incidência é a receita líquida, isto é, deduzem-se do faturamento os custos e os gastos com royalties. Trata-se de uma variante do chamado imposto sobre a renda do recurso, que apresenta propriedades de neutralidade quando se realiza uma análise de valor presente líquido [POSTALI(2002)]. Novamente, o valor de referência para as simulações será o piso de isenção² .

\subsection{Resultados gerais}

A parametrização do modelo a partir dos valores definidos na tabela 4.1 resulta nos seguintes valores para a razão preço-custo crítica de entrada $\left(p^{E}\right)$ e de saída $\left(p^{S}\right)$, para cada uma das abordagens e opções sugeridas. Consideramos três cenários possíveis para os custos de interrupção em relação ao custo operacional $(\varepsilon=0 ; 0,5 \text { e } 1)^{3}$.

A tabela 4.2 traz os valores críticos para a decisão de desenvolver a reserva $\left(p^{E}\right)$ e de paralisar $\left(p^{S}\right)^{4}$. Em primeiro lugar, nota-se que o valor crítico para o

\footnotetext{
${ }^{2}$ Cabem aqui duas observações pertinentes sobre as participações especiais. Em primeiro lugar, estamos assumindo que o IRR e as Participações Especiais previstas na Lei no $9478 / 97$ são idênticas, o que não é o caso. Em segundo lugar, as Participações Especiais só incidem sobre campos de grande produção, conforme as regras do decreto $n^{\circ} 2705 / 98$, de modo que há projetos que podem ficar livres dele.

${ }^{3}$ Os cálculos foram feitos no software Mathematica ${ }^{\circledR}$.

${ }^{4}$ Deve-se observar que não estamos fazendo a distinção entre paralisação e abandono. Supõese que este último seja definitivo enquanto o primeiro seja temporário. A distinção entre ambos pode ser modelada pelo custo de retomada, o qual varia entre dois extremos: zero, para o caso de paralisação e $I$, para o caso de abandono. Ou seja, se o agente decidir abandonar a produção, ele só poderá retomá-la se investir tudo novamente.
} 
Tabela 4.2: Resultados de referência

\begin{tabular}{|l|c|c|}
\hline \hline \multicolumn{1}{|c|}{ Modelo } & $p^{E}$ & $p^{S}$ \\
\hline \hline Valor Presente Líquido & 2,1676 & - \\
\hline Opções Reais - Sem opção de interrupção & 2,2665 & - \\
\hline Opções Reais - Com opção de interrupção sem custos & 1,6152 & 1,0087 \\
\hline Opções Reais - Com opção de interrupção c/ custo $\varepsilon=0,5$ & 1,7128 & 0,9606 \\
\hline Opções Reais - Com opção de interrupção c/ custo $\varepsilon=1$ & 1,7903 & 0,9125 \\
\hline
\end{tabular}

desenvolvimento, sob a regra do fluxo de caixa descontado é menor do que para as opções reais quando não há opção de paralisação. Tal resultado é consistente com o argumento de DIXIT \& PINDYCK (1994) de que a nova abordagem incorpora a irreversibilidade do investimento, ou seja, é necessário um preço crítico superior para induzi-lo. Com relação à presença de opção de interrupção, duas observações são interessantes: a razão indutora do desenvolvimento $\left(p^{E}\right)$, cai com esta flexibilidade, mas é crescente à medida que o custo de paralisação aumenta. Por outro lado, quanto maior o custo de paralisação, menor a razão crítica de saída $\left(p^{S}\right)$, devido ao efeito da histerese, já que o custo de interromper a produção dificulta a tomada desta decisão.

Antes de simular os efeitos dos benefícios governamentais sobre esses valores críticos, é interessante avaliar, através de um exercício de estática comparativa, o efeito dos demais parâmetros sobre a decisão de investir, isto é, sobre $p^{E 5}$.

Variando a taxa de juros - r: A figura 4-1 ilustra o efeito de variações na taxa de juros sobre o preço crítico de investimento, $p^{E}$, para cada os três primeiros casos (VPL, Sem opção de paralisação, Com opção de paralisação a custo zero). O efeito mais visível é que a flexibilidade operacional de paralisar a atividade reduz drasticamente a sensibilidade do investimento em relação à taxa de juros. Entretanto, quando se consideram o fluxo de caixa descontado e a opção real sem flexibilidade, o resultado contradiz as conclusões da teoria tradicional de que um aumento da taxa de juros tende a inibir o investimento. Conforme aponta a

\footnotetext{
${ }^{5}$ As simulações foram realizadas no software Matlab.
} 
figura 4-1, a elevação da taxa de juros contribui para antecipar o investimento, na medida em que reduz $p^{E}$. Este efeito pode parecer estranho em relação ao usual, mas deve-se ter em vista que o juro afeta o valor presente tanto das receitas quanto dos $\operatorname{custos}^{6}$ [vide equações (3.35) e (3.36) do capítulo anterior].

Este exercício ilustra como o efeito da taxa de juros pode ser ambíguo na presença de opções reais, sobretudo quando se incorpora o custo como variável de estado [McDONALD \& SIEGEL (1985)]: por um lado, taxas de juros mais elevadas inibem o investimento mas, por outro lado, o impulsionam devido ao aumento do custo de oportunidade de manter em aberto a opção de investimento (via convenience yield $)^{7}$. Isso acontece porque as reservas desenvolvidas são consideradas um ativo cujo valor cresce com o aumento da taxa de juros. Nesta abordagem, haverá uma aceleração do desenvolvimento da jazida quando a taxa de juros crescer $^{8}$.

Variando drift - $\alpha$ : A figura 4-2 mostra o efeito de variações na taxa de crescimento do preço do petróleo sobre $p^{E}$, mantidos os demais parâmetros constantes. Confirmando a intuição, um aumento da taxa esperada de valorização do petróleo irá reduzir o preço crítico, sobretudo no caso do valor presente descontado. No caso das opções reais, o valor do preço crítico decai até $\alpha$ se aproximar da taxa de juros, quando então ela explode devido a uma indeterminação assintótica. Valores de $\alpha$ acima da taxa de juros tornam o valor da opção de investir negativo ${ }^{9}$. Nota-se, novemante, a menor sensibilidade de $p^{E}$ em relação a variações no

\footnotetext{
${ }^{6}$ Quando a taxa ultrapassa valores em torno de $40 \%$, o preço crítico volta a crescer, conforme seria esperado pela teoria usual.

${ }^{7}$ INGERSOLL \& ROSS (1992) mostram que, para projetos de longa maturação, uma redução na taxa de juros esperada não ter o usual efeito acelerador sobre o investimento, pois tal mudança também reduz o custo da espera, produzindo um efeito ambíguo sobre o investimento.

${ }^{8}$ CORTAZAR \& SCHWARTZ (1993) apresentam um modelo de investimentos em estoques e chegam a conclusões análogas quanto ao efeito da taxa de juros e da incerteza sobre o preço que dispara a acumulação de estoques. Eles entendem que estes são considerados ativos e, como tal, aumentos da taxa de juros tendem a valorizá-los, apesar do usual efeito do aumento do custo de oportunidade de retê-los.

${ }^{9}$ Além disso, deve-se ter em vista que, na presença de custos estocásticos, é necessário que a relação $r>\alpha-\phi$ se mantenha para evitar que o valor da reserva se torne negativo. Por isso
} 


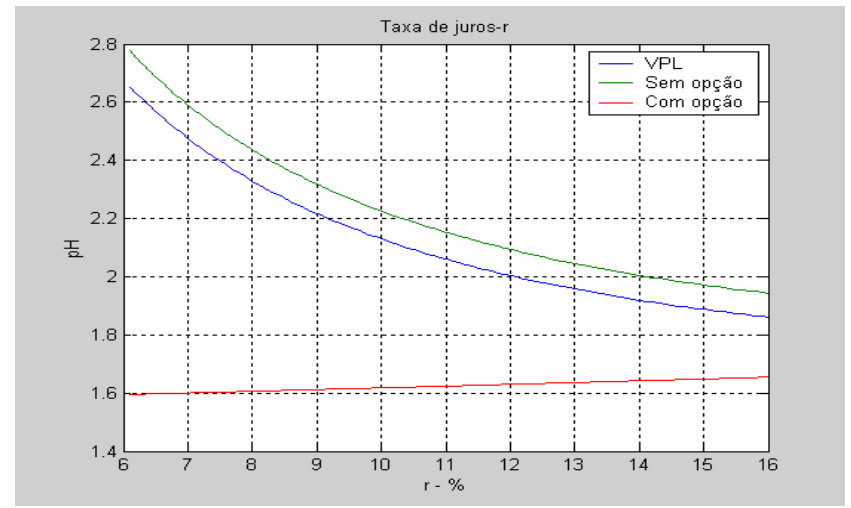

Figura 4-1: Variando taxa de juros

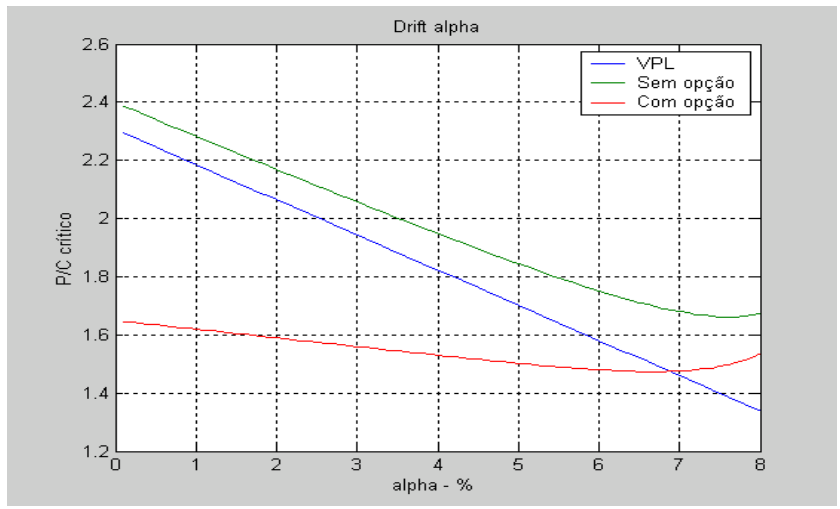

Figura 4-2: Variando taxa de crescimento do preço

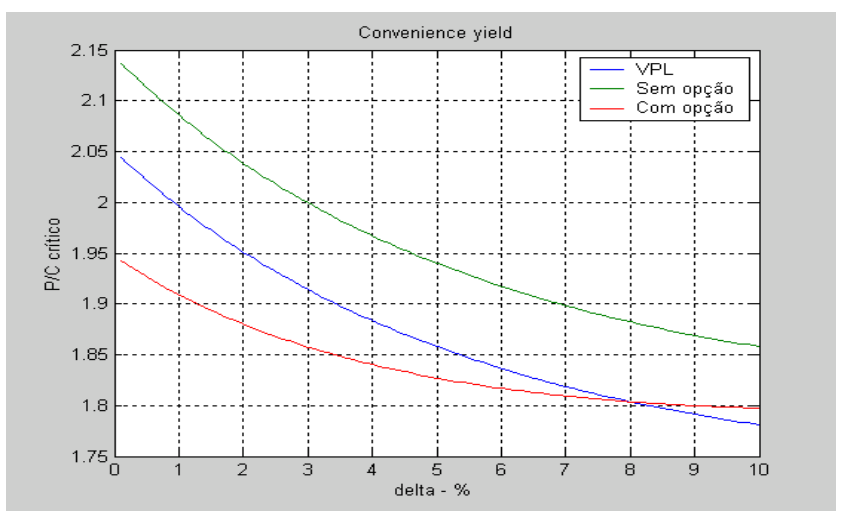

Figura 4-3: Variando o convenience yield - $\delta$ 


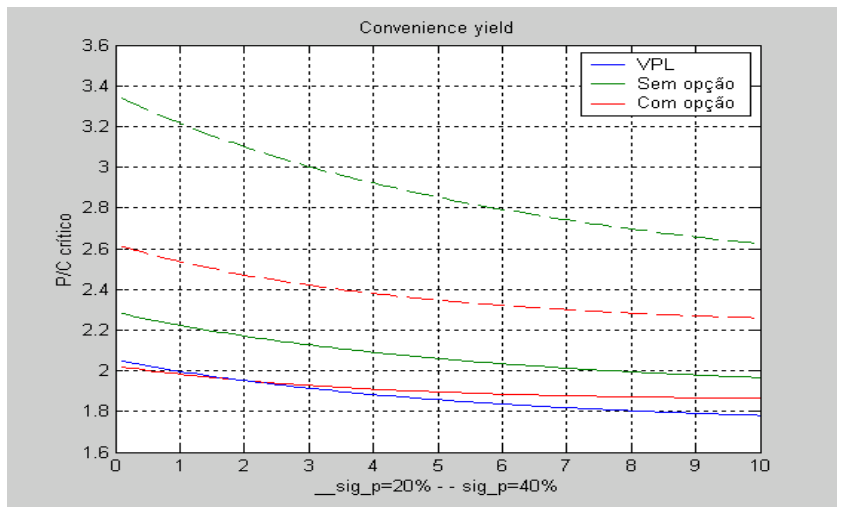

Figura 4-4: Variando $\delta$ para diferentes incertezas

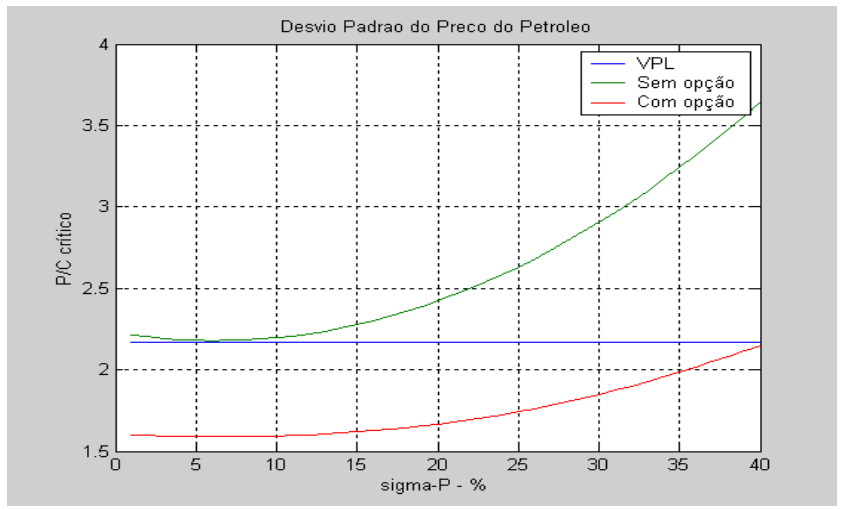

Figura 4-5: Variando desvio padrão do preço do petróleo

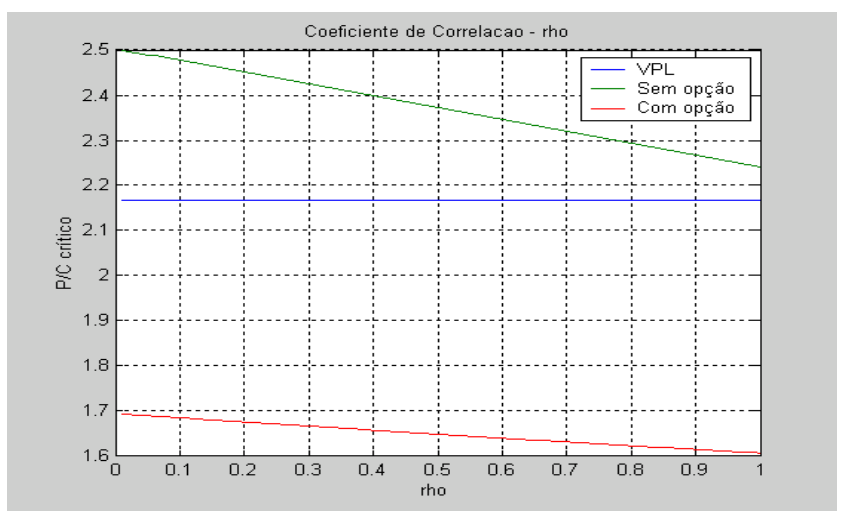

Figura 4-6: Variando o coeficiente de correlação preço-custo 


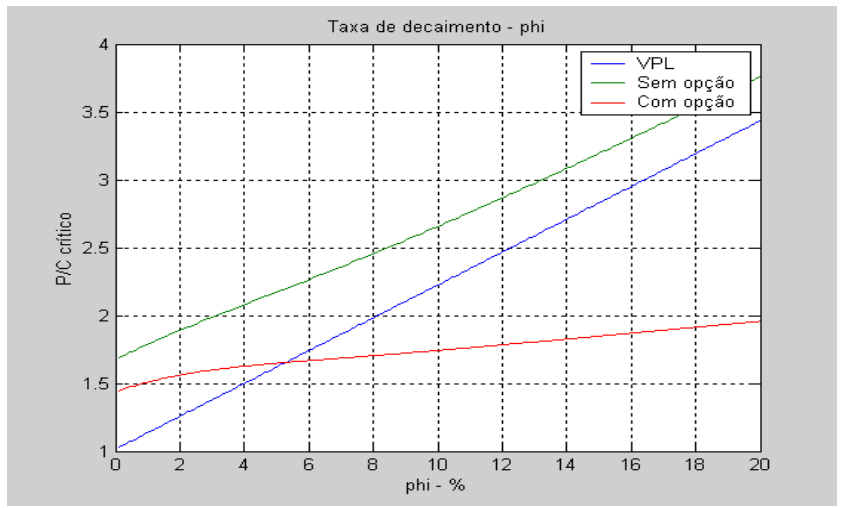

Figura 4-7: Variando a taxa de crescimento do custo unitário - $\phi$

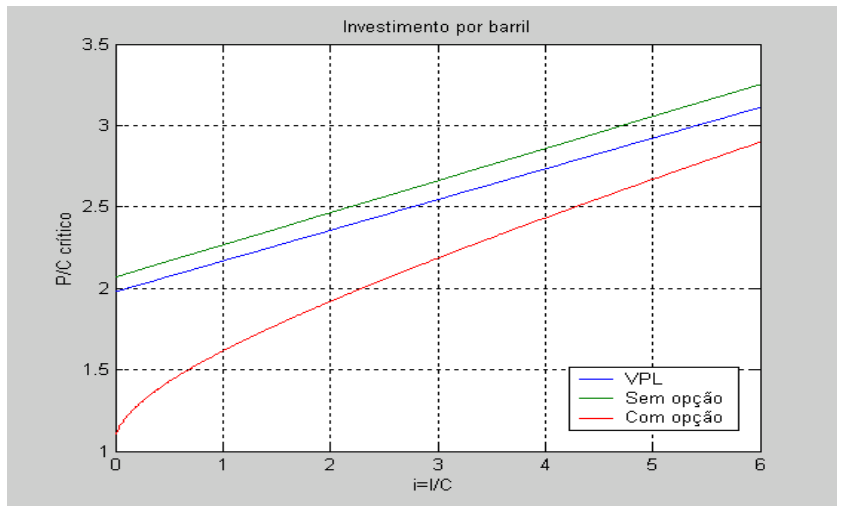

Figura 4-8: Variando investimento por barril

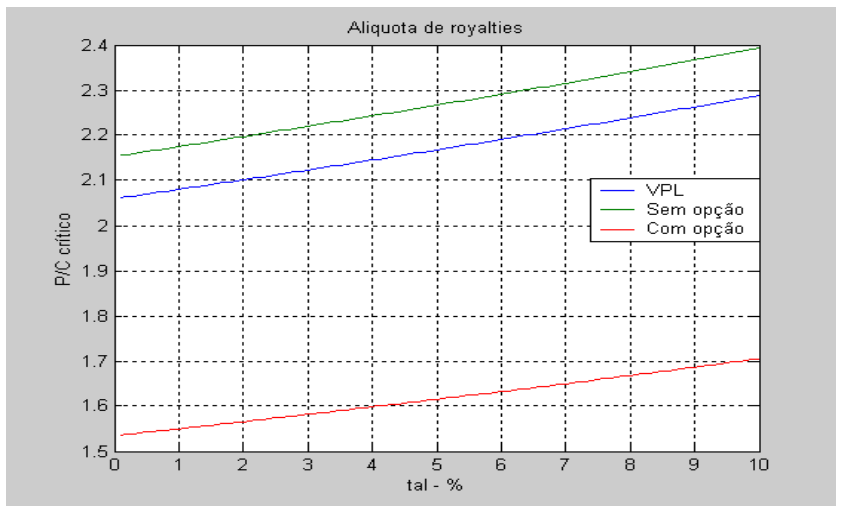

Figura 4-9: Variando alíquota dos royalties 


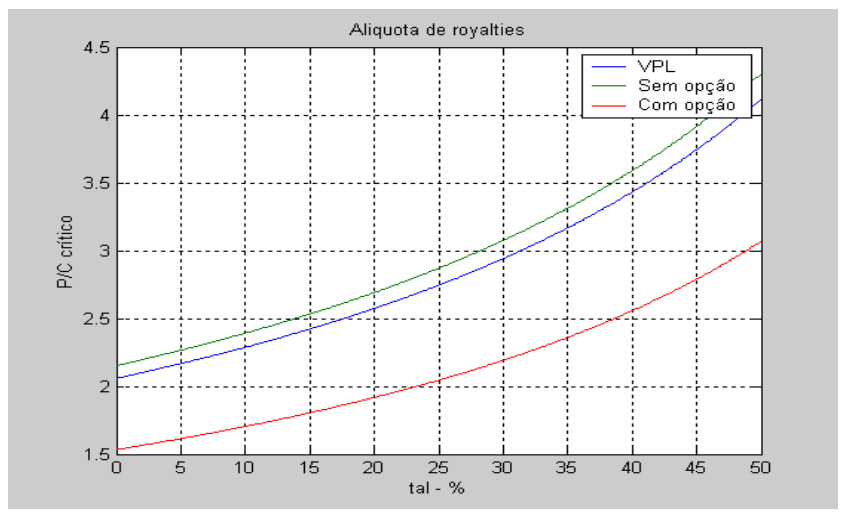

Figura 4-10: Alíquotas muito altas

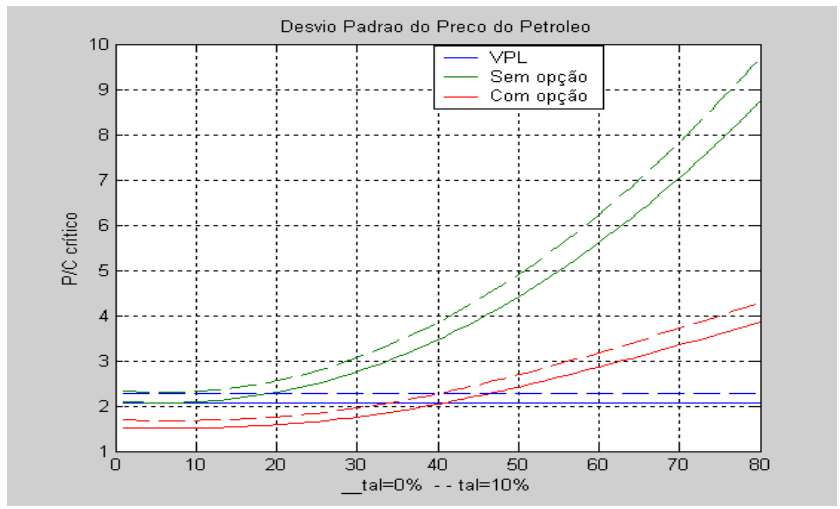

Figura 4-11: Incerteza e Royalties

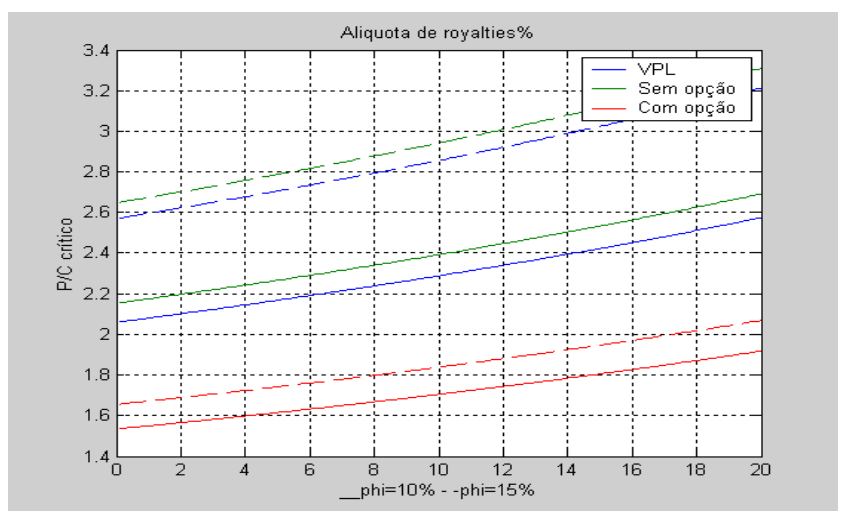

Figura 4-12: Variação de royalties para $\phi=10 \%$ e $\phi=15 \%$. 


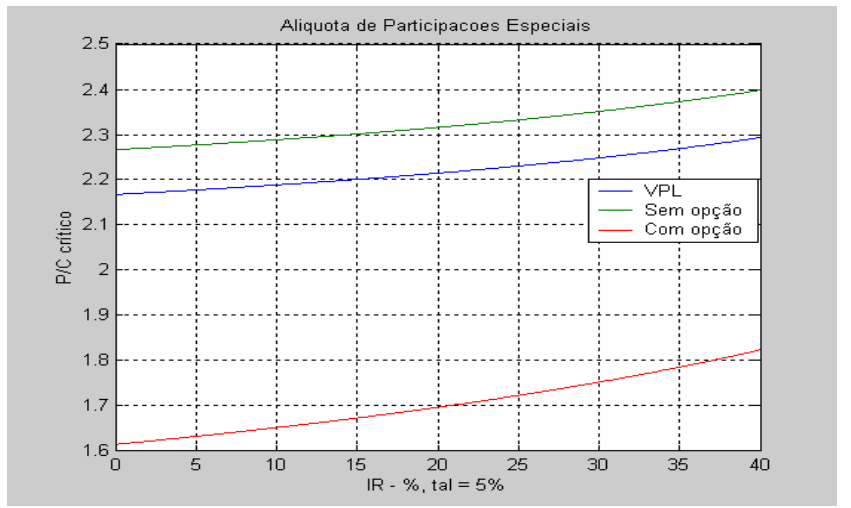

Figura 4-13: Variando alíquota de Participações Especiais - R.

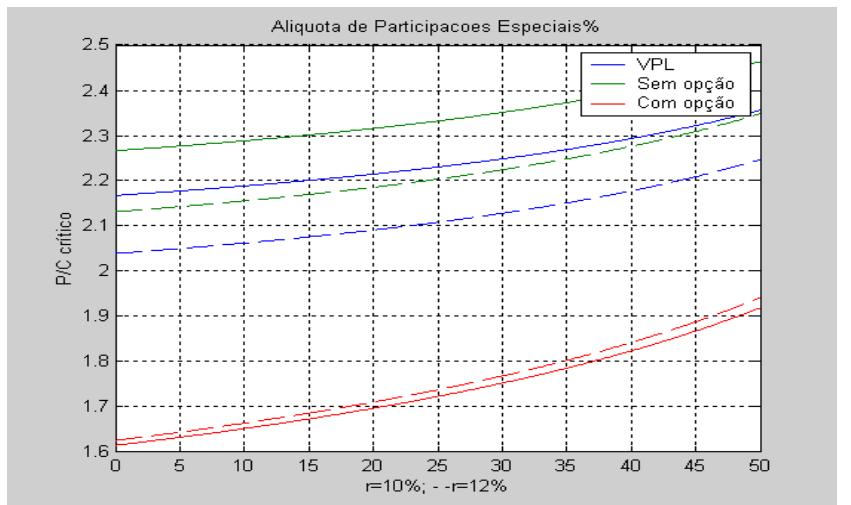

Figura 4-14: Participações especiais e taxas de juros - I

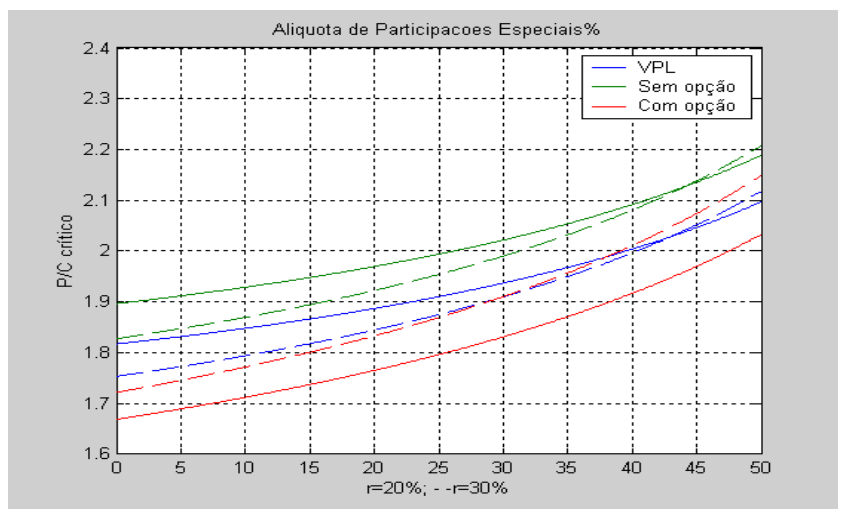

Figura 4-15: Participações especiais e taxas de juros - II 


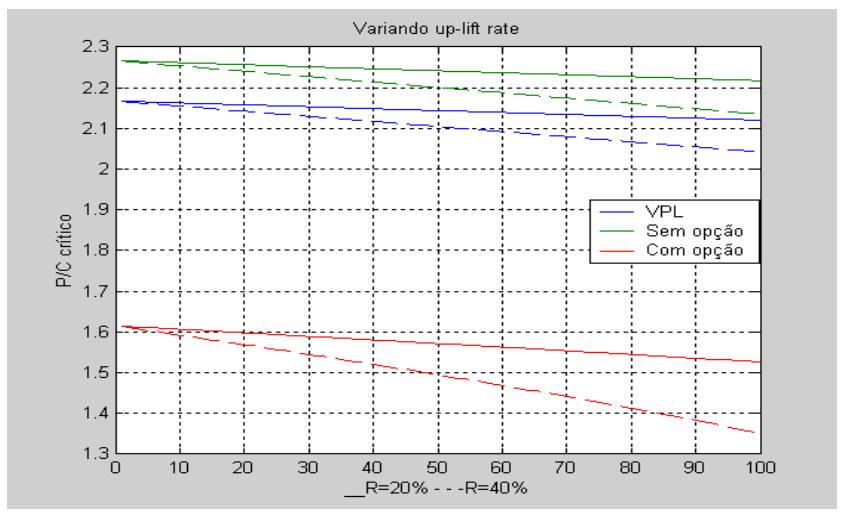

Figura 4-16: Variando up lift rate

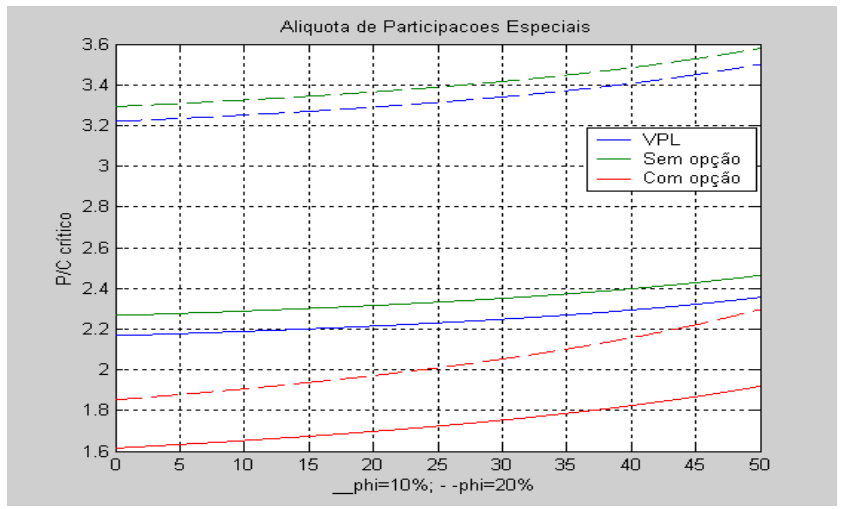

Figura 4-17: Participações especiais e taxa de aumento de custos



Figura 4-18: Participações especiais e incerteza de custo 
parâmetro de crescimento do preço.

É interessante insistir em como este resultado exibe certa consistência em relação ao princípio de Hotelling, notadamente quanto às considerações de DAVIS \& CAIRNS (1999). A condição necessária para que haja extração, segundo aquele princípio, é que a taxa de crescimento do valor sombra seja menor ou igual à taxa de juros (em equilíbrio, vale a igualdade se forem desprezadas as restrições físicas e tecnológicas para a extração do recurso) pois, caso contrário, valeria a pena para o produtor deixar os recursos no subsolo em virtude do ganho de capital daí recorrente. Isso equivale, na nossa notação, à condição de que $r>\alpha-\phi$. Assim, quando se reintroduzem explicitamente os custos de operação, a proximidade entre a teoria clássica de Hotelling e a nova abordagem das opções reais é visível, contrariando aqueles que consideram a primeira ultrapassada ${ }^{10}$.

Variando o convenience yield - $\delta$ : $\mathrm{O}$ convenience yield pode ser entendido como o fluxo de benefícios para o detentor dos recursos. Ele é dado pela diferença entre a taxa de desconto (ou no caso de uma avaliação livre de risco, a taxa de juros) e a taxa de crescimento esperada no preço do ativo $(\delta=r-\alpha)$, representando também o custo de oportunidade de se manter em aberto a opção de investimento.

Conforme sugere a figura 4-3, quanto maior o convenience yield, menor a razão preço-custo crítica para os três casos considerados. Além disso, como se pode visualizar na figura 4-4, que reproduz variações de $\delta$ para $\sigma_{P}=20 \%$ e $40 \%$, respectivamente, quanto maior o nível de incerteza, mais difícil tende a ser o investimento tanto na presença quanto na ausência de opção de paralisar (a avaliação por VPL não é afetada, por independer do desvio padrão).

Variando incerteza sobre o preço - $\sigma_{P}$ : Conforme abordamos anteriormente, uma das maiores vantagens da abordagem das opções reais em relação à avaliação pelo método do valor presente líquido é a possibilidade de incorporar o

evitou-se simular valores de a muito elevados, pois isso violaria esta condição.

${ }^{10}$ Para uma visão geral do debate, ver CAIRNS (1998). 
impacto da incerteza na avaliação do ativo, sem a necessidade de uma hipótese sobre preferências de risco ou de qual a medida da covariância entre o preço e o portfólio de mercado [PINDYCK (1991)]. A figura 4-5 ilustra o comportamento do preço crítico em relação a alterações no desvio padrão instantâneo do preço do petróleo. A incerteza não tem qualquer efeito sobre a avaliação de Valor Presente Líquido, o que explica o formato horizontal da curva azul. Conforme a incerteza aumenta, o preço crítico tende a se elevar tanto na presença quanto na ausência da opção de parada. Conforme salienta PINDYCK (1988), devido à irreversibilidade do investimento, a incerteza aumenta o custo de oportunidade de exercer sua opção de investir em uma unidade adicional de capital. Assim, na medida em que $\sigma_{P}$ eleva o valor da reserva não-desenvolvida (ou da opção de esperar), ele contribui para atrasar investimentos. O impacto da incerteza sobre os custos é análogo.

Variando coeficiente de correlação $\rho$ : Uma simulação interessante consiste em averiguar o impacto de diferentes coeficientes de correlação entre as variáveis de estado $P$ e $C$ sobre a disposição de investir. Existem evidências de que este valor é próximo à unidade [DIAS (1996)]. A figura 4-6 simula o impacto: conforme a intuição sugere, um aumento do coeficiente de correlação entre o preço e custo irá se traduzir em uma redução do valor crítico $p^{E}$, favorecendo a decisão de investir. Isso ocorre porque uma correlação positiva elevada entre preços e custos permite reduzir a incerteza global do projeto. Correlações pequenas ou negativas, por sua vez, tendem a elevar o risco do projeto como um todo, na medida em que representam um descolamento entre preços e custos. Ou seja, se ambas as variáveis de estado variarem na mesma direção, o agente possui uma maior margem de certeza quanto aos resultados de seu projeto.

Variando a taxa de crescimento do custo unitário - $\phi$ : A taxa de decaimento das reservas, $\phi$, está diretamente relacionada com a velocidade de extração do recurso. Em virtude das propriedades da função custo acima definidas (efeito Jevons), uma maior produção tem como consequiência um esgotamento mais rápi- 
do da jazida e a uma redução mais expressiva na pressão dos poços, o que impacta no crescimento dos custos marginais ao longo do tempo. A consideração deste efeito não costuma estar presente nos modelos de avaliação de investimento em petróleo por opções reais, daí nossa proposta de estudá-lo.

A figura 4-7 simula o impacto de variações em $\phi$ sobre a razão preço-custo crítica, $p^{E}$, nos mesmos moldes dos exercícios anteriores. Entretanto, com o intuito de evidenciar a diferença entre as curvas para valor presente líquido e opção sem parada, reajustamos o desvio padrão do preço, $\sigma_{P}$, para 0,245 (daí a não correspondência com a tabela 4.2 para $\phi=10 \%$ ). Uma maior taxa de vazão implica em maior taxa de crescimento do custo de produção por barril, de modo que quanto maior $\phi$ maior o preço crítico $^{11}$. O efeito para os casos de Valor Presente Líquido e Opções Reais sem paralisação são análogos conforme aumenta a taxa de extração.

No entanto, quando se considera a presença de opção de parada, o preço crítico cresce bem menos, de modo que a distorção sobre a decisão de investir é bem menor (a escala do gráfico não permite visualizar, mas o valor máximo de $p^{E}$ no caso irrealista de $\phi=100 \%$ é 2,75$)$. Isso era esperado, já que em caso de crescimento muito elevado dos custos unitários, o concessionário tem a possibilidade de interromper temporariamente a produção, evitando perdas. Desta forma, fica claro o papel da flexibilidade de paralisação sobre a disposição de investir, elevando o valor da reserva desenvolvida.

Outro detalhe curioso é que para valores baixos de $\phi$, o preço crítico com opção de parada é maior que no caso de VPL. Uma interpretação possível para isso é que, nesta situação, os custos de manter a opção de investimento aberta são muito altos, valendo a pena desenvolver imediatamente.

Variando investimento necessário - $i=I / C$ : Deve-se salientar que, até

\footnotetext{
${ }^{11}$ Voltando à interpretação de DAVIS \& CAIRNS (1999), restrições tecnológicas reduzem o valor da reserva em relação ao estimado pelo Princípio de Hotelling, aumentando o custo de oportunidade do investimento.
} 
agora, estamos trabalhando em termos puramente unitários, ou seja, toda a análise está voltada para 1 unidade de barril de petróleo. A única variável que está ligada ao tamanho físico das reservas é o investimento necessário para desenvolver uma unidade da mesma, I. A hipótese deste argumento é que reservas abundantes e/ou de alta qualidade costumam exigir um baixo volume de gastos por barril para seu desenvolvimento; em contrapartida, reservas escassas e/ou de baixa qualidade demandam maior investimento unitário para preparar sua extração. Assim, na medida em que simulamos os efeitos do investimento em desenvolvimento sobre o preço crítico de entrada, estamos indiretamente avaliando o impacto de diferentes qualidades/quantidades de recursos em uma reserva. Vale lembrar que o investimento constitui o "preço de exercício" da opção, em analogia com os instrumentos financeiros.

A figura 4-8 varia o investimento por unidade e seu efeito sobre o preço crítico para investir considerando os três $\operatorname{casos}^{12}$. Reservas de baixa qualidade, expressas em maior relação $I / C$ encarecem a opção de investir, elevando o preço crítico indutor do investimento, $p^{E}$.

Apesar de muitas das conclusões da estática comparativa, expressas nas figuras 4-1 a 4-8 serem previsíveis, um resultado comum a todos eles é que a possibilidade de fechamento temporário agrega valor à reserva desenvolvida (elevando o custo de oportunidade de esperar), tornando o investimento pouco sensível a variações nos demais parâmetros. Para todas as variações em $r, \alpha, \phi, i, \sigma_{P}$ e $\rho$ analisadas, o preço crítico na presença de opção de parada sem custos é menor do que na ausência, indicando que o investidor está menos propenso a adiar o

\footnotetext{
${ }^{12} \mathrm{Na}$ verdade, variamos $i=I / C$. O resultado de homogeneidade que tiramos para resolver os cálculos acarreta um problema, pois aumentos de $C$ reduzem o preço crítico, o que é um evidente absurdo. Entretanto, admitimos que tanto $I$ quanto $C$ decorrem das características da reserva (qualidade e quantidade) de modo que ambas as variáveis devem ser positivamente correlacionadas. Outra maneira de pensar o problema é considerar I como o investimento necessário para desenvolver a reserva e que gera um custo operacional de $C$ por unidade. Se este valor $C$ inicial for considerado igual para todas as reservas, variações de $I$ representariam um indicador de suas características físicas.
} 
investimento no desenvolvimento quando existe esta flexibilidade. Nota-se, em particular, que o efeito da opção de interrupção é significativo a ponto de mais do que compensar o efeito da irreversibilidade, o qual tende a gerar uma cunha positiva sobre o preço-custo crítico sob a hipótese de VPL. Assim, os preços críticos quando se considera a possibilidade de parada são menores do que na análise de fluxo de caixa descontado os quais, por sua vez, são inferiores aos valores críticos quando se incorpora a irreversibilidade, mas não é permitida a interrupção.

Não estamos interessados em discutir a plausibilidade de interrupção temporária na produção, com ou sem custos, quando as condições econômicas são desfavoráveis ou mesmo entrar na controversa discussão sobre a significância do valor das flexibilidades no investimento. O que interessa observar é que a possibilidade de fechamento reduz $p^{E}$, facilitando o desenvolvimento de uma reserva. Se tomarmos a opção de paralisação sem custos como um caso estilizado de flexibilidade total no gerenciamento da produção, a análise acima nos permite concluir que uma maneira de atrair investimentos no setor de petróleo e gás seria conceder ao concessionário uma maior autonomia na alocação de sua produção ao longo do ano.

Esta discussão é relevante pois, atualmente, de acordo com a Lei nº 9478/97, o concessionário deve entregar até outubro de cada ano um Plano de Produção para o ano seguinte, o qual deve ser aprovado pela Agência Nacional do Petróleo - ANP. Durante o ano, quaisquer desvios acima de 15\% em relação ao plano de produção devem ser justificados à agência. O que os resultados acima sugerem é que uma maior liberdade de operação ao longo do ano pode contribuir para facilitar a decisão de investir em desenvolvimento por parte de firmas detentoras de concessão de exploração, já que o pressuposto fundamental da análise de opções reais é permitir ao agente um gerenciamento ativo de seu projeto, reagindo a mudanças no cenário econômico. 


\subsection{Benefícios governamentais e investimento}

Passemos, agora, ao objetivo principal do capítulo, qual seja, avaliar o impacto dos benefícios governamentais sobre a decisão de investir. Estamos interessados em avaliar em que medida os preços críticos de entrada $\left(p^{E}\right)$ e saída $\left(p^{S}\right)$ são sensíveis a alterações nas alíquotas.

O artigo $45^{\circ}$ da Lei do Petróleo ( $\left.{ }^{\circ} 9478 / 97\right)$ estabelece os critérios gerais para a tributação do setor, com vistas a extrair a renda que pertence à União:

Bônus de Assinatura: Consiste no lance vencedor do leilão de licitação para áreas de exploração. Deve ser pago à vista no ato de assinatura do contrato de concessão e não guarda relação com o potencial de lucratividade ex-post do projeto. Conforme argumenta-se em POSTALI (2002) com a análise tradicional do valor presente líquido, este tributo possui conseqüências distorcivas sobre a disposição de investir, embora não altere a trajetória ótima de extração. Por se tratar de um pagamento fixo dispendido antes da fase exploratória, não o analisaremos aqui, pois o contexto da nossa análise compreende a passagem da exploração para o desenvolvimento;

Royalties: Constituem uma compensação mensal à União incidente sobre o valor total da produção de óleo e gás. Em geral, a alíquota deste tributo é de $10 \%$ sobre o valor da produção, avaliada de acordo com um preço de referência divulgado pela ANP com base na cotação internacional do petróleo. Projetos considerados mais arriscados podem ter sua alíquota reduzida até $5 \%$, percentual que utilizamos como referência para as simulações acima.

Participações Especiais: caracterizam-se por compensações extraordinárias ao Governo diante de altos volumes de produção. Aplicam-se alíquotas progressivas sobre a receita líquida da produção trimestral de cada campo, isto é, a receita bruta deduzidos os royalties, os investimentos exploratórios, os custos operacionais, a depreciação e os demais tributos legais. Tais alíquotas variam de 0 a $40 \%$ e dependem da localização da lavra, do número de anos da produção e do respectivo 
volume trimestral de produção fiscalizada ${ }^{13}$.

Taxa de ocupação ou retenção de áreas: trata-se de uma espécie de aluguel pela ocupação da área. Não iremos analisá-la, pois pode ser incorporada ao custo fixo do projeto.

Variando a alíquota de royalties - $\tau$ : Os resultados convencionais da literatura sobre os efeitos dos royalties sobre a decisão de investir indicam um grande potencial distorcivo desta modalidade sobre o nível de investimentos [GARNAUT \& ROSS (1983); FRASER (1993,1998)]. Isso ocorre pois, ao incidir sobre a receita, os royalties reduzem o preço percebido pelo produtor, podendo tornar negativo o valor presente líquido esperado, inviabilizando financeiramente o projeto.

Entretanto, a análise de valor presente não leva em consideração a possibilidade de reação do agente a alterações nas condições econômicas e a desconsideração deste elemento pode resultar em sub-avaliação do investimento. O nosso objetivo é avaliar o potencial distorcivo dos royalties quando as flexibilidades temporal (opção real) e operacional (opção de paralisação) são incorporadas na análise.

A figura 4-9 simula variações nas alíquotas de royalties e seu impacto sobre a razão preço-custo crítica de entrada em cada uma das três situações. Em todas elas, identifica-se o perfil distorcivo desta modalidade de benefício governamental à medida em que a alíquota cresce.

Para avaliar melhor como os royalties alteram a disposição em cada caso, considere a tabela 4.3 , que reporta os preços críticos de entrada e de saída, $p^{E}$ e $p^{S}$, para alíquotas de $0,5 \%$ e $10 \%$.

Conforme se observa, os royalties de $5 \%$ aumentam em cerca de $5,2 \%$ as razões

\footnotetext{
${ }^{13}$ Esta modalidade de participação do Governo possui semelhanças com o que se convencionou denominar "imposto sobre a renda do recurso" ou "Imposto de Brown", que prevê pagamentos dependentes do resultado do projeto. Em épocas de prejuízo, o imposto se transforma em subsídio. Trata-se de uma maneira do Governo assumir parte do risco do projeto. Sob a análise de VPL, esta modalidade é neutra no sentido de não distorcer a disposição de investir do agente, tendendo mesmo a favorecê-la.
} 
Tabela 4.3: Preços Críticos para valores selecionados de royalties

\begin{tabular}{c||c|c||c|c||c||c||c|c}
\hline \hline \multicolumn{1}{c||}{ Avaliação } & \multicolumn{2}{c||}{ VPL } & \multicolumn{2}{c||}{$\begin{array}{c}\text { Sem opção } \\
\text { interromper }\end{array}$} & \multicolumn{2}{c||}{ Com opção de interromper } \\
\cline { 5 - 9 } & \multicolumn{2}{l||}{} & \multicolumn{2}{c||}{ Sem custos } & \multicolumn{2}{c|}{ Com custos } \\
\hline \hline Alíquota & $p^{E}$ & $p^{S}$ & $p^{E}$ & $p^{S}$ & $p^{E}$ & $p^{S}$ & $p^{E}$ & $p^{S}$ \\
\hline \hline$\tau=0$ & 2,059 & - & 2,153 & - & 1,536 & 0,958 & 1,627 & 0,912 \\
\hline$\tau=5 \%$ & 2,167 & - & 2,266 & - & 1,617 & 1,008 & 1,712 & 0,960 \\
\hline$\tau=10 \%$ & 2,288 & - & 2,392 & - & 1,707 & 1,064 & 1,808 & 1,014 \\
\hline \hline
\end{tabular}

críticas e em cerca de 11,1\% para o caso de alíquota de 10\%, em relação à carga tributária nula, qualquer que seja o caso. O aumento de $p^{E}$ indica o atraso no investimento e a elevação de $p^{S}$ indica que o concessionário, uma vez em produção, estaria mais propenso a abandonar/paralisar a atividade em caso de situações adversas. Mesmo assim, é importante observar como o agente está mais disposto a investir com alíquota de $10 \%$ na presença de opção de interromper com custos ( $p^{E}$ de 1,808$)$ do que com uma alíquota nula e na ausência desta flexibilidade ( $p^{E}$ de 2,153$)$, ilustrando mais uma vez a importância das flexibilidades. O efeito distorcivo dos royalties decorre da percepção de um preço menor do que o efetivo por parte do investidor. Quando existe a opção de paralisação temporária, o investidor não precisa incorrer em perdas em momentos desfavoráveis, o que aumenta o custo de espera, favorecendo o empreendimento.

Deve-se ter em vista também que, embora o gráfico 4-9 sugira uma relação linear entre $\tau$ e $p^{E}$, a razão preço-custo crítica pode se tornar explosiva para alíquotas muito altas, conforme se observa no gráfico seguinte (4-10). Tais alíquotas estão muito acima da realidade da maioria dos países. Entretanto, a lição que se pode extrair desta simulação é de que propostas de unificação dos benefícios governamentais em torno de royalties com alíquotas mais altas, em substituição a todos os tributos incidentes sobre o setor podem ser má idéia.

O gráfico 4-11 reproduz o impacto do aumento da incerteza sobre $p^{E}\left(\sigma_{P}\right.$, em $\%$ aa) considerando alíquotas de royalties de 0 e10\%. Para ambos os valores, o preço-crítico é mais sensível na ausência de opção de parada do que na sua 
presença.

Por fim, o gráfico seguinte (4-12) ilustra o efeito dos royalties sob duas velocidades possíveis para o efeito Jevons - a taxa de crescimento dos custos unitários: $\phi=10 \%$ e $\phi=15 \%$. Novamente, verifica-se que a sensibilidade da decisão de investir é bem menor na presença de opção de paralisar.

Variando a alíquota das participações especiais - R: Um imposto incidente sobre a renda do recurso contém uma série de variantes, segundo as regras de apuração. Há modalidades na indústria de petróleo mundial que permitem a dedução integral dos gastos exploratórios e de desenvolvimento da base de cálculo $^{14}$. Trata-se do chamado Imposto de Brown ou Imposto sobre a Renda do Recurso - IRR ${ }^{15}$ [GARNAUT \& C. ROSS, 1983], cujo resultado prático é a transferência de parte do risco para o Governo, que acaba subsidiando parcela dos gastos correspondentes às alíquotas. Esta modalidade, quando adotada em sua forma pura, é neutra no sentido de nunca afetar o sinal algébrico do valor presente líquido esperado dos investimentos, mantendo sua ordem de lucratividade, de modo a não alterar a disposição de investir.

A montagem do exercício de simulação pressupõe uma variação de alíquota de 0 a 40\% (conforme previsto na legislação brasileira) considerando uma alíquota fixa de $5 \%$ de royalties. A maior ressalva em relação à prática é que não são todos os projetos obrigados a pagar Participação Especial à União, mas apenas os mais lucrativos. Como nosso objetivo é comparar o efeito distorcivo de ambas as modalidades separadamente, o cenário aqui proposto acaba superestimando o potencial distorcivo do IRR.

A figura 4-13 simula variações de alíquotas para o tributo sobre a renda. Os valores do eixo vertical correspondem aos preços críticos descritos na tabela 4.2

\footnotetext{
${ }^{14}$ Ver ZHANG (1997) para variantes de tributos sobre a renda no Mar do Norte.

${ }^{15}$ Há uma pequena diferença entre ambas. Segundo GARNAUT \& C.ROSS (1983), o imposto sobre a renda do recurso (IRR) permite a acumulação de todas as perdas a uma taxa dependente do juro sobre o capital para serem depreciadas do lucro na fase de produção. O Imposto de Brown, por sua vez, prevê a tributação em cada instante do projeto.
} 
para $\tau=5 \%$. Como era de se esperar, existe um impacto distorcivo, ainda que pequeno, conforme aumentam as alíquotas de IRR.

As figuras 4-14 e 4-15 representam o efeito das alíquotas de Participações especiais para quatro níveis de taxa de juros anuais: 10\%, 12\%, $20 \%$ e $30 \%$. Confirmando os resultados anteriores, a taxa de juros tem um efeito monotônico sobre $p^{E}$ na presença de opção de parada, atrasando o investimento. Na ausência desta flexibilidade, identifica-se um efeito ambíguo: para níveis de juros menores (4-14), o aumento desta variável tem como resultado o aumento do valor da reserva desenvolvida, produzindo queda no preço crítico de entrada para um dado nível de Participações Especiais; para taxas muito elevadas (4-15), o efeito tradicional pode passar a predominar, reduzindo a disposição de investir (taxas anuais acima de $45 \%)^{16}$.

Conforme se nota pela comparação dos dois gráficos no caso de opção de parada, o efeito distorcivo do IRR é potencializado quando as taxas de juros são mais altas. No caso de ausência desta opção, este padrão não se verifica.

Os sistemas tributários baseados em imposto sobre a renda permitem, em geral, que os gastos exploratórios e em desenvolvimento sejam acumulados a uma certa taxa de capitalização ${ }^{17}$ (up lift rate) e descontados da base de incidência do imposto quando o projeto passa a gerar fluxos de caixa positivos. Quando aumentamos este parâmetro, o investimento se torna mais provável em qualquer cenário de flexibilidade, conforme podemos visualizar no gráfico 4-16. Note que o estímulo ao investimento tende a ser maior quando há opção de saída.

A figura 4-17 mostra o impacto das Participações Especiais sobre $p^{E}$ para diferentes níveis de taxa de crescimento esperada de extração dos custos - $\phi=10 \%$ e $\phi=20 \%$. Novamente, identifica-se uma sensibilidade menor do investimento em relação a $R$ no caso de opção de paralisação, mas alíquotas mais altas tendem

\footnotetext{
${ }^{16}$ Novamente, isso acontece pois $r$ afeta tanto $P$ quanto $C$ na razão $p \equiv P / C$.

${ }^{17}$ Quando se trata do Imposto sobre a Renda do Recurso strictu sensu (GARNAUT \& C. ROSS, 1983), esta taxa é igual à taxa de juros. A modalidade Imposto de Brown prevê pagamentos em cada instante de tempo.
} 
Tabela 4.4: Preços críticos sem opção de paralisação

\begin{tabular}{||c||c||c||c||c||c||}
\hline \hline \multicolumn{1}{||c||}{$p^{E}$} & \multicolumn{5}{c||}{$\tau(\%)$} \\
\hline \hline$R(\%)$ & $\mathbf{0}$ & $\mathbf{2 , 5}$ & $\mathbf{5}$ & $\mathbf{7 , 5}$ & $\mathbf{1 0}$ \\
\hline \hline $\mathbf{0}$ & 2,153 & 2,208 & 2,266 & 2,328 & 2,392 \\
\hline $\mathbf{1 0}$ & 2,174 & 2,229 & 2,288 & 2,350 & 2,415 \\
\hline $\mathbf{2 0}$ & 2,200 & 2,256 & 2,315 & 2,378 & 2,444 \\
\hline $\mathbf{3 0}$ & 2,233 & 2,291 & 2,351 & 2,414 & 2,481 \\
\hline $\mathbf{4 0}$ & 2,278 & 2,336 & 2,398 & 2,462 & 2,531 \\
\hline \hline
\end{tabular}

Tabela 4.5: Preços críticos com opção de paralisação sem custos

\begin{tabular}{|c|c|c|c|c|c|c|c|c|c|c|}
\hline 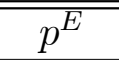 & \multicolumn{10}{|c|}{$\overline{\tau \tau(\%)}$} \\
\hline $\bar{R} R(\%)$ & \multicolumn{2}{|c|}{$\overline{\overline{0}}$} & \multicolumn{2}{|c|}{$\overline{22,5}$} & \multicolumn{2}{|c|}{$\overline{5}$} & \multicolumn{2}{|c|}{$\overline{7 \overline{7,5}}$} & \multicolumn{2}{|c|}{$\overline{10}$} \\
\hline & $\overline{p^{E}}$ & $\overline{p^{S}}$ & $\overline{p^{E}}$ & $\overline{p^{S}}$ & $\overline{p^{E}}$ & $\overline{p^{S}}$ & $\overline{p^{E}}$ & $\overline{p p^{S}}$ & $\overline{p^{E}}$ & $\overline{p p^{S}}$ \\
\hline 0 & 1,536 & 0,958 & 1,575 & 0,982 & 1,617 & 1,008 & 1,660 & 1,035 & 1,707 & 1,064 \\
\hline 10 & 1,571 & 0,958 & 1,611 & 0,982 & 1,654 & 1,008 & 1,698 & 1,035 & 1,746 & 1,064 \\
\hline 20 & 1,614 & 0,958 & 1,655 & 0,982 & 1,699 & 1,008 & 1,744 & 1,035 & 1,793 & 1,064 \\
\hline 30 & 1,666 & 0,958 & 1,709 & 0,982 & 1,754 & 1,008 & 1,801 & 1,035 & 1,851 & 1,064 \\
\hline 40 & 1,734 & 0,958 & 1,778 & 0,982 & 1,825 & 1,008 & 1,875 & 1,035 & 1,927 & 1,064 \\
\hline
\end{tabular}

a produzir um efeito maior nesta última situação.

Por fim, o gráfico 4-18 mostra o efeito das participações especiais sobre $p^{E}$ diante de dois níveis de incerteza sobre o custo: $\sigma_{C}=7 \%$ e $\sigma_{C}=25 \%$ aa. Novamente, verifica-se uma sensibilidade maior do preço crítico a variações neste parâmetro quando não há flexibilidades ${ }^{18}$.

Para uma avaliação mais acurada, consideremos as tabelas 4.4 a 4.7, que relacionam os preços críticos observados para diversas combinações de alíquotas de royalties e Participação Especial, para os casos de ausência e presença de opção de parada.

Considerando a opção de investir, avaliada por $p^{E}$, a distorção cresce conforme ambas as alíquotas são elevadas (ou seja, andamos para a direita e para baixo

\footnotetext{
${ }^{18} \mathrm{O}$ impacto de $\sigma_{P}$ é análogo.
} 
Tabela 4.6: Preços críticos com opção de paralisação e $=0,5$

\begin{tabular}{||c||c||c||c||c||c||c||c||c||c||c||}
\hline \hline \multicolumn{1}{||c||}{$p^{E}$} & \multicolumn{10}{c||}{$\tau(\%)$} \\
\hline \hline$R(\%)$ & \multicolumn{2}{|c|}{$\mathbf{0}$} & \multicolumn{2}{c||}{$\mathbf{2 , 5}$} & \multicolumn{2}{|c||}{$\mathbf{5}$} & \multicolumn{2}{|c||}{$\mathbf{7 , 5}$} & \multicolumn{2}{|c||}{$\mathbf{1 0}$} \\
\hline \hline & $p^{E}$ & $p^{S}$ & $p^{E}$ & $p^{S}$ & $p^{E}$ & $p^{S}$ & $p^{E}$ & $p^{S}$ & $p^{E}$ & $p^{S}$ \\
\hline \hline $\mathbf{0}$ & 1,627 & 0,912 & 1,668 & 0,936 & 1,712 & 0,960 & 1,759 & 0,986 & 1,808 & 1,013 \\
\hline $\mathbf{1 0}$ & 1,666 & 0,907 & 1,709 & 0,930 & 1,754 & 0,955 & 1,802 & 0,981 & 1,852 & 1,008 \\
\hline $\mathbf{2 0}$ & 1,714 & 0,901 & 1,758 & 0,924 & 1,804 & 0,948 & 1,853 & 0,974 & 1,904 & 1,001 \\
\hline $\mathbf{3 0}$ & 1,773 & 0,893 & 1,818 & 0,915 & 1,866 & 0,940 & 1,917 & 0,965 & 1,970 & 0,992 \\
\hline $\mathbf{4 0}$ & 1,848 & 0,882 & 1,895 & 0,904 & 1,945 & 0,928 & 1,998 & 0,953 & 2,053 & 0,980 \\
\hline \hline
\end{tabular}

Tabela 4.7: Preços críticos com opção de paralisação com custo e $=1$

\begin{tabular}{||c||c||c||c||c||c||c||c||c||c||c||}
\hline \hline \multicolumn{1}{||c||}{$p^{E}$} & \multicolumn{10}{c||}{$\tau(\%)$} \\
\hline \hline$R(\%)$ & \multicolumn{2}{|c|}{$\mathbf{0}$} & \multicolumn{2}{c||}{$\mathbf{2 , 5}$} & \multicolumn{2}{|c||}{$\mathbf{5}$} & \multicolumn{2}{|c||}{$\mathbf{7 , 5}$} & \multicolumn{2}{|c|}{$\mathbf{1 0}$} \\
\hline \hline \multicolumn{1}{|||||}{} & $p^{E}$ & $p^{S}$ & $p^{E}$ & $p^{S}$ & $p^{E}$ & $p^{S}$ & $p^{E}$ & $p^{S}$ & $p^{E}$ & $p^{S}$ \\
\hline \hline $\mathbf{0}$ & 1,700 & 0,867 & 1,744 & 0,889 & 1,790 & 0,912 & 1,838 & 0,937 & 1,889 & 0,963 \\
\hline $\mathbf{1 0}$ & 1,743 & 0,856 & 1,788 & 0,878 & 1,835 & 0,901 & 1,885 & 0,926 & 1,937 & 0,952 \\
\hline $\mathbf{2 0}$ & 1,794 & 0,844 & 1,840 & 0,865 & 1,889 & 0,888 & 1,940 & 0,912 & 1,994 & 0,937 \\
\hline $\mathbf{3 0}$ & 1,857 & 0,827 & 1,905 & 0,849 & 1,955 & 0,871 & 2,008 & 0,894 & 2,064 & 0,919 \\
\hline $\mathbf{4 0}$ & 1,937 & 0,806 & 1,987 & 0,826 & 2,039 & 0,848 & 2,094 & 0,871 & 2,152 & 0,895 \\
\hline
\end{tabular}

na matriz). Quando se comparam as metodologias, novamente, observa-se que o valor da flexibilidade de paralisação é significativo a ponto de mais do que compensar o efeito da irreversibilidade sobre o valor presente líquido, dadas as magnitudes de $p^{E}$. Desta forma, observa-se mais uma vez como a desconsideração das opções de operação pode conduzir a decisões erradas de investimento.

A simulação das variações de alíquotas, por sua vez, mostra dois fenômenos: a) a variação dos royalties distorce de maneira parecida os investimentos em qualquer um dos casos. Ou seja, definindo como grau de distorção a variação percentual no preço-crítico em relação à ausência total de benefícios $(\tau=R=0)$, nota-se que este cresce cerca de $11 \%$ quando os royalties são fixados em 10\%; b) o Imposto sobre a renda de recursos provoca uma distorção maior quando existe a opção de paralisação: considerando royalties nulos, a alíquota de Participação Especial em $40 \%$ (máxima da legislação brasileira) aumenta em cerca de $6 \%$ a 
Tabela 4.8: Grau de Distorção sem opção de parada

\begin{tabular}{||c||c||c||c||c||c||}
\hline \hline \multicolumn{1}{||c||}{$\Delta p^{E} / p^{E}$} & \multicolumn{5}{c||}{$\tau(\%)$} \\
\hline \hline$R(\%)$ & $\mathbf{0}$ & $\mathbf{2 , 5}$ & $\mathbf{5}$ & $\mathbf{7 , 5}$ & $\mathbf{1 0}$ \\
\hline \hline $\mathbf{0}$ & - & $2,55 \%$ & $5,25 \%$ & $8,13 \%$ & $11,10 \%$ \\
\hline $\mathbf{1 0}$ & $0,98 \%$ & $3,53 \%$ & $6,27 \%$ & $9,15 \%$ & $12,17 \%$ \\
\hline $\mathbf{2 0}$ & $2,18 \%$ & $4,78 \%$ & $7,52 \%$ & $10,45 \%$ & $13,52 \%$ \\
\hline $\mathbf{3 0}$ & $3,72 \%$ & $6,41 \%$ & $9,20 \%$ & $12,12 \%$ & $15,23 \%$ \\
\hline $\mathbf{4 0}$ & $5,81 \%$ & $8,50 \%$ & $11,38 \%$ & $14,35 \%$ & $17,56 \%$ \\
\hline \hline
\end{tabular}

razão crítica na ausência da opção (tabela 4.8) e cerca de $14 \%$ em sua presença (tabela 4.9). Nota-se, inclusive, que apesar de $p^{E}$ ser menor em valor absoluto neste caso, a sensibilidade do investimento é maior ao IRR do que aos royalties. Este resultado é um tanto contra-intuitivo, pois seria de esperar um efeito menor do IRR, dada suas propriedades de neutralidade outrora estudadas.

De um modo geral, o aumento das alíquotas acarreta uma elevação do grau de distorção, o que corresponde a uma redução do valor da reserva desenvolvida. DAVIS \& CAIRNS (1999) afirmam que a presença de restrições regulatórias reduzem o valor da reserva em relação ao Princípio de Hotelling. Tais resultados podem ser interpretados neste sentido, isto é, alíquotas maiores representam restrições regulatórias crescentes.

O efeito dos benefícios governamentais sobre a opção de saída, avaliada por $p^{S}$, é interessante: enquanto os royalties elevam a disposição de abandono na medida em que aumentam a razão crítica, o imposto sobre a renda é neutro na ausência de custos de paralisação (já que não alteram $p^{S}$, como se observa na tabela 4.5); quando há custos de paralisação, por sua vez, o aumento da alíquota do IRR reduz a razão $p^{S}$, isto é, reduzem a probabilidade de abandono ou paralisação. A intuição para o resultado é que o IRR apresenta um perfil de redução de riscos para o investidor.

Entretanto, a análise das tabelas a mostra que, do ponto da vista do investimento, a combinação intermediária de alíquotas pode ser preferível a extremos, 
Tabela 4.9: Grau de distorção com opção de interrupção ao custo e $=1$

\begin{tabular}{|c|c|c|c|c|c|c|c|c|c|c|}
\hline$\overline{\Delta \Delta p^{E} / p^{E}}$ & \multicolumn{10}{|c|}{$\overline{\tau \tau(\%)}$} \\
\hline 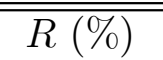 & \multicolumn{2}{|c|}{$\overline{\overline{0}}$} & \multicolumn{2}{|c|}{$\overline{\overline{2,5}}$} & \multicolumn{2}{|c|}{$\overline{\overline{5}}$} & \multicolumn{2}{|c|}{$\overline{7,5}$} & \multicolumn{2}{|c|}{$\overline{10}$} \\
\hline & $\bar{p}^{E}$ & $\overline{\bar{p} p^{S}}$ & $\overline{p^{E}}$ & $\overline{p^{S}}$ & $\overline{p^{E}}$ & $\overline{p^{S}}$ & $\overline{p^{E}}$ & $\overline{p^{S}}$ & $\overline{p^{E}}$ & $\overline{p^{S}}$ \\
\hline$\overline{\overline{0}}$ & $=$ & - & $2,6 \%$ & $2,5 \%$ & 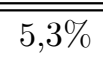 & 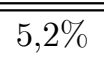 & $8,8,1 \%$ & 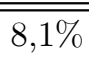 & $\overline{11,1 \%}$ & $\overline{11,1 \%}$ \\
\hline 10 & $2,5 \%$ & $-1,3 \%$ & $5,2 \%$ & $1,3 \%$ & $7,9 \%$ & $3,9 \%$ & $10,9 \%$ & $6,8 \%$ & $13,9 \%$ & $9,8 \%$ \\
\hline 20 & $5,5 \%$ & $-2,7 \%$ & $8,2 \%$ & $-0,2 \%$ & $11,1 \%$ & $2,4 \%$ & $14,1 \%$ & $5,2 \%$ & $17,3 \%$ & $8,1 \%$ \\
\hline 30 & $9,2 \%$ & $-4,6 \%$ & $12,1 \%$ & $-2,1 \%$ & $15,0 \%$ & $0,5 \%$ & $18,1 \%$ & $3,1 \%$ & $21,4 \%$ & $6,0 \%$ \\
\hline 40 & $13,9 \%$ & $-7,0 \%$ & $16,9 \%$ & $-4,7 \%$ & $19,9 \%$ & $-2,2 \%$ & $23,2 \%$ & $0,5 \%$ & $26,6 \%$ & $3,2 \%$ \\
\hline
\end{tabular}

sobretudo no caso de não-flexibilidade: o preço limite $p^{E}$ para uma combinação $(\tau, R)$ de $(2,5 \%, 20 \%)$ é menor do que para o par $(10 \%, 0)$ para todos os cenários de custo de saída. Além disso, no par $(2,5 \%, 20 \%)$ a disposição de paralisar é menor do que na situação em que existe uma alíquota única de $10 \%$ de royalties. Note-se, ainda, que no par $(5 \%, 20 \%)$, o grau de distorção para o investimento é semelhante ao do $(10 \%, 0)$ e a opção de saída fica menos atrativa.

Todavia, isso não significa que combinações intermediárias sejam melhores, já que é necessário fazer a análise da eficiência arrecadatória do tributo em cada situação. O governo pode estar interessado em empreender uma combinação de alíquotas que lhe proporcione a maior receita esperada por barril produzido. Os valores arrecadados (correspondentes ao gasto das empresas com os tributos) irão depender do preço do petróleo (no caso dos royalties) e do custo da firma (no caso de $R$ ), de modo que a melhor combinação pode mudar de acordo com essas variáveis. Deve-se observar também que enquanto o preço é publicamente observado, é possível que haja um problema de assimetria de informação na administração das participações especiais, pois estas dependem do custo, um parâmetro que não é necessariamente observado pelo principal [OSMUNDSEN (1998)].

As receitas em qualquer situação variam diretamente com o preço, que fixaremos em $\$ 28$. Consideremos dois tipos de agentes: uma firma que se depara com boas reservas e investimento unitário $(I=\$ 3)$ e uma firma com recursos de 
Tabela 4.10: Receita esperada por barril, em dólar, para $\mathrm{P}=28, \mathrm{C}=\mathrm{I}=3$

\begin{tabular}{||c||c||c||c||c||c||}
\hline \hline \multicolumn{1}{||c||}{ Receita /barril (\$) } & \multicolumn{5}{|c||}{$\tau \mathbf{( \% )}$} \\
\hline \hline$R(\%)$ & $\mathbf{0}$ & $\mathbf{2 , 5}$ & $\mathbf{5}$ & $\mathbf{7 , 5}$ & $\mathbf{1 0}$ \\
\hline \hline $\mathbf{0}$ & 0,00 & 3,71 & 7,43 & 11,14 & 14,85 \\
\hline $\mathbf{1 0}$ & 8,85 & 12,20 & 15,54 & 18,88 & 22,22 \\
\hline $\mathbf{2 0}$ & 17,71 & 20,68 & 23,65 & 26,62 & 29,59 \\
\hline $\mathbf{3 0}$ & 26,56 & 29,16 & 31,76 & 34,36 & 36,96 \\
\hline $\mathbf{4 0}$ & 35,42 & 37,64 & 39,87 & 42,10 & 44,33 \\
\hline \hline
\end{tabular}

baixa qualidade $(I=\$ 9)$. A tabela a seguir simula o valor presente da receita arrecadada por barril de petróleo na primeira situação ${ }^{19}$.

No caso de investimento igual a $\$ 3$ (tabela 4.10), o valor presente esperado da receita da União por barril será maior para sistemas que privilegiam o imposto sobre a renda ao invés dos royalties. Por exemplo, na ausência de IRR e royalties de $10 \%$, o Governo arrecadaria US $\$ 14,85$ por barril, enquanto arrecadaria cerca de US\$20,68 com royalties de $2,5 \%$ e IRR de $20 \%$, situação em que o grau de distorção é menor sob qualquer hipótese em relação à opção de parada. Na ausência de royalties, o Governo consegue obter receitas maiores com $R$ de até $30 \%$ com distorção menor sobre o preço crítico do que no caso de alíquota única de royalties de $10 \%$. Além disso, deve-se ter em mente que resultados da teoria convencional [e.g.: FRASER $(1993,1998)]$ mostram que os royalties distorcem para baixo a trajetória de extração, o que pode reduzir a arrecadação global do Governo quando se concentra em alíquotas uniformes e universais deste tributo.

A tabela 4.11 mostra que, em se tratando de reservas de baixa qualidade, tais resultados não são mantidos, ou seja, agora é necessária uma certa cautela na utilização de sistemas tributários centrados na renda, pois a receita por barril pode ser menor. Apesar de alíquotas intermediárias de cada modalidade serem preferíveis aos casos extremos do ponto de vista da disposição de investir ou de paralisar/abandonar, a União pode perder parcelas significativas de receita se

\footnotetext{
${ }^{19}$ Os demais parâmetros são idênticos aos da tabela 4.1 .
} 
Tabela 4.11: Receita esperada por barril, para $\mathrm{P}=28, \mathrm{C}=3, \mathrm{I}=9$

\begin{tabular}{||c||c||c||c||c||c||}
\hline \hline Receita /barril (\$) & \multicolumn{5}{|c||}{$\tau \mathbf{( \% )}$} \\
\hline \hline$R(\%)$ & $\mathbf{0}$ & $\mathbf{2 , 5}$ & $\mathbf{5}$ & $\mathbf{7 , 5}$ & $\mathbf{1 0}$ \\
\hline \hline $\mathbf{0}$ & 0 & 3,71 & 7,43 & 11,14 & 14,85 \\
\hline $\mathbf{1 0}$ & 2,85 & 6,20 & 9,54 & 12,88 & 16,22 \\
\hline $\mathbf{2 0}$ & 5,71 & 8,68 & 11,65 & 14,62 & 17,59 \\
\hline $\mathbf{3 0}$ & 8,56 & 11,16 & 13,76 & 16,36 & 18,96 \\
\hline $\mathbf{4 0}$ & 11,42 & 13,64 & 15,87 & 18,10 & 20,33 \\
\hline \hline
\end{tabular}

aumentar a participação do imposto sobre a renda. No entanto, esta análise não permite averiguar o comportamento da receita total, pois não estamos trabalhando com a quantidade produzida, de modo que, apesar de arrecadar uma quantidade maior por barril com royalties a 10\%, este perfil tributário pode reduzir os investimentos em desenvolvimento de reservas de baixa qualidade, podendo diminuir a receita global do governo.

Uma conclusão importante que pode ser extraída dos resultados acima é que a heterogeneidade de qualidades de projetos, bem como diferenças de flexibilidade podem requerer estruturas tributárias distintas, mesmo que isso represente receitas menores para o governo. Em particular, jazidas com qualidades ruins podem não resistir a benefícios concentrados em royalties: por exemplo, em qualquer das situações assumidas para a flexibilidade operacional (com ou sem opção de parada), um projeto pode ser atrativo a um par $(\tau, R)$ de alíquotas de $(2,5 \%, 20 \%)$ e não o ser a $(10 \%, 0)$ e as receitas por barril podem ser parecidas, dependendo da qualidade da jazida (vide tabela 4.10). Além disso, deve-se ter em vista que os royalties tendem a distorcer para baixo o volume de produção, de modo que a União poderia arrecadar mais como um todo, embora as receitas por barril sejam menores.

Isso significa que a flexibilização das alíquotas pode ser um poderoso instrumento no sentido de preservar investimentos menos lucrativos (evitando o seu abandono) e, dependendo das características do projeto, aumentar a receita co- 
mo um todo.

Além disso, tendo em vista que a receita esperada do Governo (por barril) coincide com o gasto da firma, uma estrutura tributária composta por um trade off entre royalties e participações especiais pode ser implementada como um mecanismo direto de revelação na forma de um menu de contratos com vistas a induzir a firma a revelar seu verdadeiro parâmetro de custos (e, por conseguinte, a qualidade/quantidade de suas reservas): firmas com custos elevados tenderiam a escolher contratos concentrados no imposto sobre a renda, pois isso implica menores gastos por barril; firmas com reservas de boa qualidade, por sua vez, tenderiam a preferir os royalties, pois implicam em menores custos por barril, conforme se depreendem das tabelas anteriores. É claro que esta opção implicaria em menores receitas para a União, mas contribuiria para a preservação de investimentos em reservas marginais. 


\section{Capítulo 5}

\section{Conclusões}

Apesar da facilidade operacional, a análise de valor presente líquido apresenta uma série de limitações, na medida em que não incorpora de forma satisfatória a incerteza, a irreversibilidade dos investimentos e as flexibilidades operacionais (opções de paralisação, abandono, ampliação e redução). Tais elementos influenciam o valor do projeto, alterando a disposição de investir do agente.

O setor de petróleo e gás apresenta um perfil peculiar que o torna um campo fértil para a aplicação desta ferramenta: o perfil de longa maturidade dos projetos, a elevada incerteza e a especificidade dos equipamentos da indústria petrolífera, acentuando a irreversibilidade dos investimentos, podem acarretar erros de avaliação quando se ignoram tais características em uma análise de fluxo de caixa descontado.

Com vistas a avaliar a viabilidade do investimento, foi necessário definir um processo estocástico para o preço do petróleo, a variável de estado determinante do valor da reserva não-desenvolvida e desenvolvida. Procuramos mostrar que a utilização do movimento browniano geométrico como proxy para a evolução do valor do barril do petróleo, em substituição a processos mais parametrizados, não conduz a erros significativos de avaliação, na medida em que os choques no preço são de dissipação muito lenta, de modo que a dependência do valor em relação 
ao preço de equilíbrio pode ser desconsiderada. A grande vantagem do MBG é sua facilidade analítica e operacional, além de permitir uma melhor incorporação da interação entre a irreversibilidade e a incerteza.

As aplicações da teoria das opções reais em investimentos de petróleo e gás costumam ignorar o chamado efeito Jevons, isto é, o crescimento progressivo dos custos unitários em decorrência da redução na pressão das jazidas. A incorporação deste efeito altera a disposição de investir e, quanto mais rápida a extração, maior a velocidade de crescimento dos custos, elevando a razão preço-custo crítica que torna o agente indiferente entre investir ou não.

O efeito da irreversibilidade costuma introduzir uma cunha entre o preço crítico (gatilho) sob valor presente líquido e o preço crítico sob opções reais, de modo que é mais difícil observar uma decisão de investimento nesta condição. Por outro lado, quando se incorpora a opção de paralisação temporária da produção, sem custos, o preço crítico cai abaixo do valor observado sob VPL, indicando que a redução na disposição de investir decorrente da incorporação da irreversibilidade é mais do que compensada pelo efeito estimulador produzido pela flexibilidade de parada. Se esta opção for tomada como um caso estilizado de máxima flexibilidade operacional (em oposição à pré-definição e pré-planejamento de extração determinados pela Lei do Petróleo no Brasil), observa-se que a liberdade de extração contribui para diminuir o preço-custo limite, de modo que os concessionários deveriam ter maior liberdade de alocação temporal de sua produção, conforme as condições econômicas. O efeito da incorporação de custos de saída não altera de forma qualitativa estas conclusões.

Deve-se destacar também que a flexibilidade operacional na forma de opção de parada reduz fortemente a sensibilidade da razão preço-custo limite à mudanças na taxa de decaimento das reservas. A mencionada opção também reduz a sensibilidade do preço de entrada em relação a variações na taxa de juros, na taxa de crescimento do valor do barril e no convenience yield.

O efeito dos benefícios governamentais sobre a decisão de investir depende da 
hipótese adotada sobre a presença ou não da opção de paralisação: tanto no caso do VPL quanto na análise de opções reais sem esta flexibilidade operacional, os mecanismos centrados nos royalties são mais distorcivos do que aqueles baseados em tributação sobre lucros ou rendas, ao passo que na presença de opção de paralisação estes últimos tendem a ser mais distorcivos, o que contradiz alguns dos resultados convencionais de que tributação baseada no lucro e renda tende a distorcer menos o investimento do que os royalties.

Do ponto de vista da receita por barril, é necessária cautela antes de qualquer conclusão, pois os resultados dependem da qualidade da reserva: o governo é capaz de extrair maiores receitas por unidade em reservas de alta qualidade se utilizar combinações intermediárias de alíquotas ao invés de maximizar os royalties, com a vantagem de garantir a viabilidade de alguns investimentos que de outro modo não seriam realizados. O resultado não vale para reservas de baixa qualidade. Todavia, a heterogeneidade de custos e qualidades de jazidas aconselha a adoção de um leque mais variado de alíquotas de ambas as modalidades de benefícios governamentais, com vistas a preservar a viabilidade de alguns investimentos considerados pouco viáveis.

A abertura do setor de petróleo e gás no Brasil já está para completar uma década e ainda há muitos obstáculos a serem superados na definição do marco regulatório do setor, o que é crucial para que os investimentos sejam otimizados e as rendas do petróleo sejam revertidas em benefício da sociedade. As pesquisas na área de opções reais aplicadas são bastante promissoras e há diversas extensões possíveis para esta tese, seja no sentido de adequar o modelo à legislação brasileira, seja para representar melhor as características estilizadas da indústria do petróleo. Eis alguns exemplos:

a) utilização de processos estocásticos mais complicados para caracterizar o valor do barril - como movimento de reversão à média com saltos de Poisson ou movimentos estado-contingentes;

b) inclusão de mais variáveis de estado para o valor da reserva (modelos 
multifatoriais), como o preço de longo prazo, a taxa de juros, a volatilidade, dentre outros;

c) análise de estruturas tributárias mais complexas e/ou progressivas, cujas alíquotas dependam do volume extraído;

d) inclusão de mais flexibilidades operacionais na avaliação do projeto (como opção de expansão da capacidade, opção de redução ou ampliação do ritmo de produção, time to build).

Mesmo com as limitações já apontadas, acreditamos que este trabalho tenha contribuído para a discussão sobre flexibilidades relevantes para a decisão de investir, bem como sobre a estrutura de benefícios governamentais menos distorciva para os investimentos no setor de petróleo e gás. 


\section{Bibliografia}

[1] ABEL, A.B., A. DIXIT, J.C. EBERLY \& R. PINDYCK, 1996."Options, The Value of Capital, and Investment". The Quartely Journal of Economics 111 (3), pp. 753-777.

[2] AZEVEDO, P.F., E.M.M.Q. FARINA, P. PICCHETTI, 1998. "A Reestruturação dos Setores de Infra-Estrutura e a Definição dos Marcos Regulatórios: Princípios Gerais, Características e Problemas". IPEA, 1998.

[3] BAKER, M.P., E.S. MAYFIELD, J.E. PARSONS, 1998, "Alternative Models of uncertain Commodity Prices for Use with Modern Asset Pricing". Energy Journal 19 (1), Jan/98, pp. 115-148.

[4] BJERKSUND, P., S. EKERN, 1990. "Managing Investment Opportunities under price uncertainty: From 'Last Chance' to 'Wait and See' Strategies'. Financial Management 19 (Autumn), pp.65-83.

[5] BJERKSUND, P., S. EKERN,1995. "Contingent Claims Evaluation of Mean-Reverting Cash Flows in Shipping". In TRIGEORGIS, L. (org.), Real Options in Capital Investment: Models, Strategies, and Applications. Praeger Ed., 1995.

[6] BRADLEY, P.G, 1998. "On the use of modern asset pricing theory for comparing alternative royalty systems for petroleum development projects". Energy Journal 19, nº 1 , Jan/98, pp. 47-81. 
[7] BRENNAN, M.J. e E.S. SCHWARTZ, 1985. "Evaluating Natural Resource Investments". Journal of Business 58, nº2, 135-157.

[8] BRENNAN, M. J. e L. TRIGEORGIS (orgs.), 2000. Project Flexibility, Agency, and Competition: New Developments in the Theory and Aplication of Real Options. Nova York: Oxford University, 2000.

[9] CAIRNS, R.D., 1990. "The Economics of Exploration for Non-Renewable Resources". Journal of Economic Surveys 4, nº 4, Dez. 1990, 361-395.

[10] CAIRNS, R.D., 1994. "On Gray's Rule and the Stylized Facts of NonRenewable Resources". Journal of Economic Issues 28, nº3, Set.94, 777798.

[11] CAIRNS, R.D., 1998. "Are mineral deposits valuable? A reconciliation of theory and practice". Resources Policy 24, nº, Mar/98, pp.19-24.

[12] CAMPBELL, H.F. e. R.K. LINDNER, 1985a. "Mineral Exploration and the Neutrality of Rent royalties". Economic Record 61, nº172, Mar/85, 445-449.

[13] CAMPBELL, H.F. e. R.K. LINDNER, 1985b. "A Model of mineral Exploration and Resource Taxation". Economic Journal 95, n³77, Mar/85, 146-160.

[14] CAPOZZA, D. e Y. LI, 1994."The Intensity and Timing of Investment: The Case of Land". American Economic Review 84, (4) pp. 889-904.

[15] CARVAlHINHO Fo . J. C. L, 2003. O valor da flexibilidade em cláusulas "take-or-pay" de contratos para o fornecimento de gás natural industrial. Dissertação de Mestrado, FEA, USP, 2003.

[16] CHERIAN, J.A, J. PATEL e I. KHIRIPKO, 2000. "Optimal Extraction of Nonrenewable Resources When Costs Cumulate". In BRENNAN, M. J. e L. TRIGEORGIS (orgs.), 2000. Project Flexibility, Agency, and Competition: 
New Developments in the Theory and Aplication of Real Options. Nova York: Oxford University, 2000.

[17] CLEWLOW, L. e C. STRICKLAND, 1998. Implementing Derivatives Models. John Wiley \& Sons, Chichester.

[18] CLEWLOW, L. e C. STRICKLAND, 2000. Energy Derivatives: Pricing and Risk Management. Lacima, London.

[19] COPELAND, T. e V. ANTIKAROV, 2002. Opções Reais. Campus Ed., Rio de Janeiro, 2002.

[20] COPELAND, T., 2002. "Real options and strategic decisions". Strategic Finance 83, vol.10, april, pp. 8-10.

[21] CORTAZAR, G. e E. SCHWARTZ, 1993. "A Compound Option Model of Production and Intermediate Inventories". Journal of Business 66 (4) pp. 517-540.

[22] COX, J.C, S.A. ROSS e M. RUBINSTEIN, 1979. "Option Pricing: A Simplified Approach". Journal of Financial Economics 7 (3), Sept/1979, 229-263.

[23] DASGUPTA, P., G.M. HEAL \& J. STIGLITZ, 1980, "The taxation of Exhaustible Resources". In Public Policy and the Tax System. G.A. Hughes e G.M. ed. George Allen \& Unwin Ltd. Londres, 1980.

[24] DAVIS, G. A. e R. D. CAIRNS, 1999."Valuing petroleum reserves using current net price". Economic Inquiry, v. 37 (2), (April), pp. 295-311.

[25] DIAS, M.A.G. e K.M.C. ROCHA, 1999."Petroleum Concessions with Extendible Options: Investment timing and Value using Mean Reversion and Jump Processes for Oil Prices". IPEA, Rio de Janeiro, texto para discussão $n^{\circ} 620$. 
[26] DIAS, M.A.G., 1996. Investimento sob Incerteza na Exploração e Produção de Petróleo. Dissertação de Mestrado, PUC/RJ, não Publicada.

[27] DIAS, M.A.G., 2001. "Real Options in Upstream Petroleum: Overview of Models and Applications". Mimeo.

[28] DIXIT, A., 1989. "Entry and Exit Decisions under Uncertainty". Journal of Political Economy 97 (3), pp. 620-638.

[29] DIXIT, A., 1992. "Investment and hysteresis". Journal of Economic Perspectives $6(1), 107-132$.

[30] DIXIT, A., 1993. "Choosing among alternative discrete investment projects under uncertainty". Economic Letters 41, 265-268.

[31] DIXIT, A. K. e R. S. PINDYCK, 1994. Investment under Uncertainty. Princeton University Press. Nova Jersey.

[32] EDLESON, M. E. e F. REINHARDT, 1995. "Investment in Pollution Compliance Options: The Case of Georgia Power". In TRIGEORGIS, L. (org.), Real Options in Capital Investment: Models, Strategies, and Applications. Praeger Ed., 1995.

[33] EMERY, J.C. e K.J.McKENZIE, 1996. "Damned If You Do, Damned If You Don't: An Option Value Approach to Evaluating the Subsidy of the CPR Mainline”. Canadian Journal of Economics 29 (2) (May, 1996), pp. 255-270.

[34] FAVERO, C. A., 1992. "Taxation and the Optimization of Oil Exploration and Production: The UK Continental Shelf". Oxford Economic Papers 44 (2), Apr. 92, 187-208.

[35] FRASER, R., 1993. "On the neutrality of the Resource Rent Tax". Economic Record 69, nº204, março/1993, 56-60. 
[36] FRASER, R., 1998. "An analysis of the relationship between uncertaintyreducing exploration and resource taxation". Resources Policy 24, no 4 , dez./1998, 199-205.

[37] FRASER, R. e R. KINGWELL, 1997. "Can expected tax revenue be increased by an investment-preserving switch from ad valorem royalties to a resource rent tax?". Resources Policy 23, n³, set./1997, pp. 103-108.

[38] GARNAUT, R. e A. CLUNIES ROSS, 1983. Taxation of Mineral Rents. Oxford University Press, Nova York.

[39] GIBSON, R. e E. SCHWARTZ, 1990, "Stochastic convenience yield and the Pricing of Oil Contingent Claims". Journal of Finance 45 (3), July 1990, pp. 959-976.

[40] GRAY, L.C., 1914. "Rent under Assumption of Exhaustibility". The Quartely Journal of Economics 28, nº3, may/1914, 466-489.

[41] GRENADIER, S., 1996. "The Strategic Exercise of Options: Development Cascades and Overbuilding in Real Estate Markets". Journal of Finance 51 (5), pp. 1653-1679.

[42] HAYES, R. e D. GARVIN, 1982. "Managing As If Tomorrow Mattered". Harvard Business Review (May-June 82).

[43] HENRY,C., 1974. "Investment Decisions Under Uncertainty: 'The Irreversibility Effect"'. American Economic Review 64 (6), 1006-1012.

[44] HERTZ, D. 1964. "Risk Analysis in Capital Investment". Harvard Business Review 42 (Jan-Feb 64), pp. 95-106.

[45] HILLIARD, J.E. e J. REIS, 1998. "Valuation of Commodities Futures and Options Under Stochastic convenience yields, Interest Rates, and Jump 
Diffusions in the Spot". Journal of Financial and Quantitative Analysis 33 (1), 61-86.

[46] HOTELLING, H., 1931, "The Economics of Exhaustible Resources". Journal of Political Economy, Abr/1931, pp.137-175.

[47] HULL, J., 1993. Options, Futures and Other Derivative Securities. PrenticeHall, 1993.

[48] INGERSOLL, J. e S. ROSS, 1992. "Waiting to Invest: Investment and Uncertainty". Journal of Business 65, $\mathrm{n}^{\circ} 1$ (Janeiro/92), pp. 1-29.

[49] JACOBY, H.D. e D.G. LAUGHTON, 1992. "Project Evaluation: A Practical Asset Pricing Method". Energy Journal 13, nº, pp. 19-47.

[50] KEMNA, A., 1993. "Case Studies on Real Options". Financial Management 22, 3 (Autumn), 259-270.

[51] KONISHI, A. e R.E. DATTATREYA (org.), 1997. Frontiers in Derivatives: State-of-the-Art Models, Valuation, Strategies $\&$ Products. Irwin Professional Publishing, 1997.

[52] KRETZER, U. , 1993. "Allocating oil leases: overcapitalization in licensing systems based on size of work programme". Resources Policy 19, nº4, dez/1993, pp.299-311.

[53] KULATILAKA, N., 1995a."The Value of Flexibility: A General Model of Real Options". In TRIGEORGIS, L. (org.), Real Options in Capital Investment: Models, Strategies, and Applications. Praeger Ed., 1995.

[54] KULATILAKA, N.,1995b. "Operating Flexibilities in Capital Budgeting: Substitutability and Complementarity in Real Options". In TRIGEORGIS, L. (org.), Real Options in Capital Investment: Models, Strategies, and Applications. Praeger Ed., 1995. 
[55] KULATILAKA, N. e. L. TRIGEORGIS, 1994. "The General Flexibility to Switch: Real Options Revisited". International Journal of Finance vol. 6 (2), pp. 778-797.

[56] KULATILAKA, N., e. S. G. MARKS, 1988. "The Strategic Value of Flexibility: Reducing the Ability to Compromise". American Economic Review $78(3), 574-580$.

[57] KWIATKOWSKY, D., P. PHILLIPS, P. SCHMIDT \& Y. SHIN, 1992. "Testing the null hypothesis of stationarity against the alternative of a unit root". Journal of Econometrics 54, 1992, pp. 159-178.

[58] LAFFONT, J.J e J. TIROLE, 1993. A Theory of Incentives in Procurement and Regulation. The MIT Press. Cambridge.

[59] LAUGHTON, D. 1998a. "The Potential for Using Modern Asset Pricing Methods for Upstream Petroleum Projects Evaluation: Introductory Remarks". Energy Journal 19 (1), 1-11.

[60] LAUGHTON, D. 1998b. "The Management of Flexibility in the Upstream Petroleum Industry". Energy Journal 19 (1), 83-114.

[61] LAUGHTON, D. e H. JACOBY, 1995. "The Effects of Reversion on Commodity Projects of Different Length". In TRIGEORGIS, L. (org.), Real Options in Capital Investment: Models, Strategies, and Applications. Praeger Ed., 1995.

[62] LEE, J. e. M. STRAZICICH, 2003. "Minimum LM Unit Root Test with Two Structural Breaks". Review of Economics and Statistics 85 (4), Nov/2003, p.1082-1089

[63] MAGEE, J., 1964. "How to Use Decision Trees in Capital Investment" . Harvard Business Review 42 (Sept-Oct-1964). 
[64] MAJD, S. e R. PINDYCK, 1987."Time to build, Option Value and Investment Decisions". Journal of Financial Economics 18 (march), pp. 7-27.

[65] MAUER, D.C. e S.H. OTT, 2000. "Agency Costs, Underinvestment, and Optimal Capital Structure". In BRENNAN, M. J. e L. TRIGEORGIS (orgs.), 2000. Project Flexibility, Agency, and Competition: New Developments in the Theory and Aplication of Real Options. Nova York: Oxford University, 2000.

[66] MAYO, W., 1979, "Rent royalties". Economic Journal 55, nº150, set/1979, 202-213.

[67] McCORMACK , J., D. CALISTRATE e G. SICK, 2001 ."Applying Real Options to Assessing Proven Undeveloped Petroleum Reserves". 5th Annual Real Options Conference 2001, UCLA, Los Angeles.

[68] McDONALD, R. L. e D.R. SIEGEL, 1985. "Investment and the Valuation of Firms when there is an option to shut down". International Economic Review 26, No2, Jun/85, pp. 331-349.

[69] MERTON, R. 1973. "An intertemporal capital asset pricing model”. Econometrica 41, pp.867-887.

[70] MILLER, M., \& L. ZHANG, 1996. "Oil Price Hikes and Development Triggers in Peace and War". Economic Journal v. 106 (435), Mar. 1996, 445457.

[71] MILTERSEN, K. e E. SCHWARTZ, 1998. "Pricing of Options on Commodity Futures with Stochastic Term Structures of convenience yields and Interest Rates". Journal of Financial and Quantitative Analysis 33 (1), 33-59.

[72] MOSZKOWICZ, V. N., 2003. Validação do Critério de Avaliação de Projetos Utilizando a Teoria das Opções Reais: E \& P de campos de petróleo 
nacionais, supondo preços como movimento geométrico browniano. Dissertação de Mestrado, Departamento de Engenharia Industrial, PUC/RJ (Não publicada).

[73] MYERS, S.C. e S. MAJD, 1990. "Abandonment Value and Project Life". Advances in Futures and Options Research 4, pp. 1-21.

[74] MYERS, S.C., 1977, "Determinants of Corporate Borrowing", Journal of Financial Economics $n^{\circ} 5$ (2), 147-175.

[75] MYERS, S.C.1987, "Finance Theory and Financial Strategy". Midland Corporate Finance Journal 5 (1), pp. 6-13.

[76] OSMUNDSEN, P., 1998. "Dynamic taxation of non-renewable natural resources under asymmetric information about reserves". Canadian Journal of Economics 31, nº4, out./98, pp. 933-951.

[77] OTTO, J.M., 1998. "Global changes in mining laws, agreements and tax systems". Resources Policy 24, no2, junho/98, pp.79-86.

[78] PADDOCK, J.L, D.R. SIEGEL e J.L SMITH, 1988. "Option valuation of claims on real assets: the case of offshore petroleum leases". The Quartely Journal of Economics 103, Ago/88, pp.479-508.

[79] PERRON, P. 1989. "The Great Crash, the Oil Price Shock, and the Unit Root Hypothesis". Econometrica 57 (6), 1361-1401.

[80] PICKLES, E. e J.L. SMITH, 1993. "Petroleum property valuation: a binomial lattice implementation of option pricing theory". The Energy Journal 14, pp.1-26.

[81] PILIPOVIC, D., 1997. Energy Risk: Valuing and Managing Energy Derivatives. McGraw Hill. 
[82] PINDYCK, R.S, 1980. "Uncertainty and exhaustible resource markets". Journal of Political Economy 88, pp. 1203-1255.

[83] PINDYCK, R.S, 1988. "Irreversible Investment, Capacity Choice, and the Value of the Firm". American Economic Review 78, n5 (December), pp. 969-985.

[84] PINDYCK, R.S, 1991. "Irreversibility, Uncertainty, and Investment". Journal of Economic Literarture 29, 3 (Sept.), pp. 1110-1148.

[85] PINDYCK, R.S, 1993. "The present value model of rational commodity pricing”. Economic Journal 103, Maio/93, pp.511-530.

[86] PINDYCK, R.S, 1999. "The Long Run Evolution of Energy Prices". Energy Journal 20 (2), 1-27.

[87] PINDYCK, R.S, 2001a. "The Dynamics of Commodity Spot and Future Markets: A Primer". CEEPR Working Paper (002/2001), MIT.

[88] PINDYCK, R.S, 2001b. "Volatility and Commodity Price Dynamics". CEEPR Working Paper (007/2001), MIT.

[89] POSTALI, F.A.S, 2002, Renda Mineral, Divisão de Riscos e Benefícios Governamentais na Exploração de Petróleo no Brasil. BNDES, Rio de Janeiro.

[90] QUIGG, L., 1995."Optimal Land Development". In TRIGEORGIS, L. (org.), Real Options in Capital Investment: Models, Strategies, and Applications. Praeger Ed., 1995.

[91] RIGOLON, F.J., 1999, "Opções reais, análise de projetos e financiamentos de longo prazo". Revista do BNDES 11, junho de 1999. 
[92] SALAHOR, G. 1998. "Implications of Output Price Risk and Operating Leverage for the Evaluation of Petroleum Development Project". Energy Journal 19 (1), pp. 13-46.

[93] SAMMER, J., 2002, "Thinking in real (options) time". Business Finance 8 (3) (march).

[94] SCHWARTZ, E. S. \& L. TRIGEORGIS (orgs.), 2001. Real Options and Investment under uncertainty: classical readings and recent contributions. Cambridge: MIT, 2001.

[95] SCHWARTZ, E.S. \& J.E. SMITH, 2000. "Short-Term Variations and Long-Trm Dynamics in Commodity Prices". Management Science 46(7), Jul/2000, pp. 893-911.

[96] SCHWARTZ, E.S., 1997,"The Stochastic Behavior of Commodity Prices: Implications for Valuation and Hedging". Journal of Finance 52 (3), July 1997, pp. 923-973.

[97] SUNNEVÅG, K., 1998. "An option pricing approach to exploration licensing strategy". Resources Policy 24, nº1, mar/1998, pp. 25-38.

[98] TEISBERG, E., 1993. "Capital investment strategies under uncertain regulation". Rand Journal of Economics 24 (4), 591-604.

[99] TEISBERG, E., 1995. "Methods for Evaluating Capital Investment Decisions under Uncertainty". In TRIGEORGIS, L. (org.), Real Options in Capital Investment: Models, Strategies, and Applications. Praeger Ed., 1995.

[100] TOURINHO, O.A.F.,1979, The Valuation of Reserves of Natural Resources: An Option Pricing Approach. University of California, Berkeley, PhD Dissertation, November 1979. 
[101] TRIGEORGIS, L., 1993. "The Nature of Option Interaction and the Valuation of Investments with Multiple Real Options". Journal of Financial and Quantitative Analysis 28, $\mathrm{n}^{\circ} 1$ (March), 1-20.

[102] TRIGEORGIS, L.,1995. Real Options in Capital Investment: Models, Strategies, and Applications.(org.) Praeger, 1995.

[103] TRIGEORGIS, L.,1996a. Real options - managerial flexibility and strategy in resource allocation. MIT Press, 1996.

[104] TRIGEORGIS, L.,1996b. "Evaluating leases with complex operating options". European Journal of Operational Research 91, pp. 315-329.

[105] TRIGEORGIS, L. e S. MASON, 1987."Valuing Managerial Flexibility". Midland Corporate Finance Journal (Spring), 14-21.

[106] VASICEK, O. 1977. "An equilibrium characterization of the term structure". Journal of Financial Economics 5, 177-186.

[107] WEEDS, H. 2002 ."Real Options and Game Theory: When should Real Options Valuation be applied?" 6th Annual Real Options Conference 2021, Paphos, Chipre.

[108] WILMOTT, P., S. SHOWISON e J. DEWYNNE, 1995. The Mathematics of Financial Derivatives: A Student Introduction. Cambridge University Press.

[109] ZAMITH, R., 2001. A indústria Para-Petroleira Nacional. São Paulo: Annablume, 2001.

[110] ZHANG, L., 1997."Neutrality and Efficiency of Petroleum Revenue Tax: A Theoretical Assessment". Economic Journal $10^{\text {r7 }}$ (443), jul/97, pp. 11061120. 